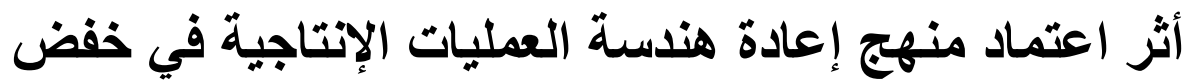

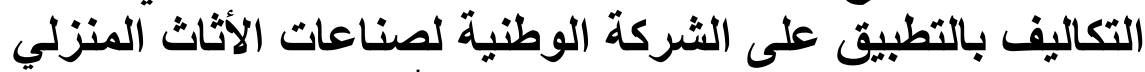
في محافظة نينوى الثرة

\author{
الاء وضاح محمود ثابت \\ الدكتور صالح إبراهيم يونس الشعباني \\ مدرس مساعد - قسم المحاسبة

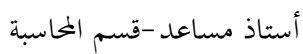 \\ كلية الإدارة والاقتصاد - جامعة الموصل

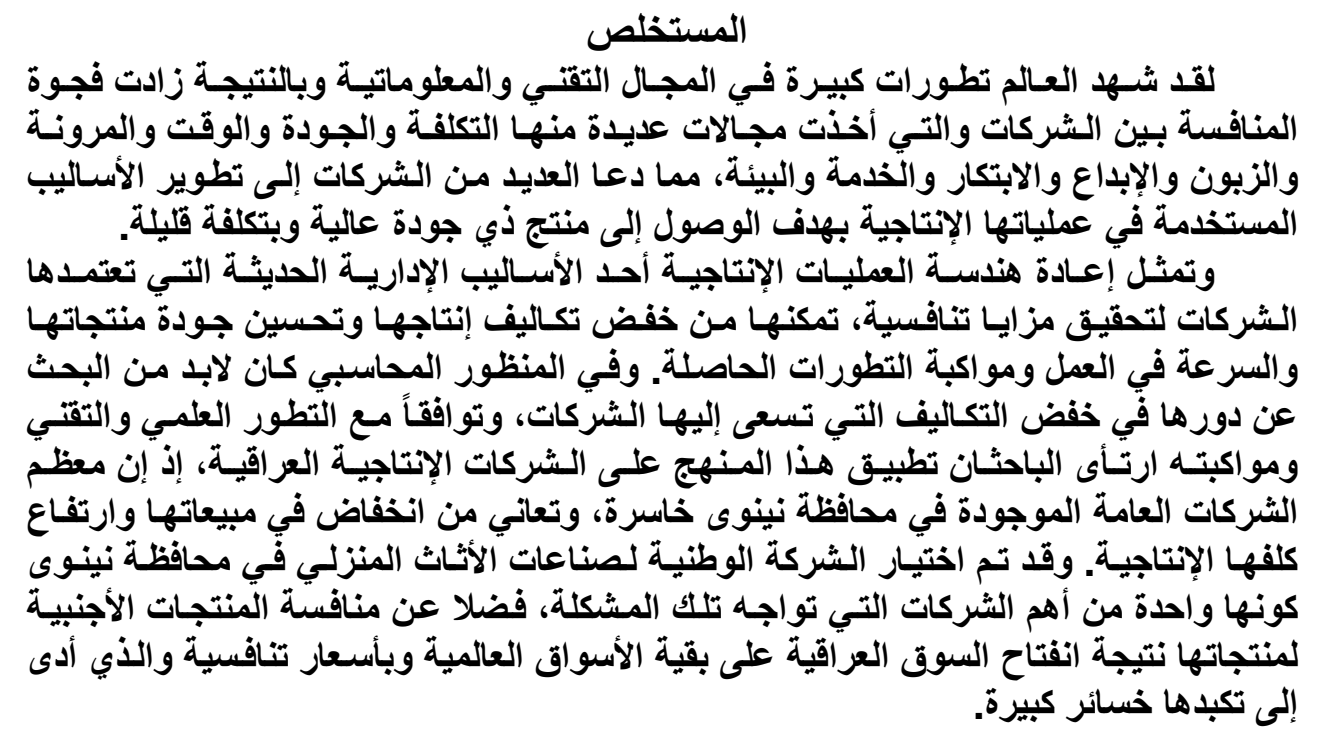

الكلمات المفتاحية:

أعـادة هندسـة العمليـات، التكلفـة المستهـفة، تخفيض التكلفـة، هندسـة القيمة.

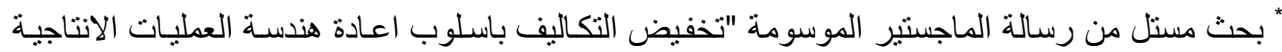

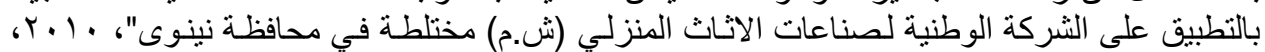
كلية الإدارة والاقتصاد، جامعة الموصل.

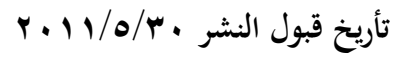

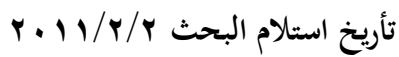




\title{
The Effect Of An Approach Dependence Reengineering Production Processes Eith Application In The National Company For Furnishing Industries In Ninevah City
}

\author{
Salih Y. Al-Shaabani (PhD) \\ Assistant Professor \\ Department of Accountancy \\ University of Mosul
}

\author{
Alaa W. Thabit \\ Assistant Lecturer \\ Department of Accountancy \\ University of Mosul
}

\begin{abstract}
The world has witnessed significant developments in the field of technical and information and as a result increasing the competition gap between the companies which have taken many areas including cost, quality and time, flexibility, customer and creativity and innovation, service and environment, which brought many companies to develop methods used in their production processes, in order to access the product of high quality and low cost. The re-engineering production processes, modern management techniques are adopted by companies to achieve competitive advantages, enabling them to reduce production costs and improve product quality and quick work and keep up with developments. In an accounting perspective, it is necessary to search for its role in reducing the costs sought by the companies, in line with the development of science. The researchers envisaged to apply this method to the Iraqi production companies, as most public companies in Nineveh lost and suffer low sales and high mandated productivity. The Company of National Furniture Industries in Nineveh, has been selected as one of the most important companies facing this problem, as well as to compete with foreign products of its products as a result of opening the Iraqi market to the rest of the world markets in competitive prices, which led to large losses.
\end{abstract}

\section{Key Words:}

Reengineering Processes, Target Cost, Reduction Cost, Quality Value.

يتسم العالم اليوم بالتغير الدائم، إذ يشهد الكثير من التطورات والتغير ات السريعة في جميع مجالات الحياة، والتي انعكست آثار ها على كثير من الأعمال. وفي القطاع الصناعي الصني

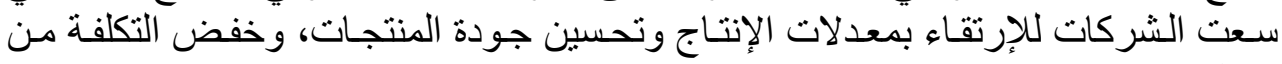
خلال تطبيق نظريات ومناهج علمية جديدة.

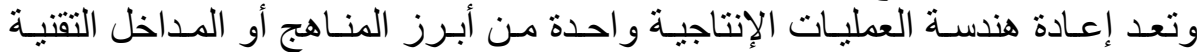

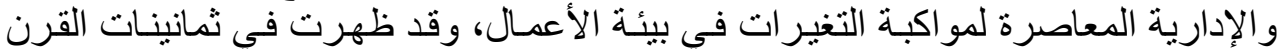
الماضي لتحقيق الهدف الرئيس الذي تسعى إلبه الشركات اليوم، و المتمثل في تلبية متطلبـات الزبون من خلال خفض التكلفة وتحسين جودة المنتج أو المحافظة عليها.

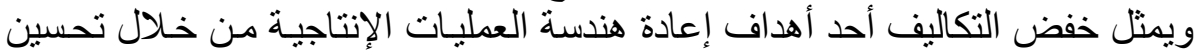

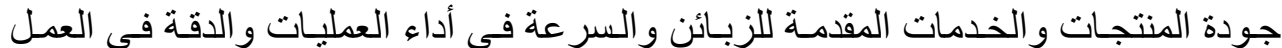

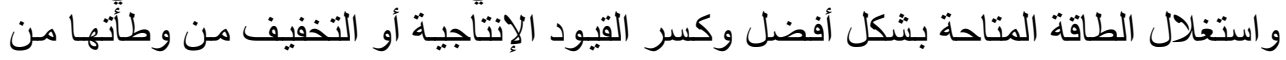




\section{الشعباني وثابت[ [}

خلال الاستعانة بالمقارنة المرجعية Benchmarking مع الصناعات المماتلـة و الر ائدة، وفي التي

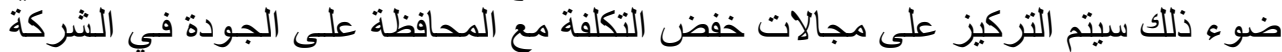

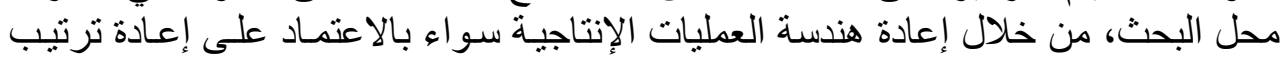

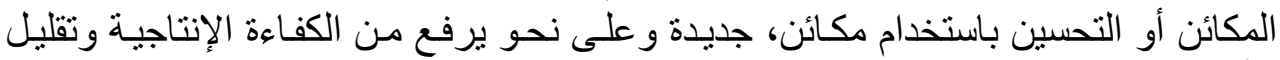

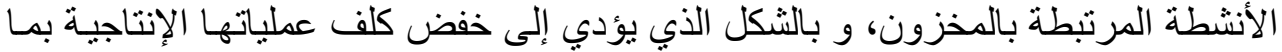
لا يؤثز على جودة المنتج، وفي الوقت نفسه ينعكس ذلك بلك إيجابا على ربحية الثركة.

\section{مشكلة البحث}

إن الكثير من الثركات تعاني اليوم من حالة انخفاض الربحيـة بسبب ارتفاع تكاليف

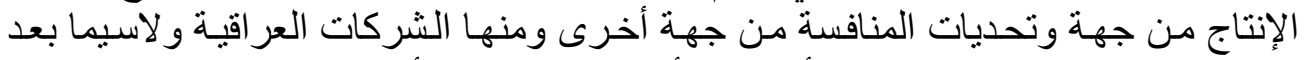

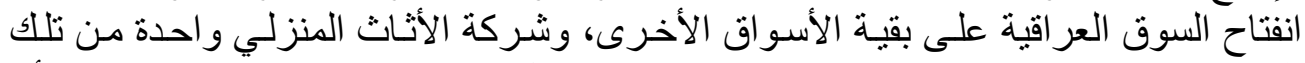

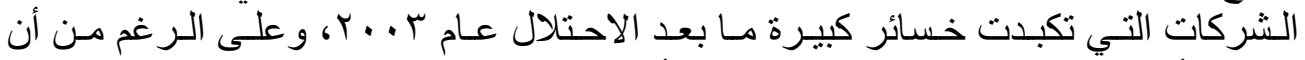

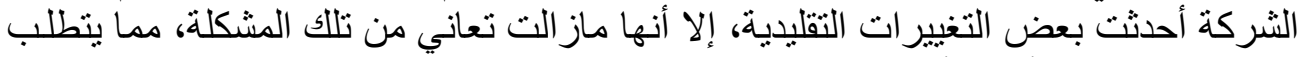

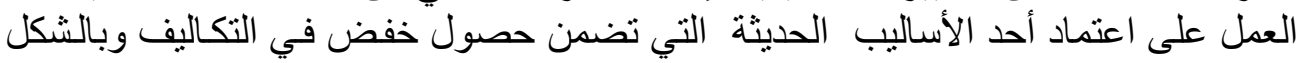
الذي لا يؤثر في جودة المنتج . العمل الني

تكمن أهمية البحث في بيان كيفيـة توظيف إعـادة ترتيب الأنشطة الفنبـة أو العمليات

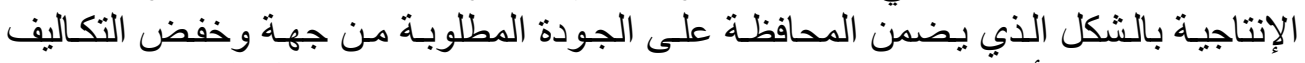

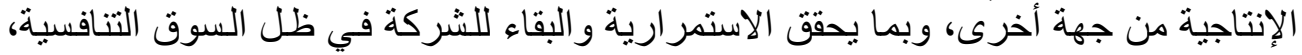

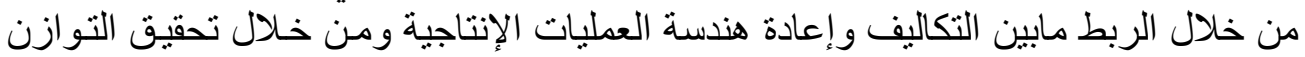
بين بعدي التكلفة والجودة مابن التئ

يهدف البحث بشكل رئيس إلى بيان أثر استخدام إعـادة هندسـة العمليـات الإنتاجيـة في الإني

\section{هدف البحث}

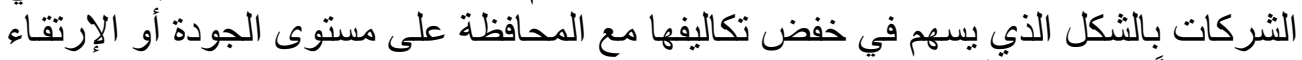

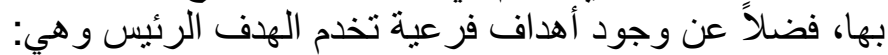
ا ـ. بيان مناهج خفض التكاليف و لاسيما الإنتاجية منها.

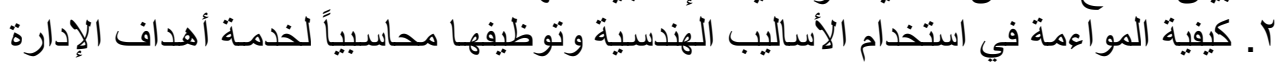
من خلال خفض الكلف وتحسين الربحية.

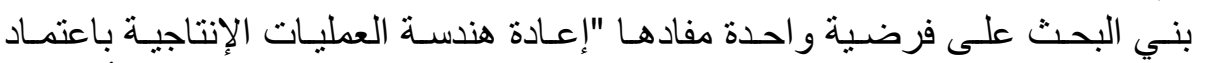

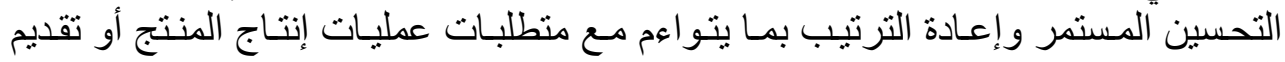

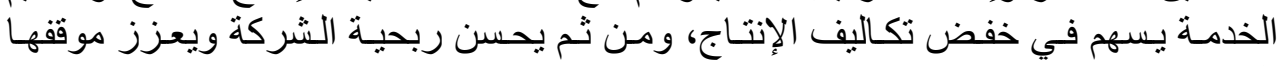




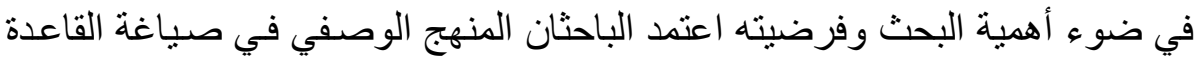

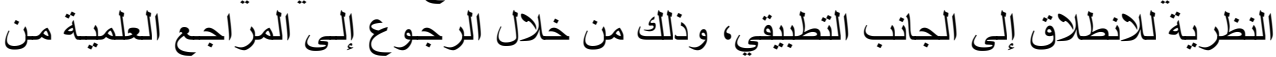

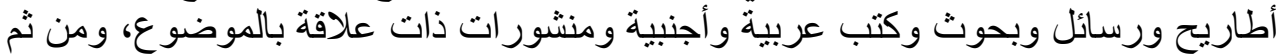

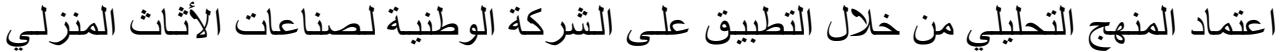

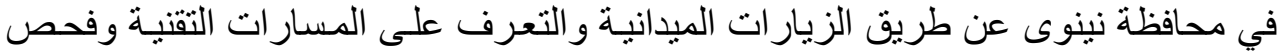

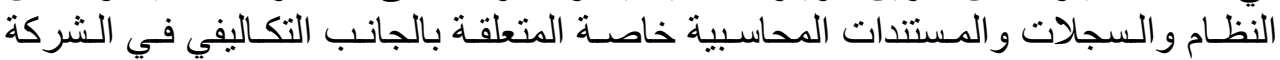
و إجر اء المقابلات الثخصية مع المسؤولين في الثركة قيد البحث. باتهات

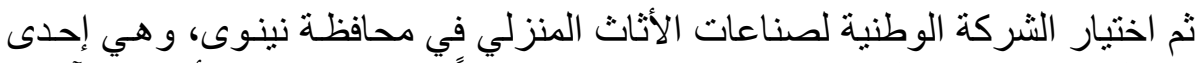

$$
\text { ميذان البحث }
$$

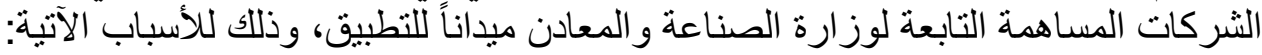

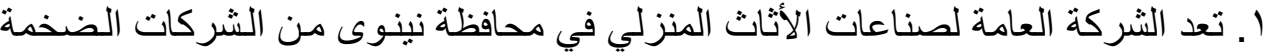

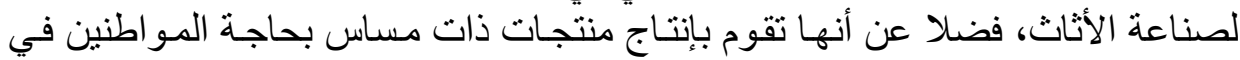
r. تعد طبيعـة إنتاج الشركة ملائمسة لمنهج إعـادة هندسـة العمليـات، مـن حيث المسار ات التقنية للعمليات الإنتاجية.

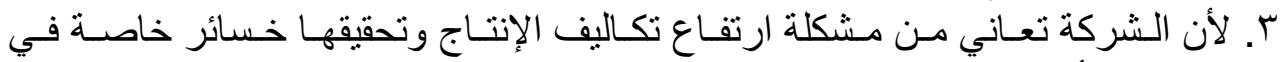

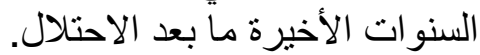

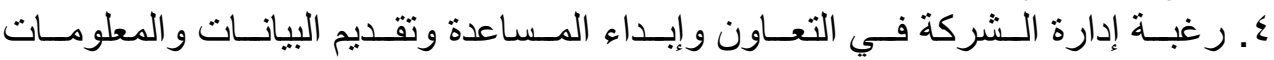

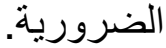

كرس البحث هذه فقط لإعادة هندسة العمليات الإنتاجية في الشركة موضو عة البها البحث حدود البحث

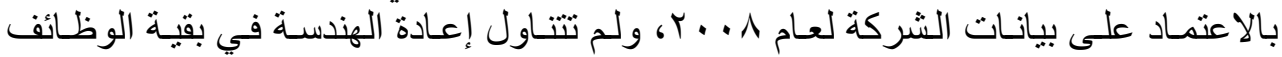
الأخرى (التسويقية و الإدارية).

لغرض تحقيق هدف البحث وحل مشكلته واختبار فرضيته بشكل علمي رصين، تم تقسيمه على وفق المحاور الآتية: المحور الأول: الإطار المفاهيمي لإعادة هندسة العمليات الإنتاجية.

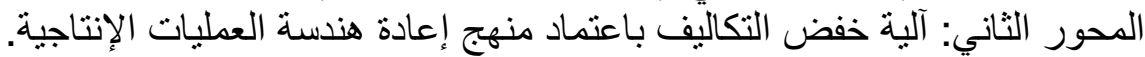

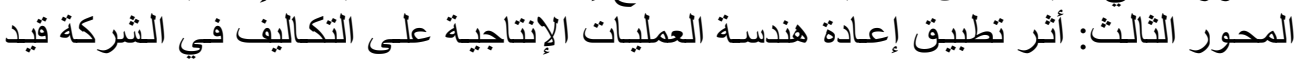




\section{المحور الأول- الإطار المفاهيمي لإعادة هندسة العمليات الإنتاجية

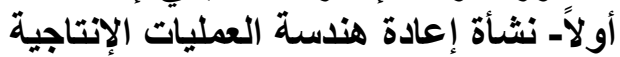

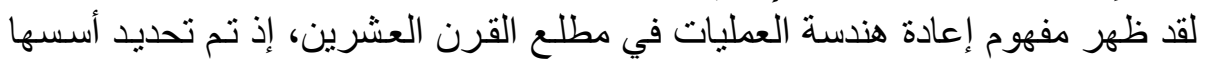

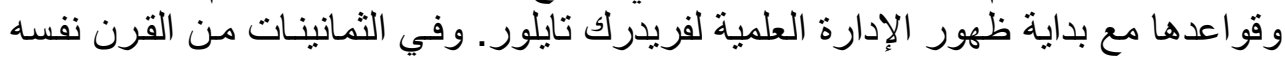

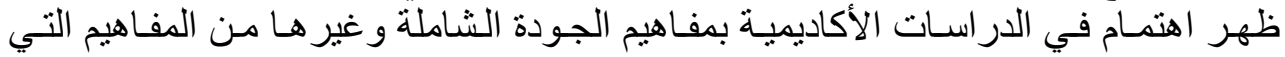

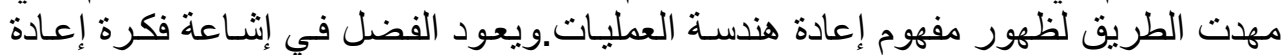

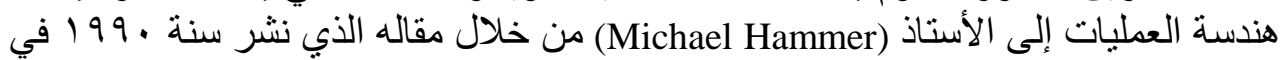
مجلة (Harvard Business) والذي كان بعنوان مeengineering work: Don't Automate) ، Obliterate) فورد للسيار ات (Hammer,1990,2) .

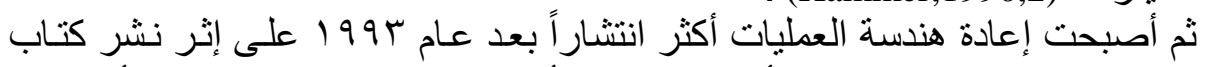

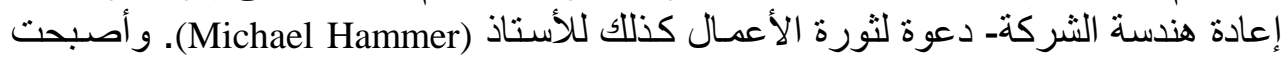

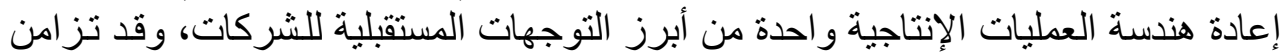

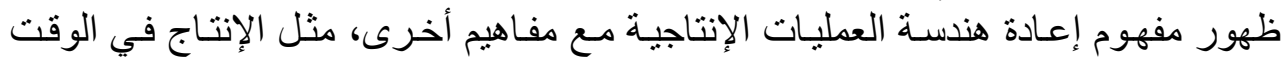

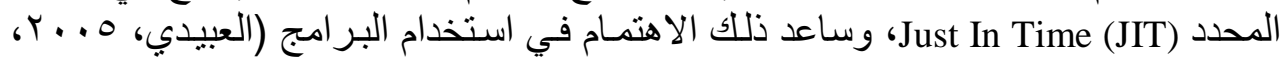

ثانياً مفهوم إعادة هندسة العمليات الإنتاجية

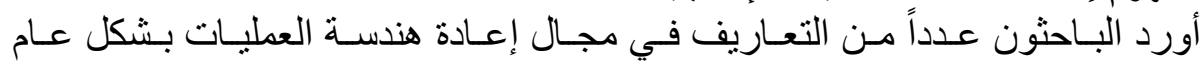

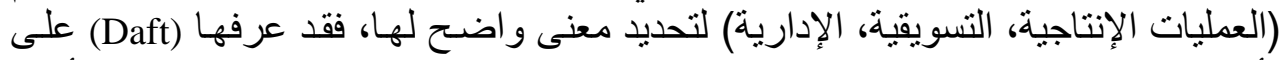

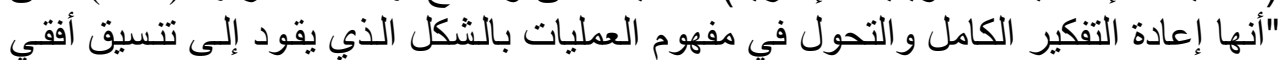

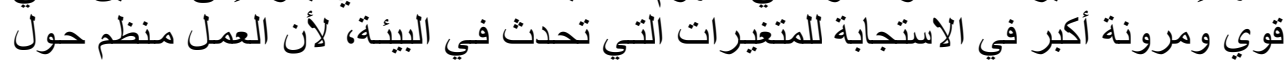
العملية وليس الوظيفة" (240-3aft, 2000, 339).

و عرفها آخرون بأنها "مجموعة متناسقة ومتتاغمة من الأنشطة التي تم تصميمها معا

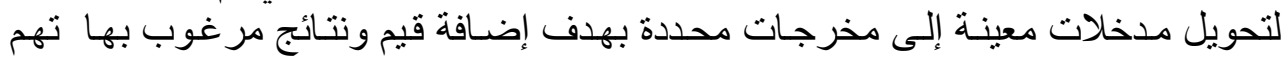

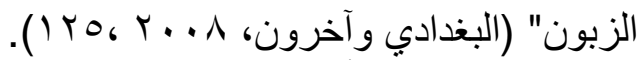

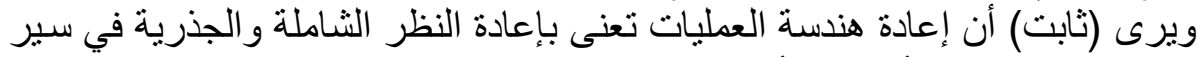

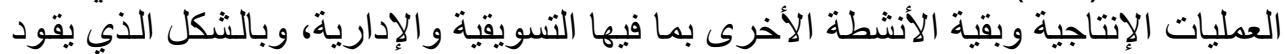

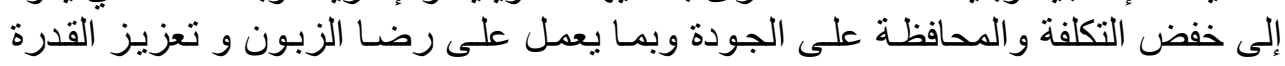

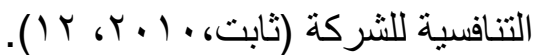

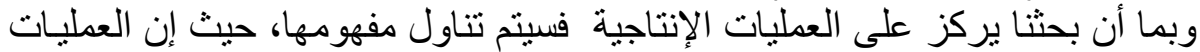

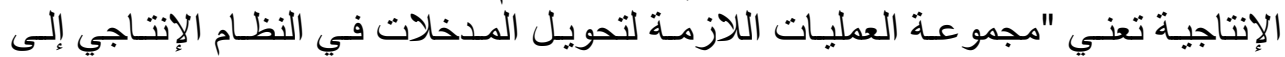

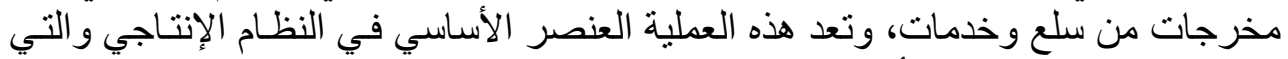

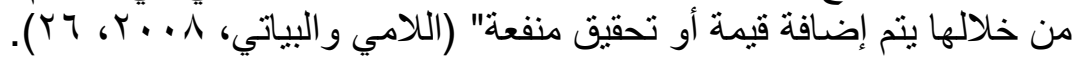
ومن منظور المجمع العربي للمحاسبين القانونيين فإن إعادة هندسة العمليات الإنتاجية

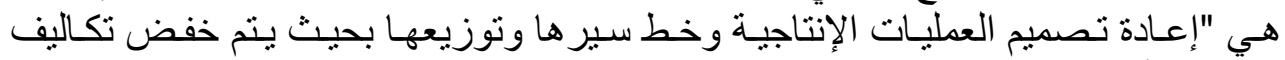

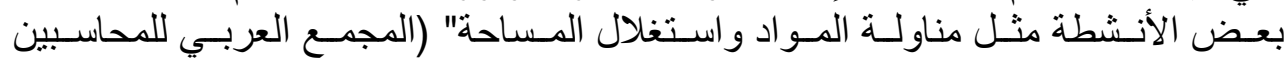

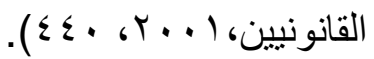


كما عرفت إعادة هندسة العمليات الإنتاجية على أنها "إعادة تصميم وتخطيط العملية

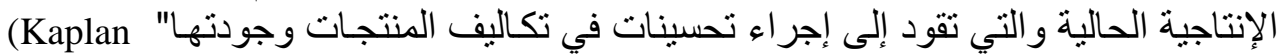
. and Atkinso, 1998, 229)

ويمكن تعريفها من وجهة نظر الباحثين على أنها "إعادة تصميم العمليات و الأنشطة

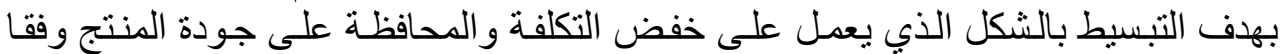
لر غبات ومتطلبات الزبائن، وبما يعزز القدرة التبان التنافسية للشركة".

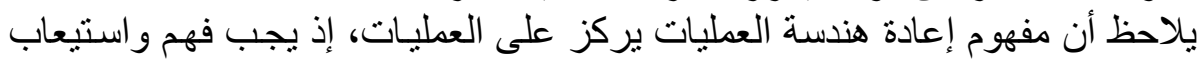

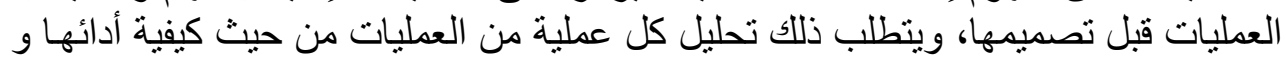

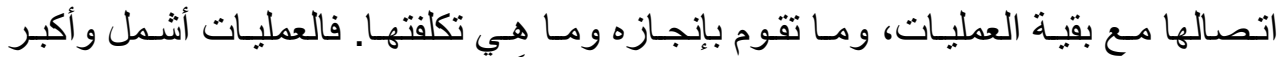

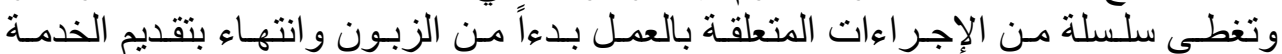

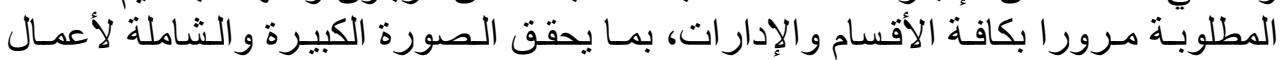

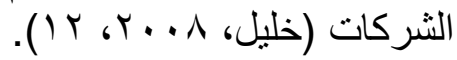

ثالثاً. المرتكزات والمقومات الأسساسية لتطبيق إعادة هندسة العمليات الإنتاجية

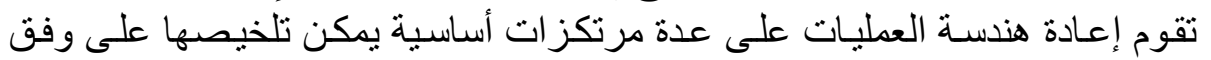

$$
\begin{aligned}
& \text { الآتي (Drury, 2000, 900): } \\
& \text { ا ا إعادة التفكير الأساسي. } \\
& \text { r. أن يكون التغيير جذرياً. } \\
& \text { ؟. أن تكون التحسينات ضخمة النغيرة } \\
& \text { ع. أن يعتمد التغيير على تقنية المعلومات. } \\
& \text { ه. التركيز على العمليات. }
\end{aligned}
$$

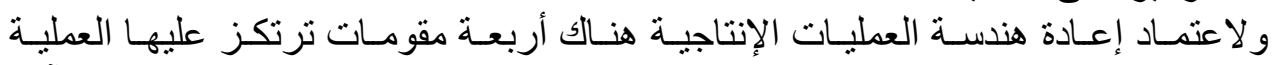

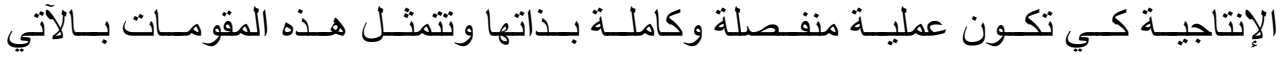

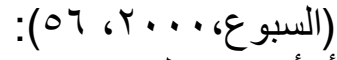
أ. أن يكون لها مدخلات قابلة للتوقع و التحديد.

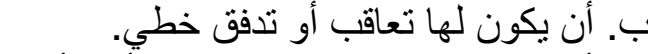

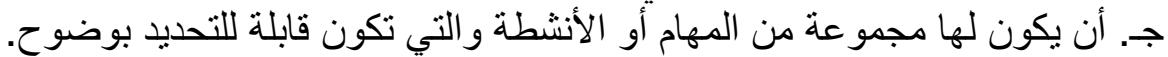
د. أن يكون لها مخرجات قابلة للتوقع أو التحديد.

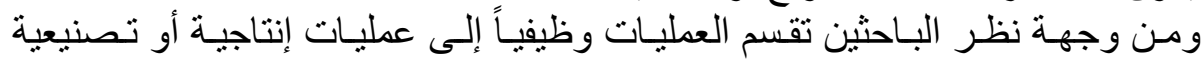

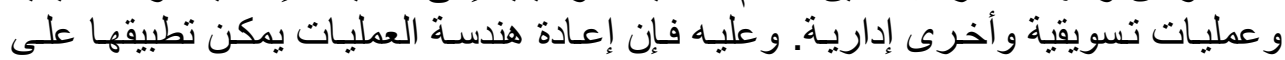

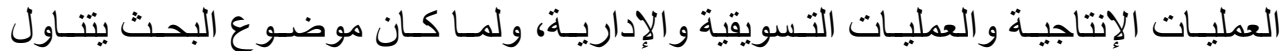

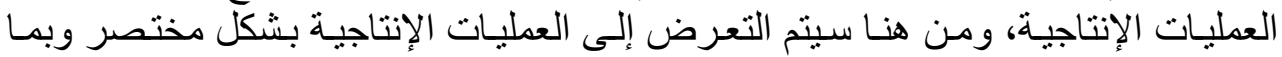

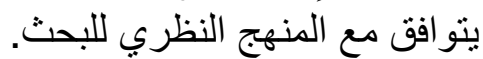

$$
\text { رابعاً- أهداف إعادة هندسة العمليات الإنتاجية }
$$

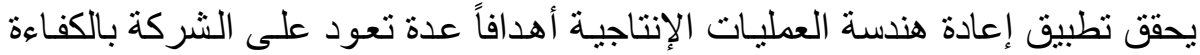

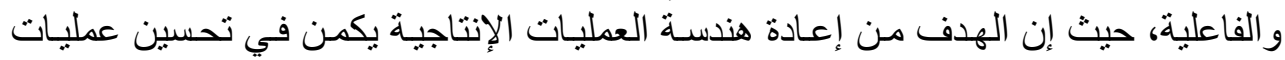




\section{الشعباني وثابت[0 ك}

الشركة الرئيسة بـالتركيز على التبسيط وخفض التكلفة وتحسين الجودة ورضئسا الزبون،

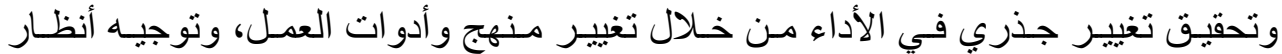

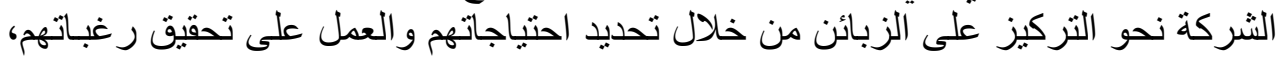

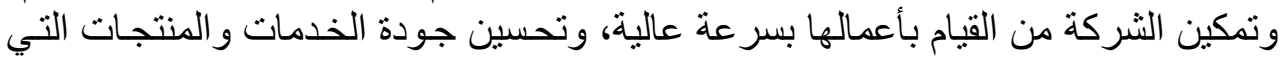

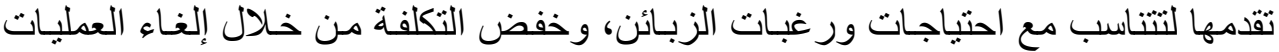

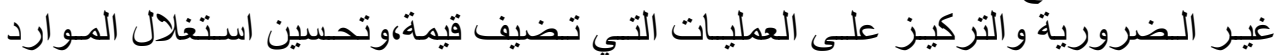

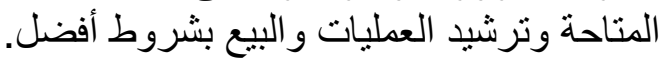

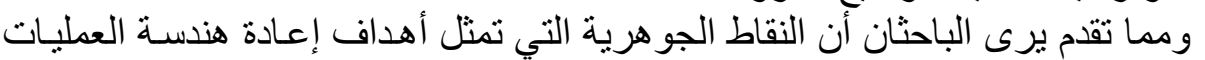

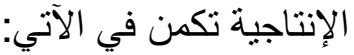

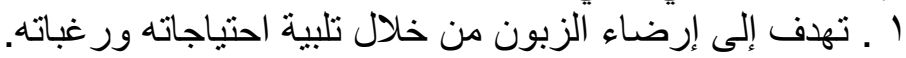

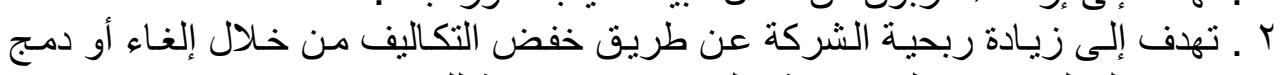

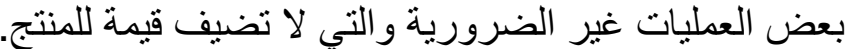
r ـ ـ تهدف إلى تحسين جودة المنتجات أو الخدمات التي تقدمها التشركات.

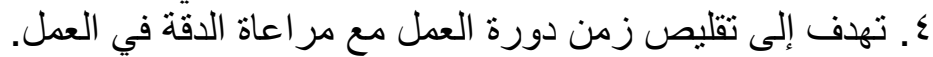

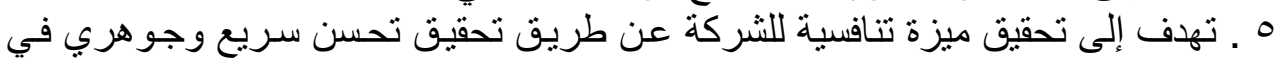

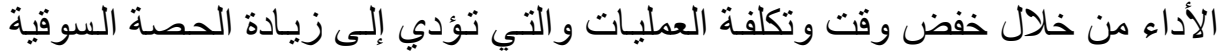

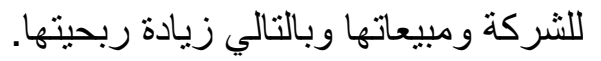

خامساً مسببات اعتماد إعادة هندسة العمليات الإنتاجية

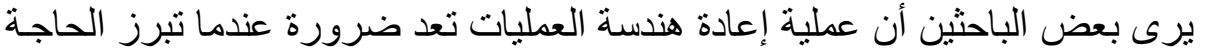

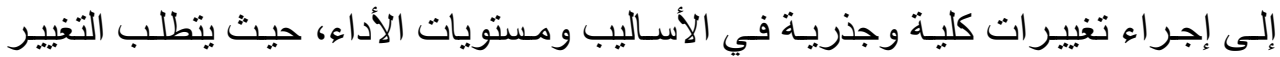

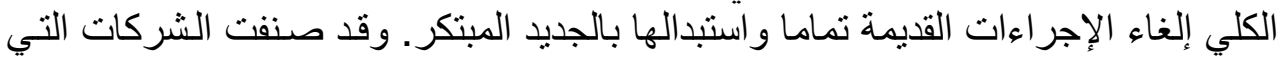
تحتاج إلى إعادة هندسة عملياتها على ثلاث فئات الأت هي (هامر وشامبي،

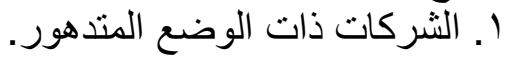

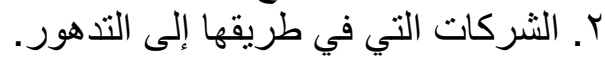

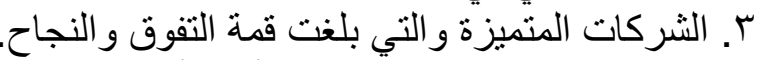

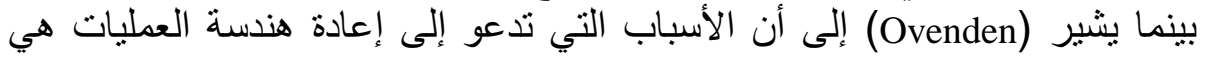

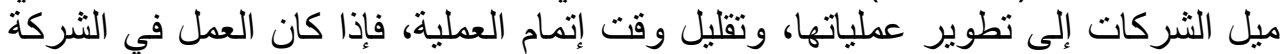

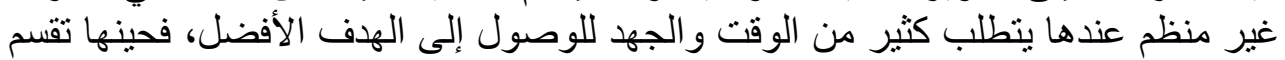

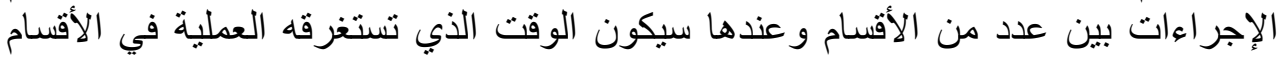

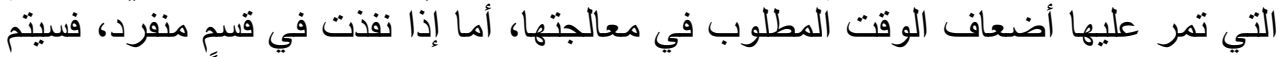

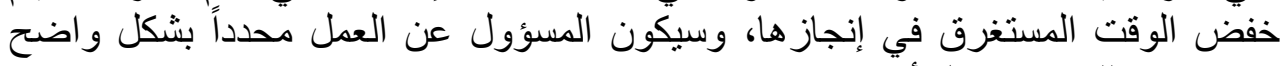

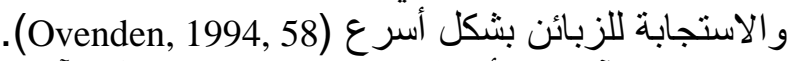

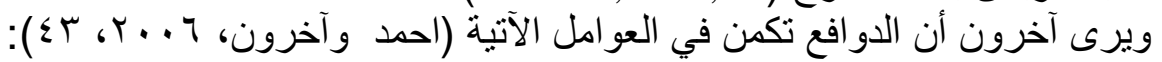

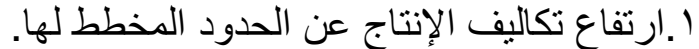

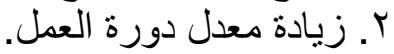

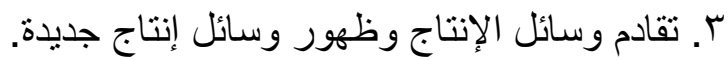
ع. اهتزاز سمعة الثركة في بيئتها الخارجية. 


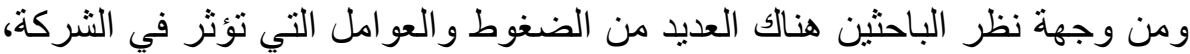
مما يتطلب اعتماد إعادة الهندسة للعمليات الإنتاجية ومن تلك العن العوامل العل الآتي:

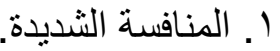

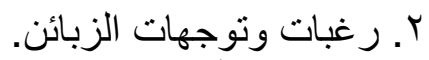

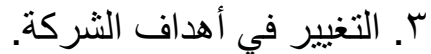
ع. التغيير ات التقنية.

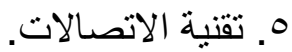
7 ا هو وجود قيود إنتاجية داخلية وخارجية أو كليهما.

فتحاول الثركة عند إعادة هندسة عملياتها الإجابة عن الأسئلة الآتية:

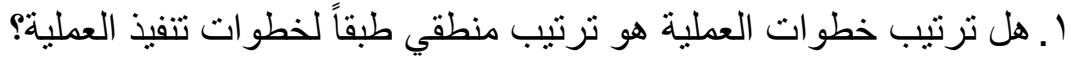

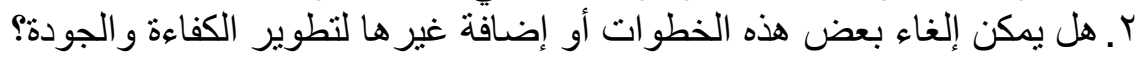

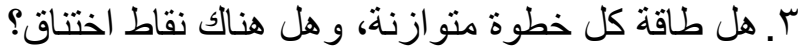

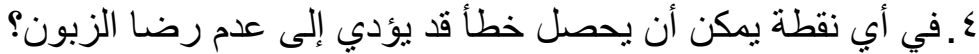

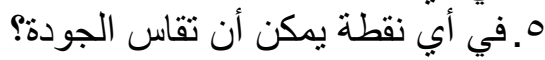

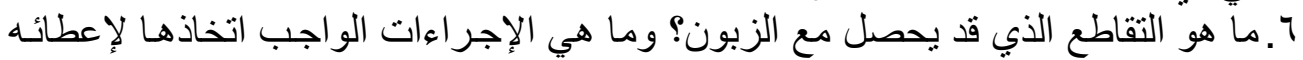
تصور إيجابي?

\section{سادساً- مر احل تطبيق إعادة هندسة العمليات الإنتاجية}

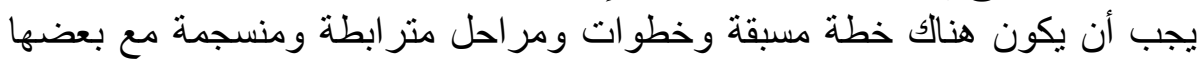

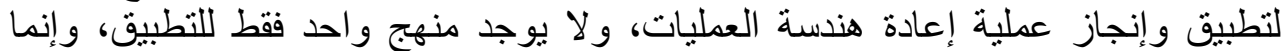

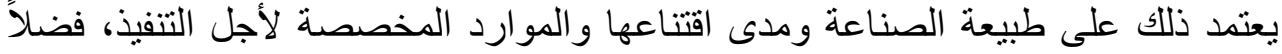

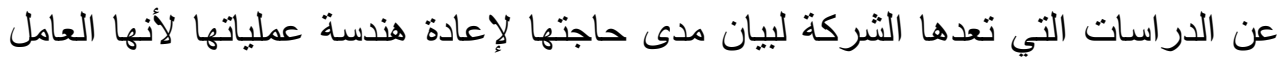

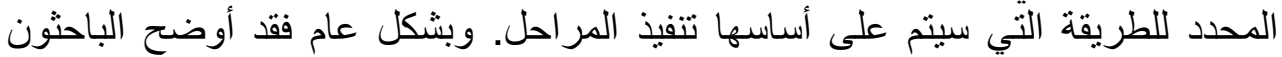

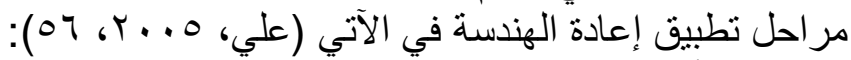
المرحلة الأولى:إعطاء صورة إعلى واضنة في العية حول إعادة هندسة العمليات.

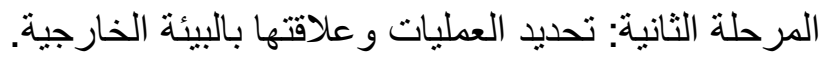
المرحلة الثالثة : ترشيح العمليات المر اد إعادة هندستها.

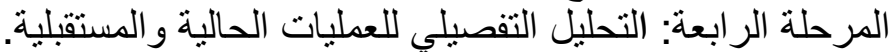

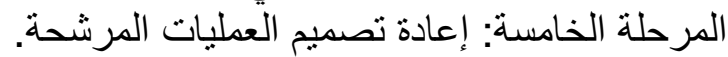

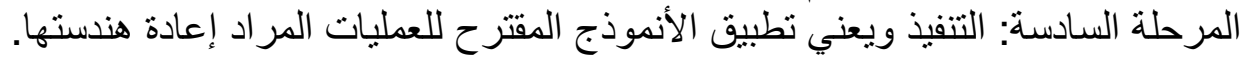

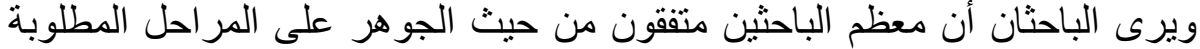
لإعادة هندسة العمليات، وإن اختلف عددها من بان باحث لآخر. ويمكن تحديد هذه المر احل

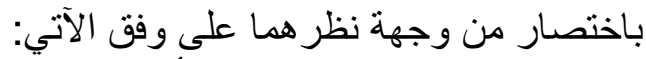

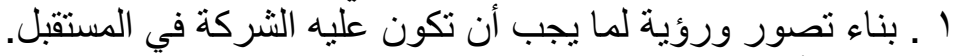
r r ـ تحليل أداء العمليات التشغيلية داخل الثركة مع رسم مخطط بياني لسير تتفيذها.

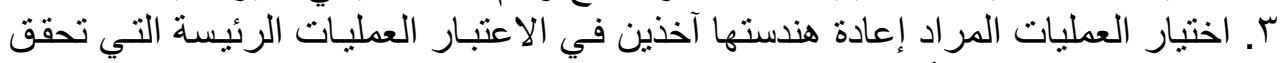
قيمة للزبون وذات تأثثر في الثركة الثرة الثنات 


\section{الشعباني وثابت]}

ع. إعادة تصميم العمليات المرشحة مـع الأخذ بنظر الاعتبـار التصور بعيد الأمد والقدرة على الإبداع في العمليات بأداء التغيير ات التهات التي تحقق ذلك. ه. توفير الموارد المادية والبشرية اللازمة لعملية إعادة هندسة العمليات الإنتاجية.

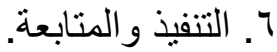

المحور الثاني- آلية خفض التكاليف باعتماد منهج إعادة هندة العمليات الإنتاجية وتكامله

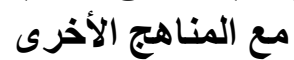

يعد السعي لخفض التكاليف من الأهداف الأساسية للشركات، لأنسه يشكل عاملاً مهمـا

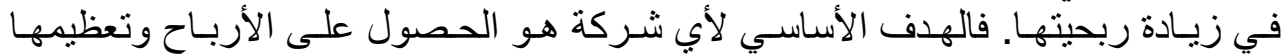

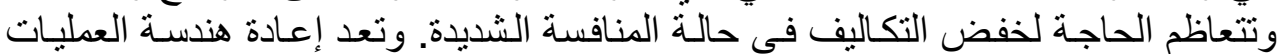

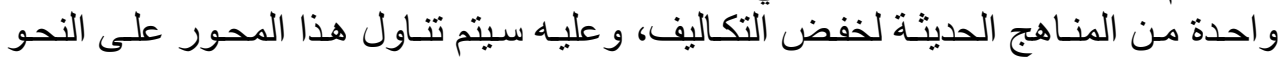

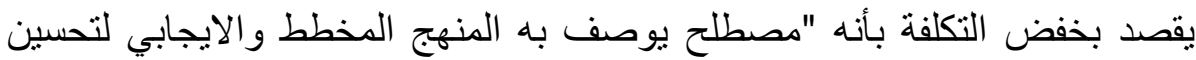

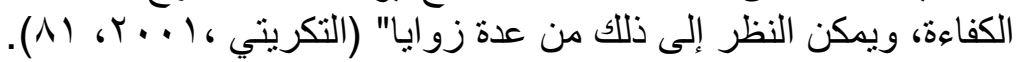
1 استبعاد الفاقد. r. السر عة في إنجاز العماد العيات.

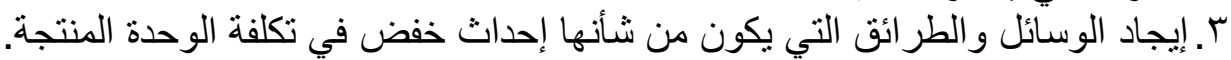

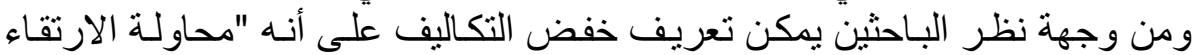

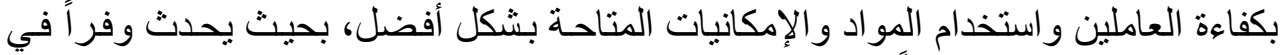

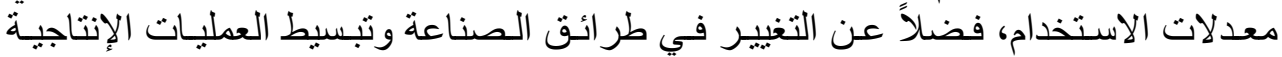

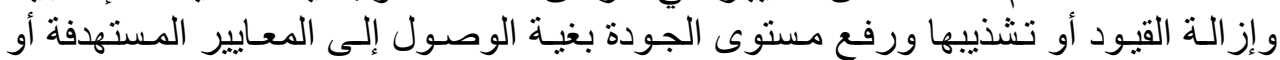
تخطيها".

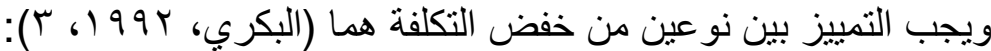
1. الخفض غير الحقيقي للتكاليف (الوهمي) ويتحقق هذا النوع من خفض البك التكاليف بمنهجين

$$
\begin{aligned}
& \text { أ. زيادة الإنتاج ضمن المدى الملائُ. } \\
& \text { ب. زيادة أسعار بيع المنتجات. }
\end{aligned}
$$

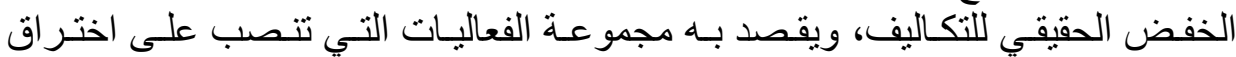
المعايير وتحديها بهدف خفض تكلفة الوحدة الواحدة والتكلفة الكلية بكل السبل المتاحة.

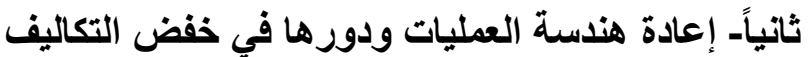

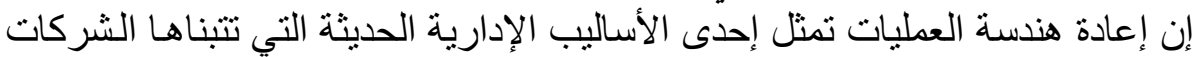

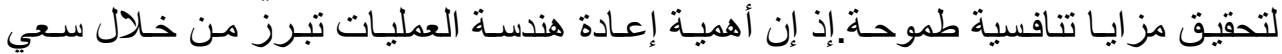

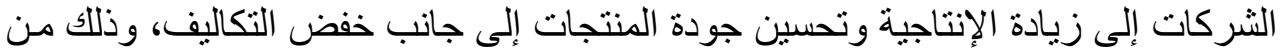

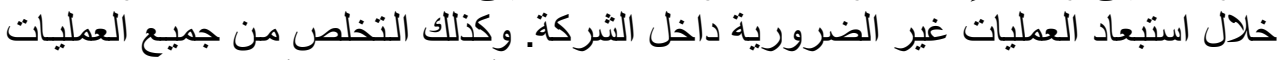

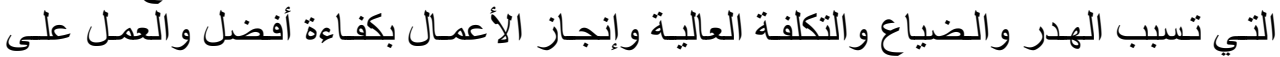
تطوير الخدمات المقدمة إلى الزبائن (Sofroniou, 1998, 147). 


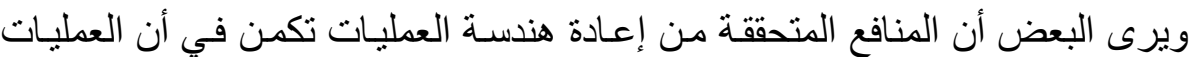

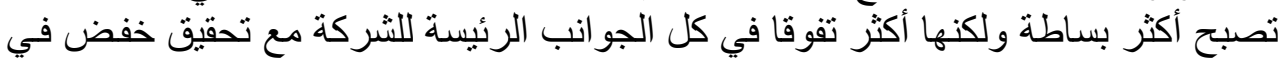
التكاليف (Weetman, 1996,318).

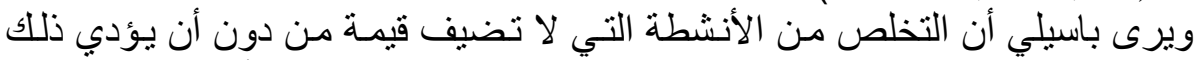

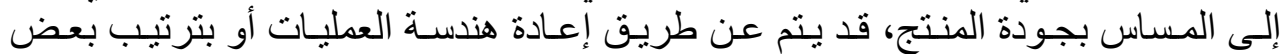

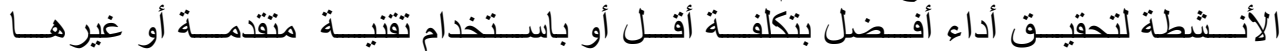

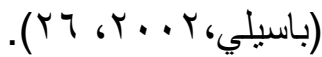

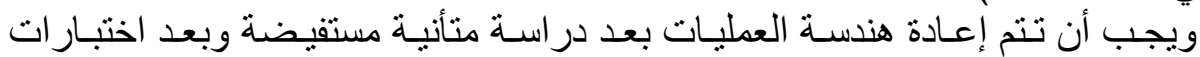

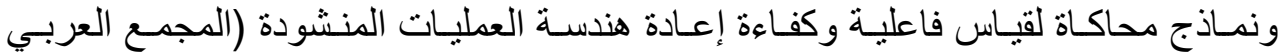

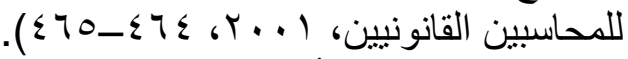

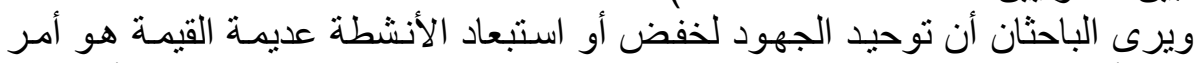

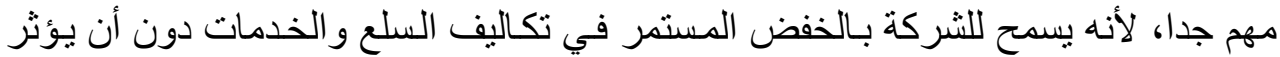
ذلك سلبا في القيمة التي يعطيها الزبون لهذه السلعة و الخدمات وبذلك تحقق الشركة ميزة

تنافسية جو هرية.

ثالثاً. تكامل إعادة هندسة العمليات مع مناهج خفض التكاليف الأخرى

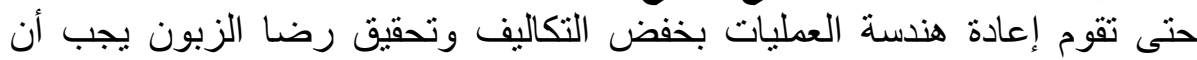

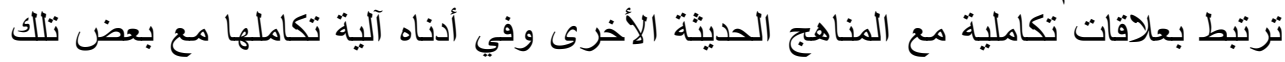

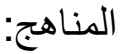

أ ـ إعادة هندسة العمليات باعتماد الإدارة على أساس الأنشطة (ABM)

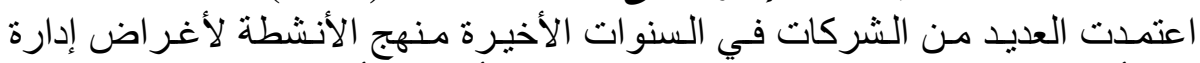

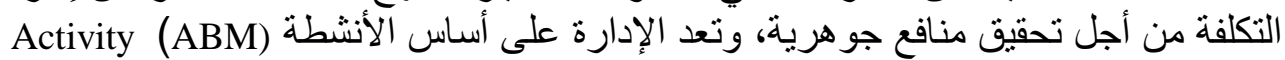
Based Management

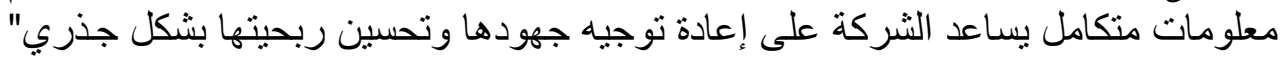
.(Frances, 1994, 38)

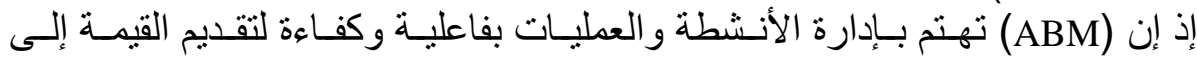

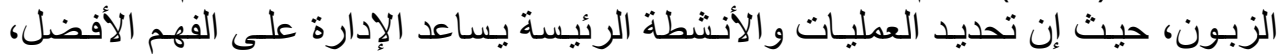

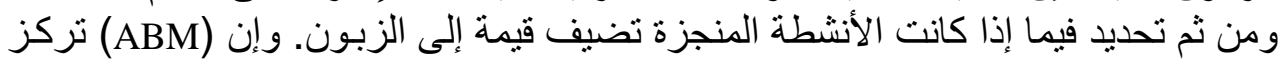

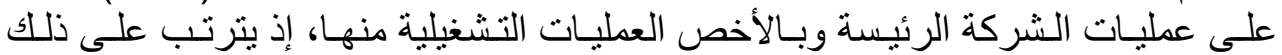

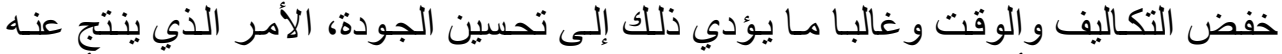

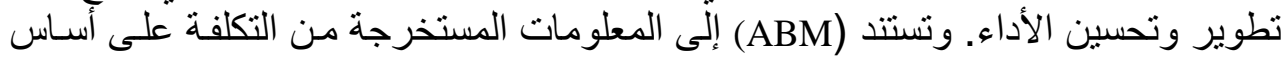

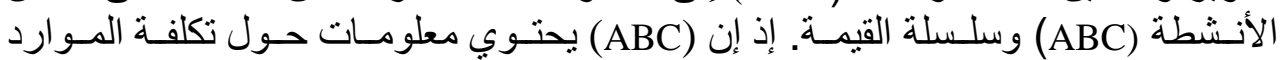

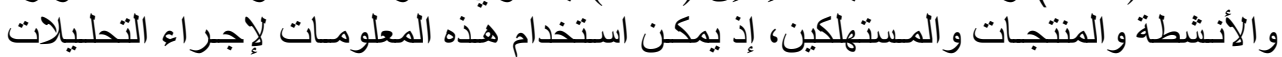

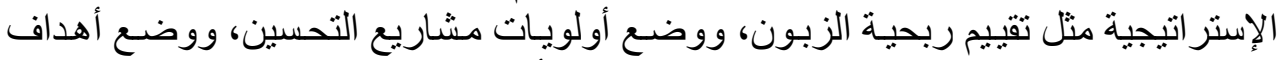

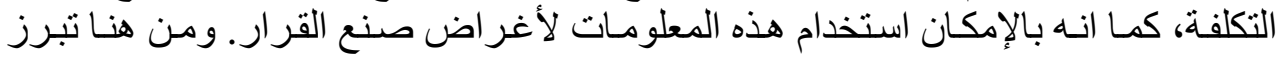

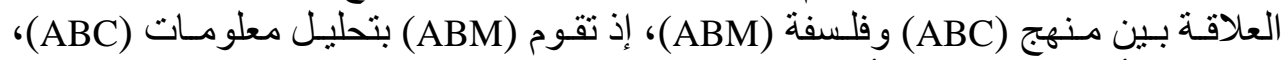

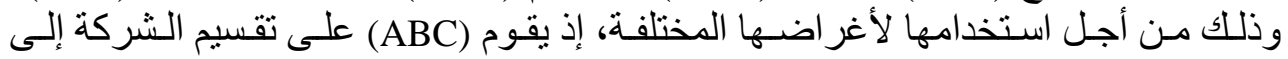




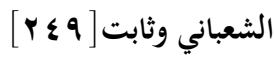

أنشطة وتحليل تلك الأنشطة وربطها بعلاقة سبيية مـ التكاليف غير المباشـرة، فتتبع أثر

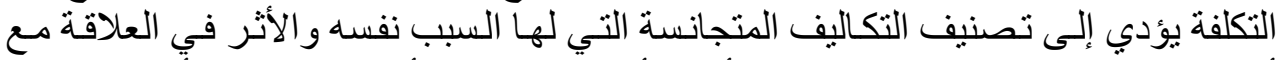

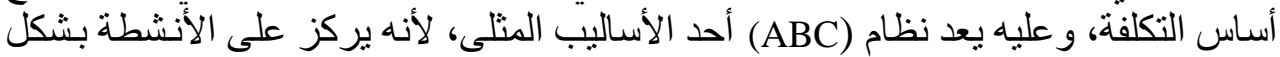

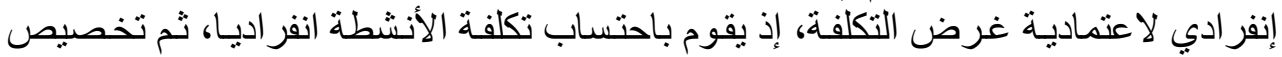

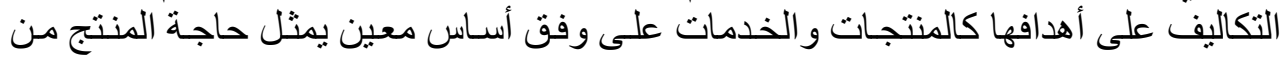

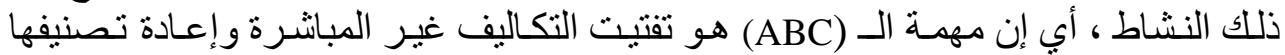

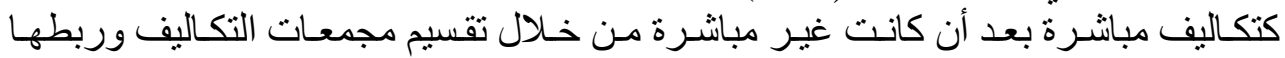

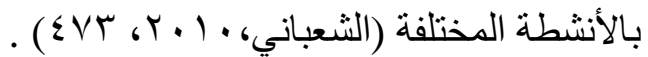

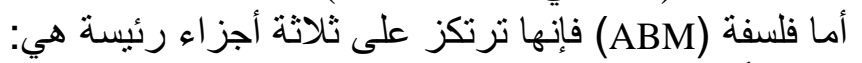
أ. أ. تصنيف الأنشطة على النحو الآتي:

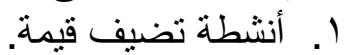

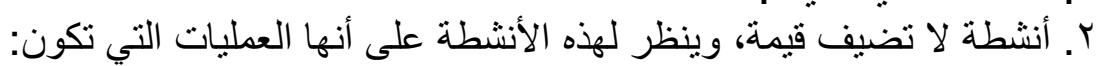

$$
\text { - غير ضرورية ويمكن الاستغناء عنها. }
$$
ـ ض ضرورية ولكنها غير كفوة و وغير قابلة للتحسين.

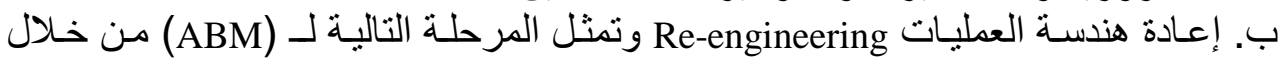

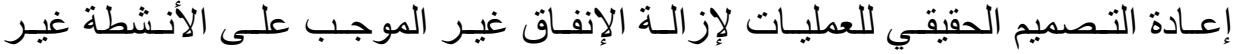

المضيفة للقيمة.

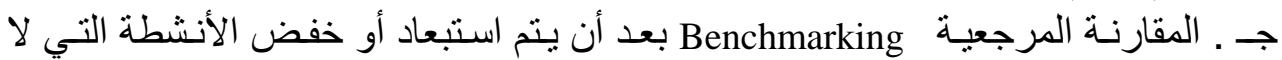

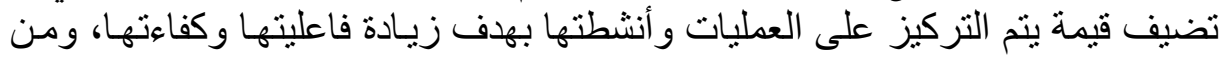

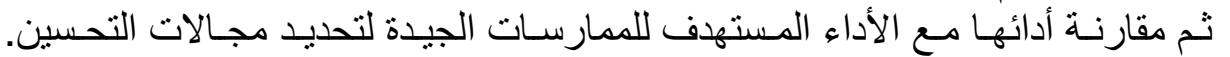

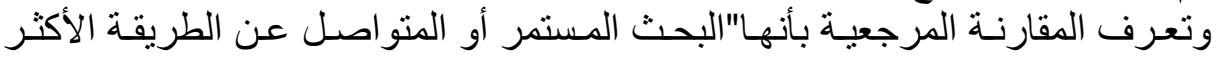

فعالية في إنجاز أو إتمام المهمات أو المعارسات الإدارية (Hilton et al, 2006, 10).

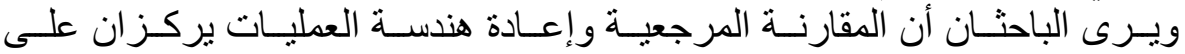

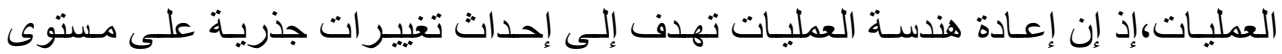

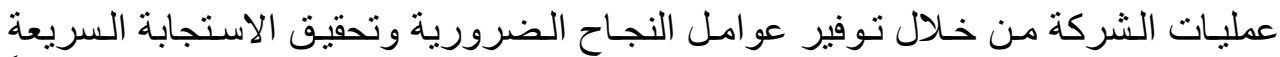

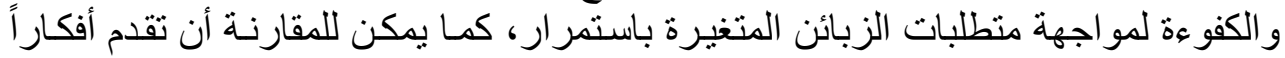

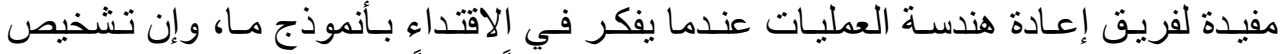

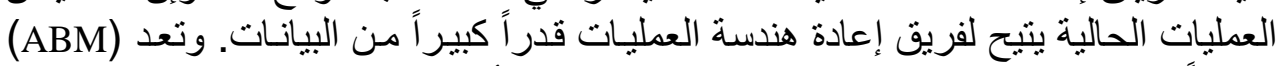

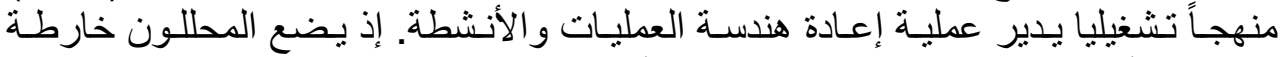

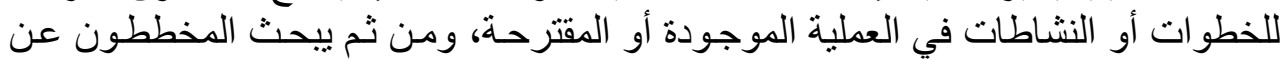

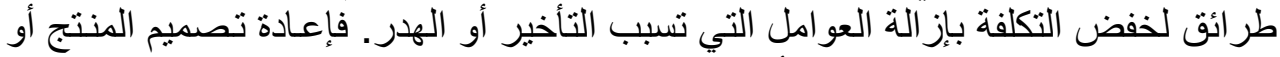

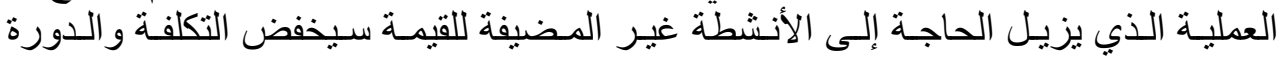
الزمنية، وغالبا ما يؤدي إلى زيادة جودة المنتج.وبناء عليه يمكن للنشركة أن تخفض تكاليفة اللفها

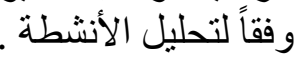

ب. إعادة هندسة العمليات باعتماد منهج التكلفة المستهذفة

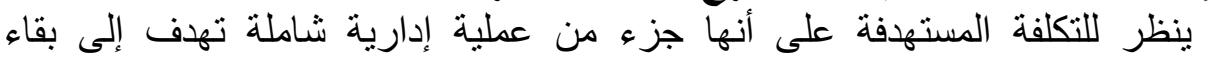

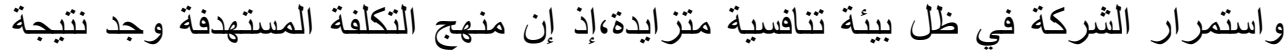

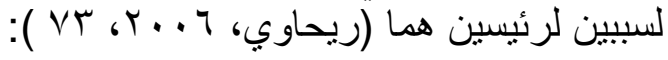




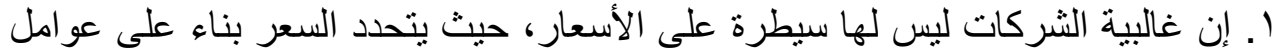
العرض و الطلب والثركة التي تتجاهل ذللك تتعرض للخطرة التهر، لذللك فان سعر السوق

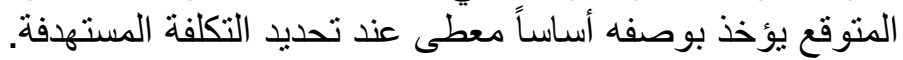

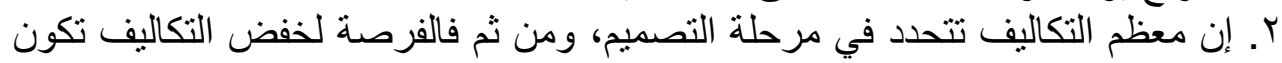

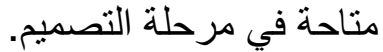
عليه فإن منهج التكلفة المستهدفة يعتمد على تلتابع خطو ات التفكير لتحديد تكلفة المنتج

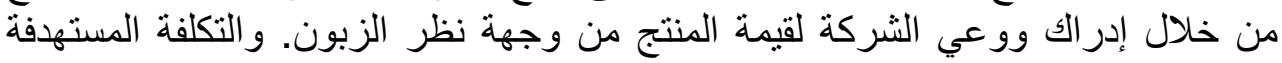

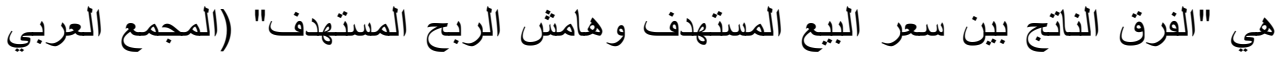

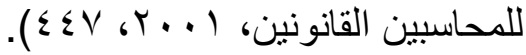

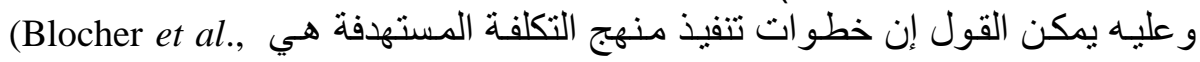
:2005, 136)

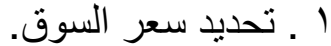
r ا ـ الحديد الربح المستهدف.

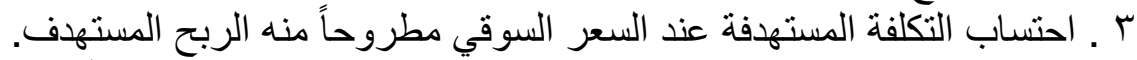

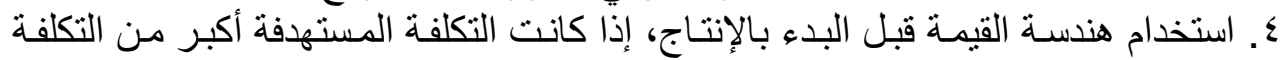
المخططـة لتحديـد طر ائق خفض تكلفـة المنتجه، إذ إن هندسـة القيمـة تتطلب استـعمال التحليل الوظائفي الذي يتضمن تحليل المنتج إلى العديد من العناصـر لتحديد الوظـائف لإنف

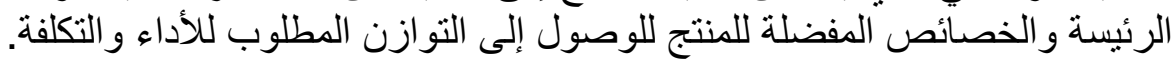

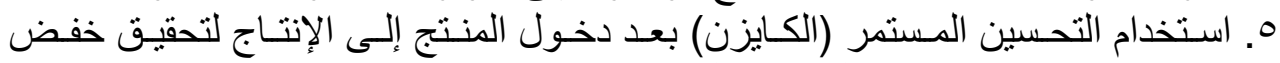
إضافي في التكلفة، إذ يتم التركيز على العملية وليس المنتج نفسه.

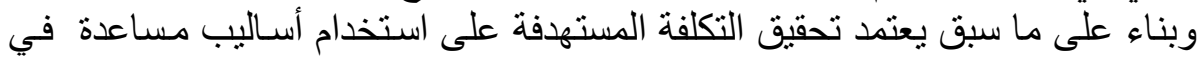

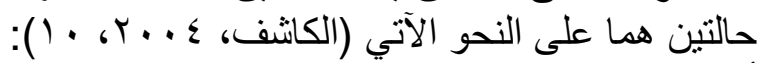

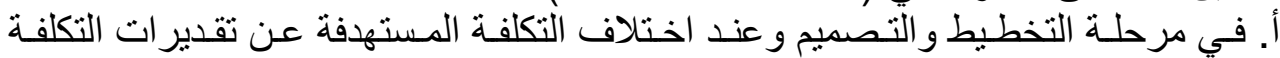

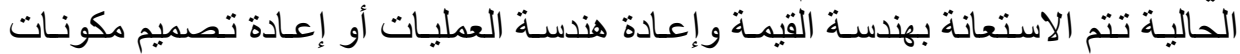

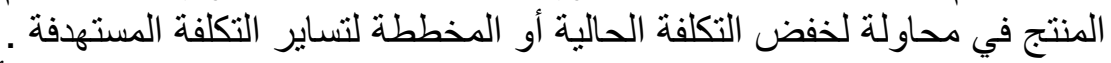

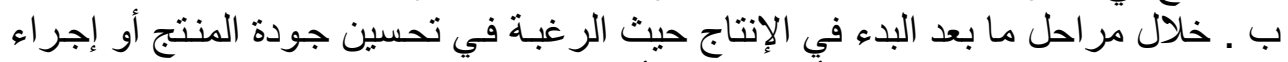

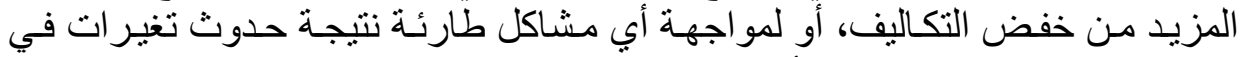
ظروف السوق، مما بستدعي الأمر اللجوء اللى منهج التحسين المستمر للعمليات.

ج ـ إعادة هندسة العمليات ومنهج هندسة القيمة

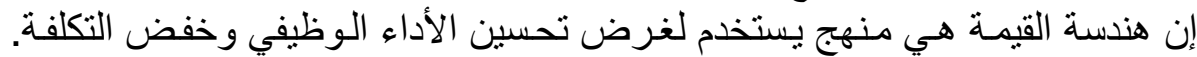

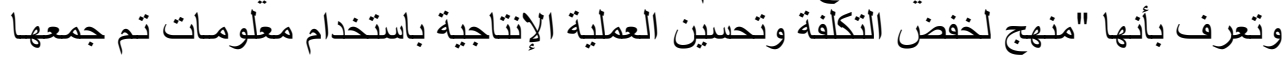

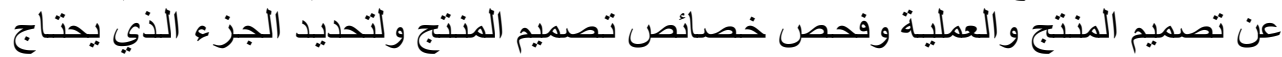
إلى جهود معينة لتحسينه" (Hilton et a.l, 2006, 220).

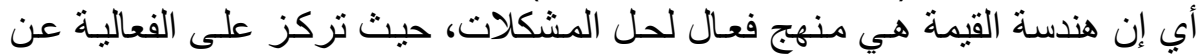

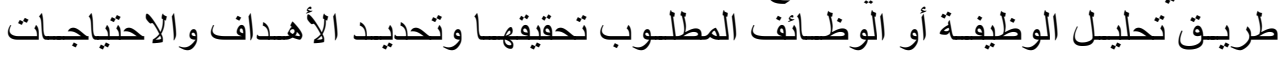

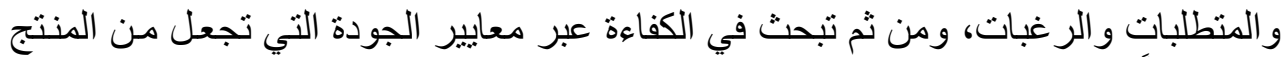

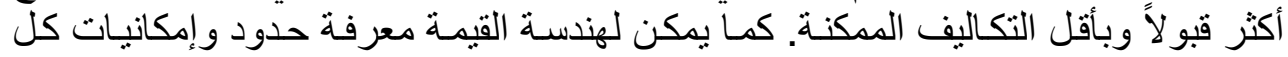




\section{الشعباني وثابت[ [}

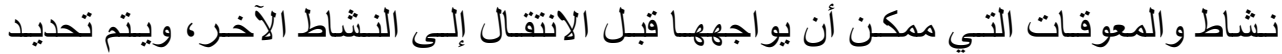
خصائص القيمة للمنتج على وفق جلسات الإبتكار و الإبداع للبحث عن بدائل لأجز اء التهاء المنتج

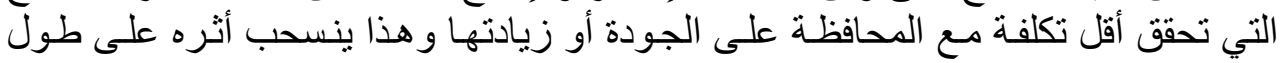

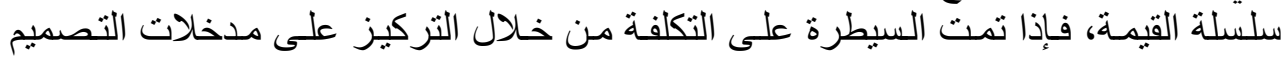

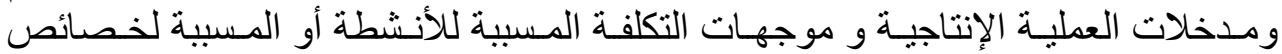

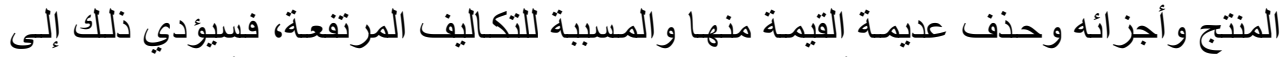

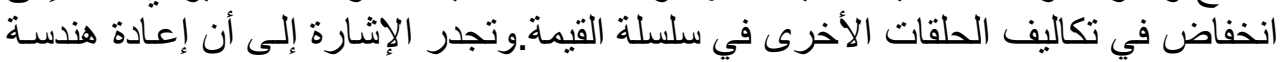

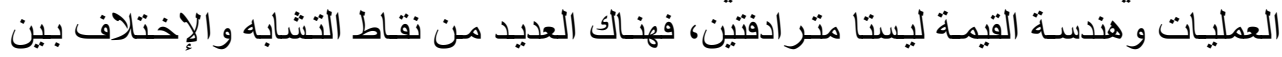

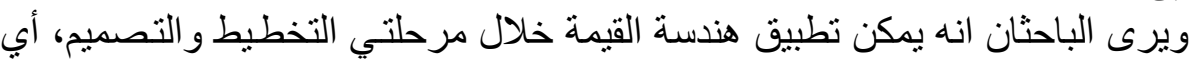
المنهجين.

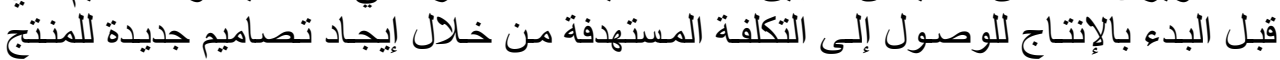

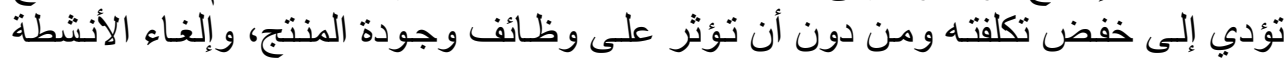

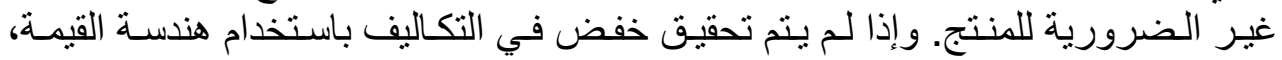

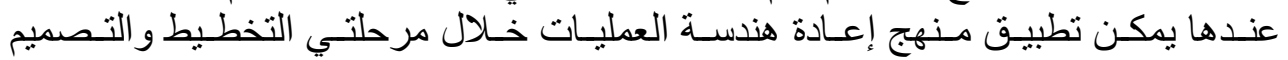

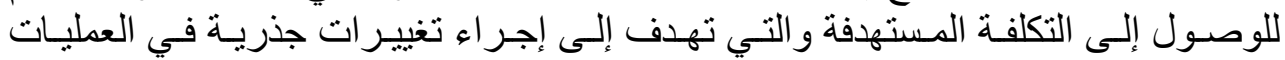

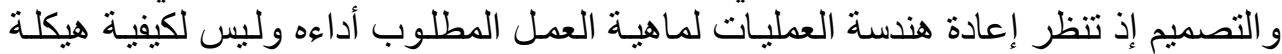

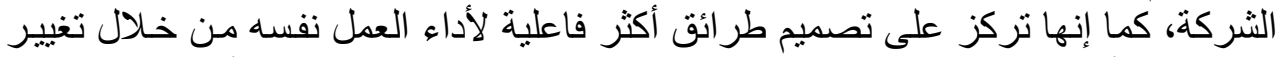

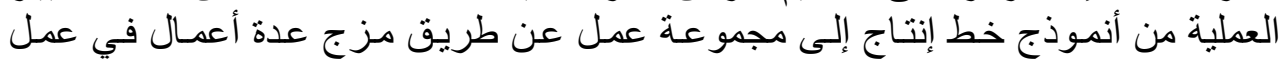

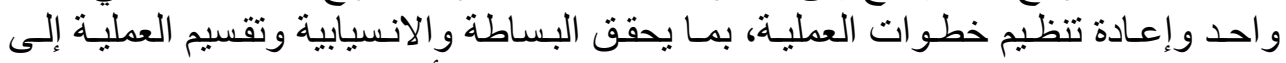

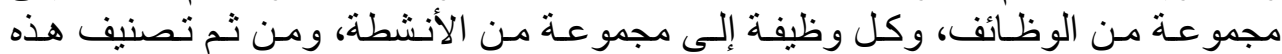

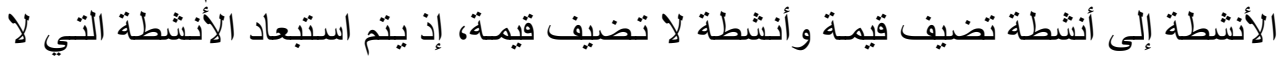

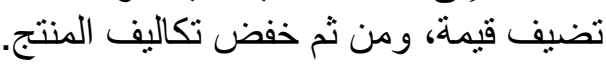

\section{دـ إعادة هندسة العمليات ومنهج التحسين المستمر}

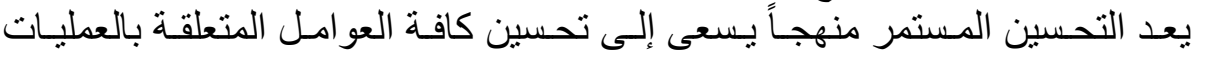

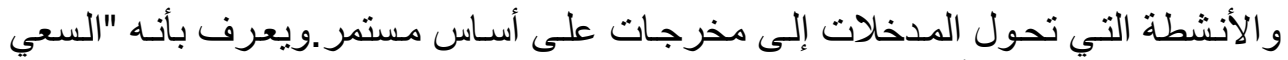

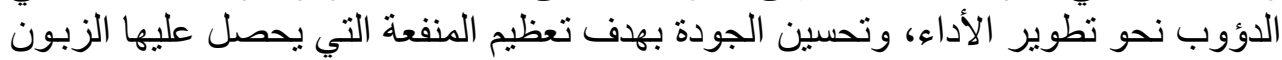

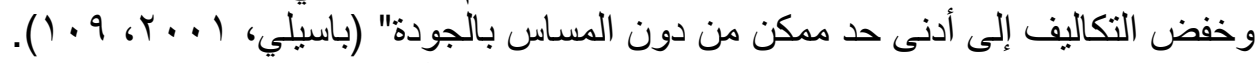

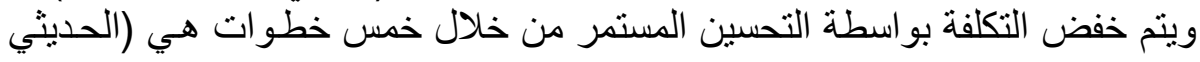

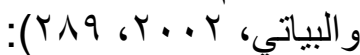

$$
\begin{aligned}
& \text { ا و الصبانة. } \\
& \text { r. ب.النظافة. } \\
& \text { ץ. الترتيب. } \\
& \text { ع ـالتظظي. } \\
& \text { 0. الانضباط. }
\end{aligned}
$$

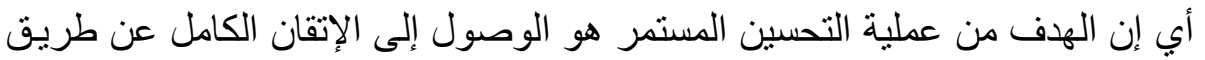

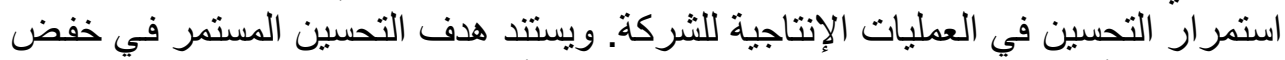

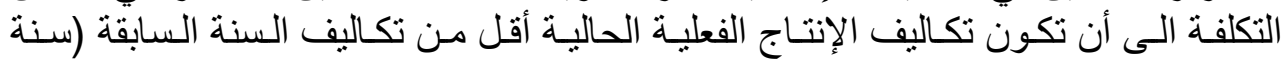




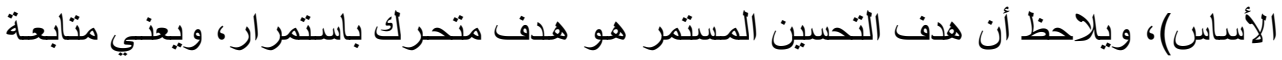

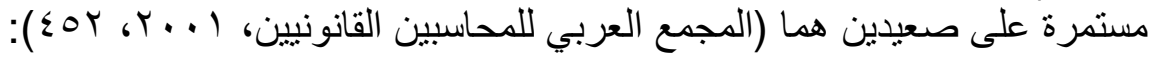

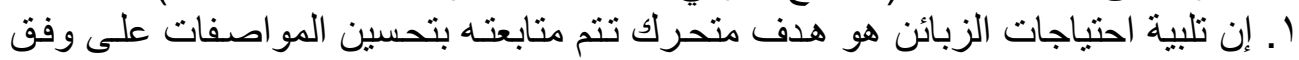
متطلبات الزبائن المتغيرة.

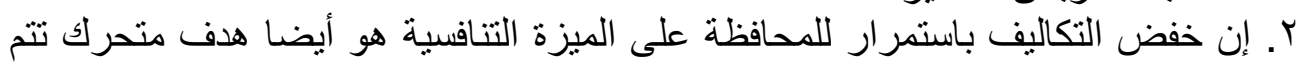

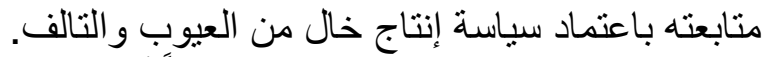

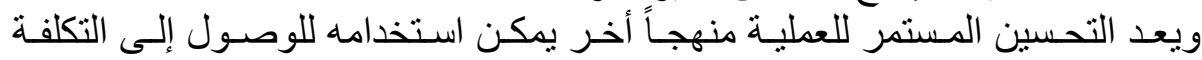

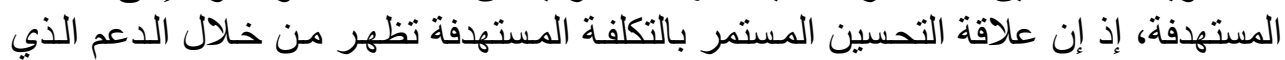

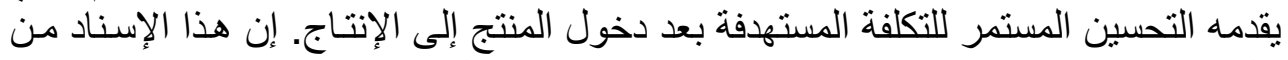

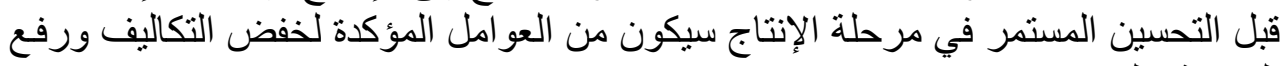

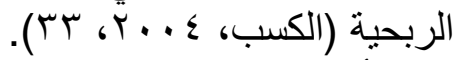

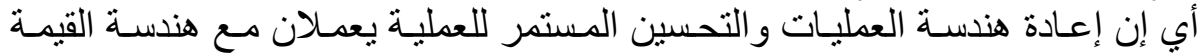
لتحقيق الخفض المستهدف في التكلفة عند زيـادة تقديرات التكلفة الحالية للمنتج عن تكلفته التهات

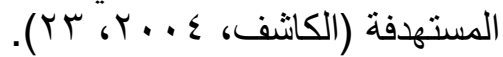

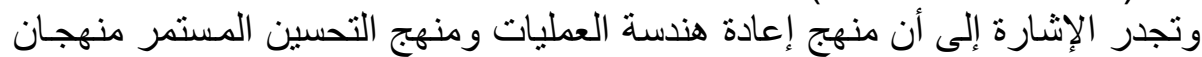

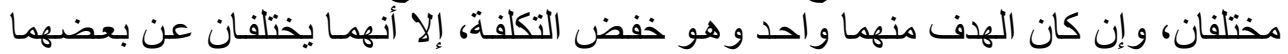

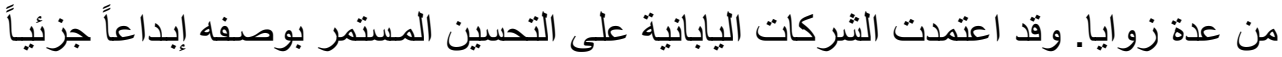

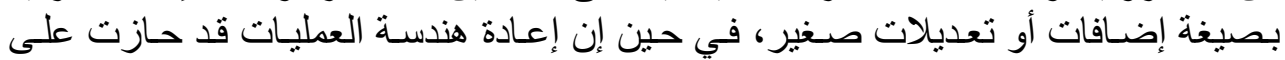

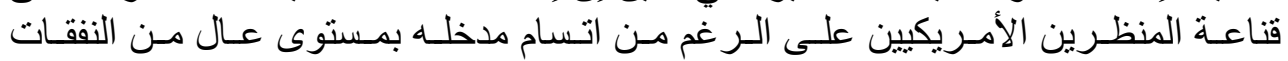

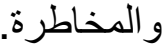

هـ. إعادة هندسة العمليات وإدارة الجودة الثاملة

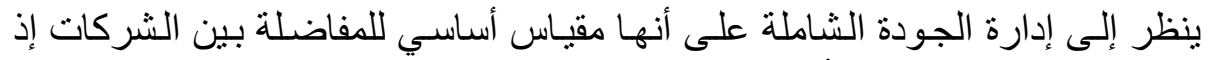

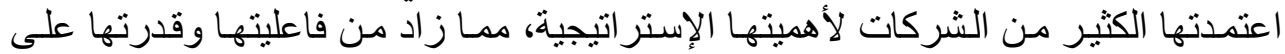

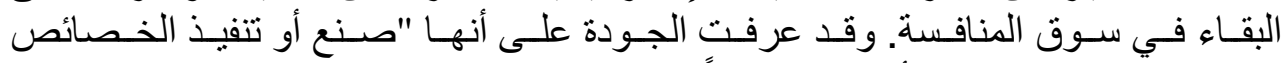

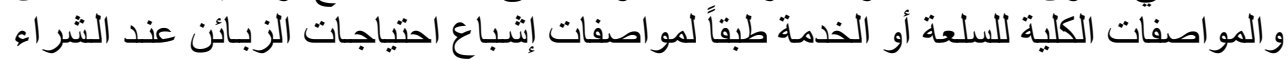

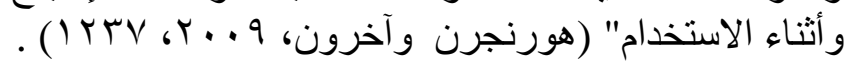

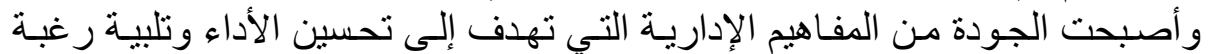

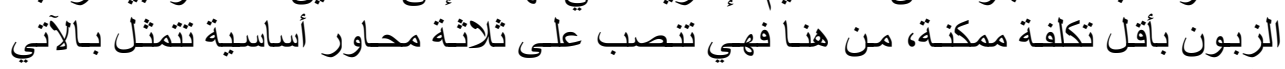

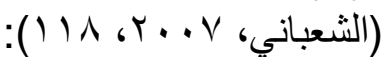
أ. الريادة في تلبية حاجة الزبون الزيون.

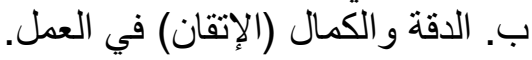

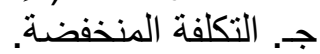

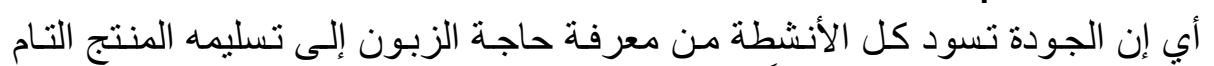

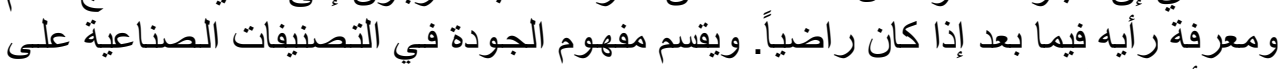

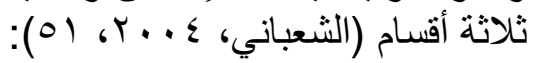

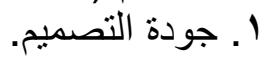

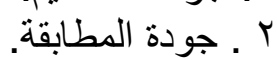




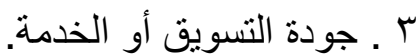

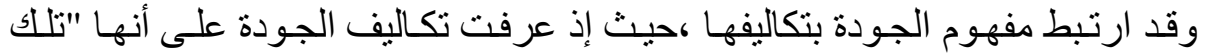

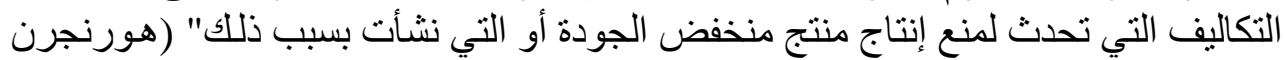

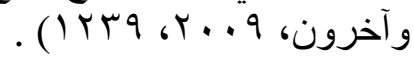

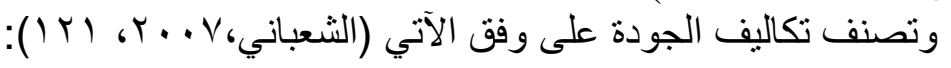

$$
\begin{aligned}
& \text { 1. تكاليف ظاهرية: وتضم } \\
& \text { أ. تكاليف الرقابة وتتضمن: } \\
& \text { (1) (كاليف التقويم و المنع). } \\
& \text { ب (r) تكاليف التقويم. } \\
& \text { ب . تكاليف الفنشل وتتضمن: } \\
& \text { (Y) (باليف الفنشل الداخلي. } \\
& \text { r. (Y) تكاليف الفنّل الخارجي. } \\
& \text { r. التكاليف الخفية للجودة }
\end{aligned}
$$

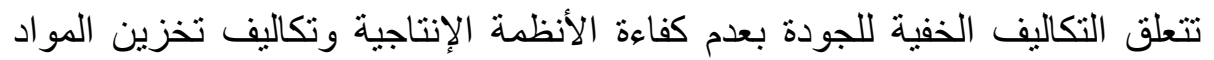

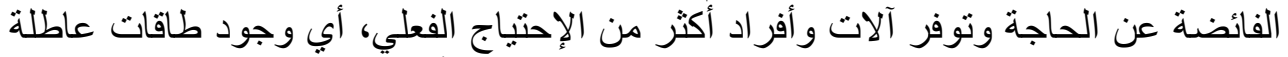

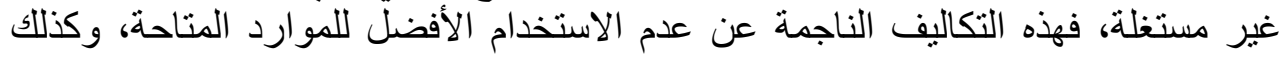

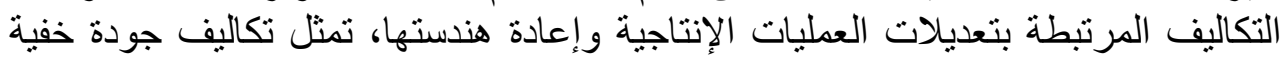

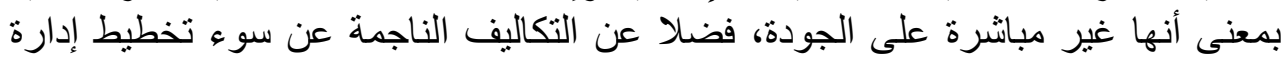

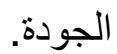

وقد أثنار العديد من الباحثين إلى وجود بعض من أوجه الإختلاف و الإتفاق بين إدارة

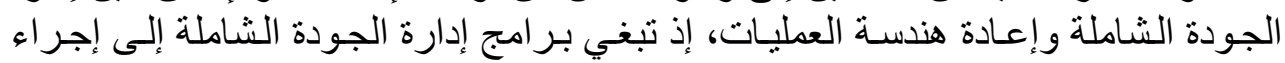

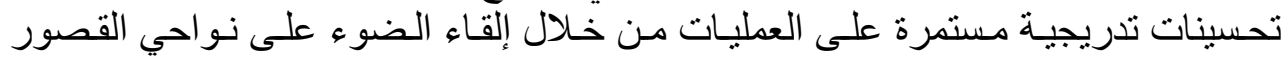

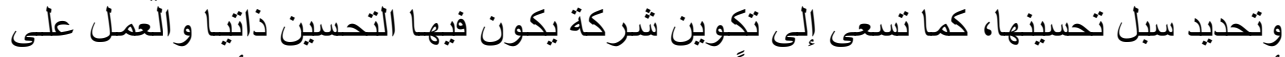

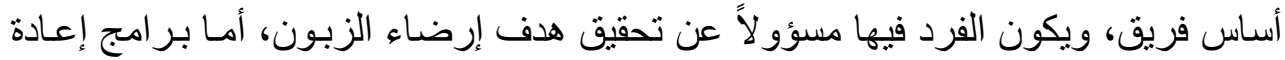

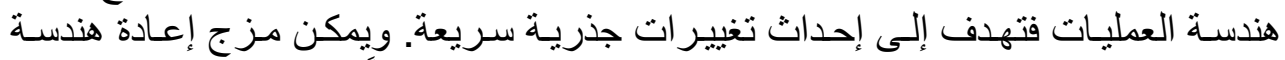

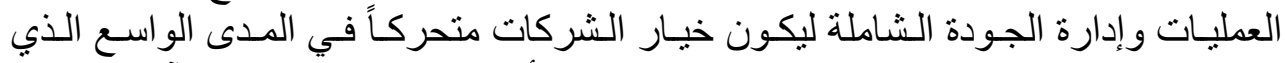

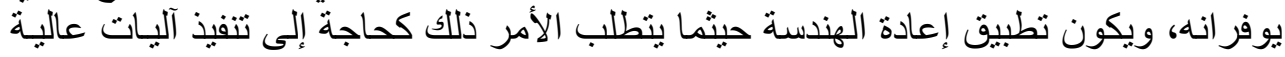

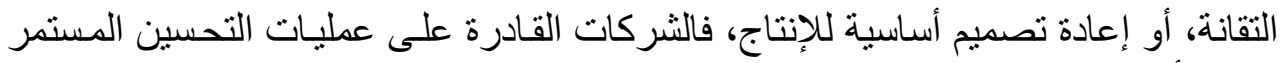

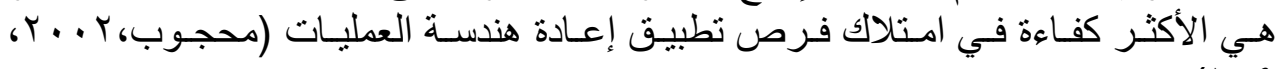

ويرى الباحثان أن إدارة تكاليف الجودة سوف تؤدي إلى خفض تكاليف الإنتاج من

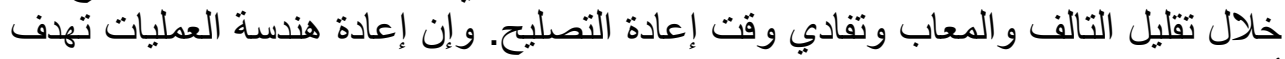

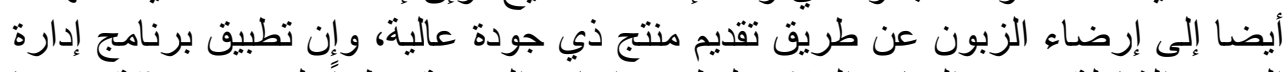

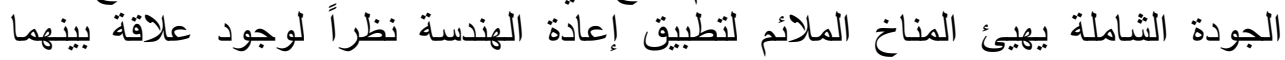

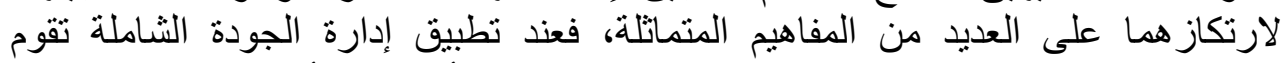

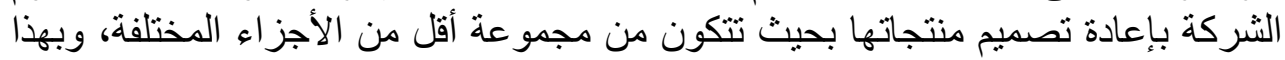
يمكنها من تحقيق رقابة محكمة على جودة منتجاتها التي يتم تجهيز ها، وتتم كذلت التك إعادة 
هندسة العمليات الإنتاجية من خلالها لخفض العيوب في الإنتاج. وهذا ما يسهل نجاح تطبيق إعادة الهندسة.

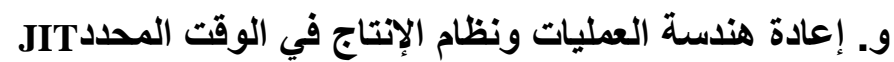

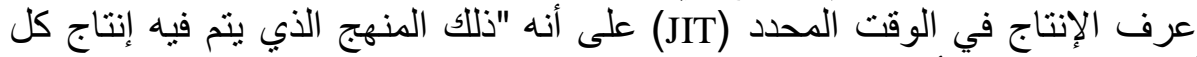

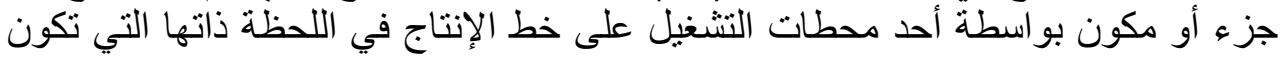

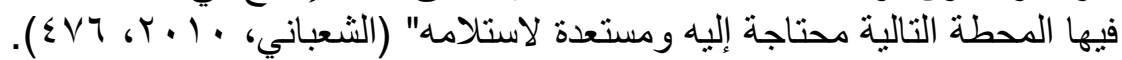

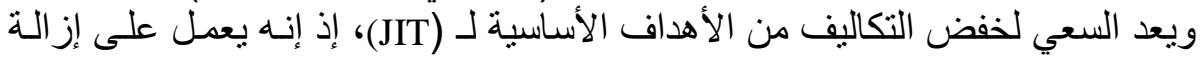

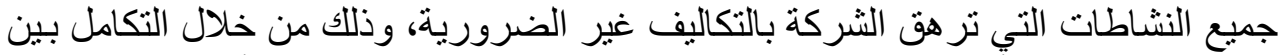

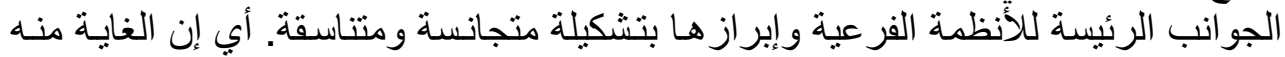

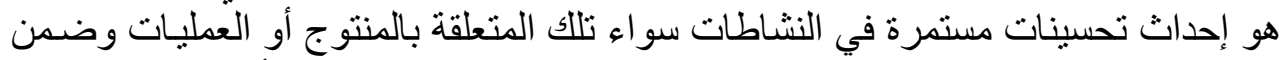

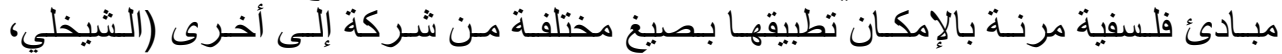
.(Ar 6) 991

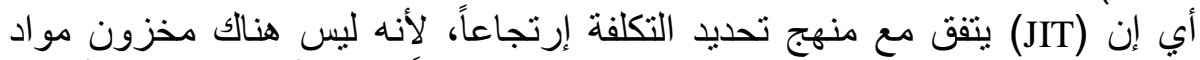

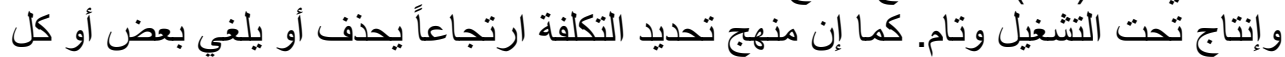

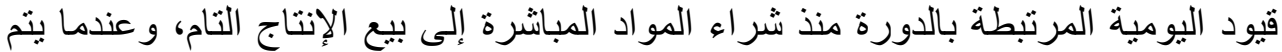

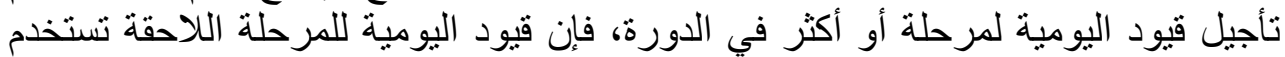

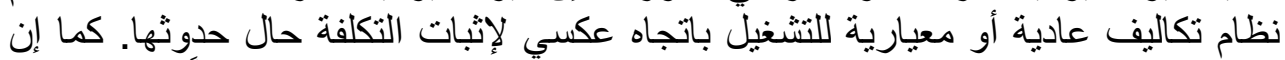

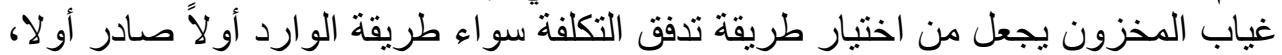

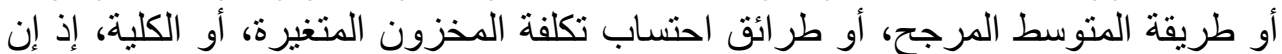

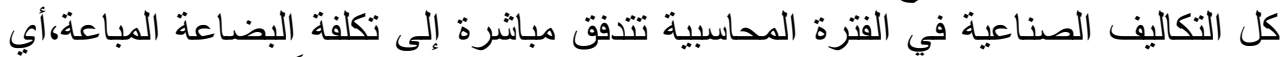

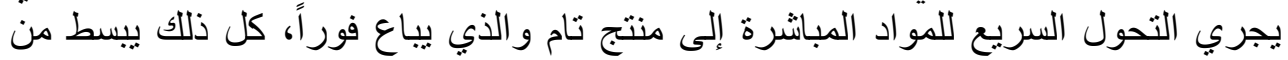

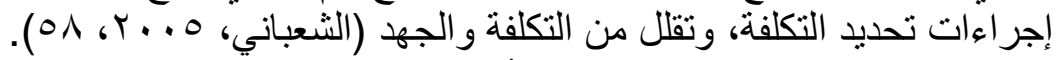

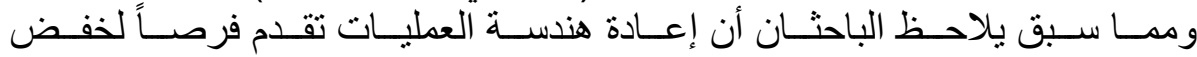

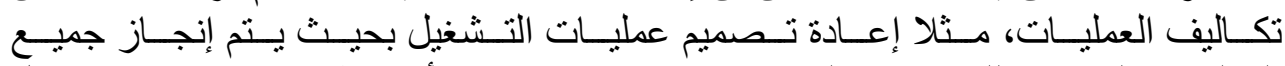

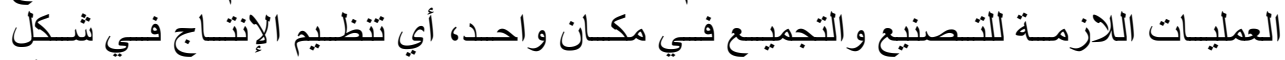

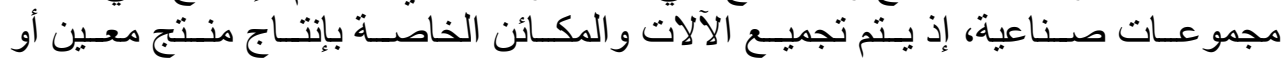

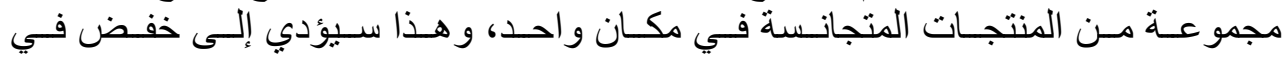

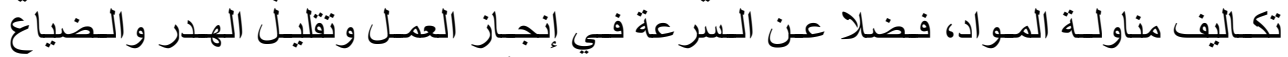

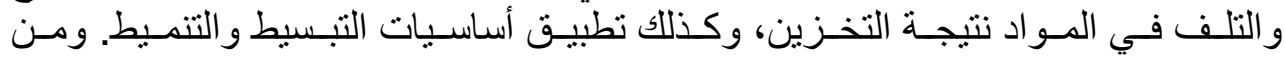

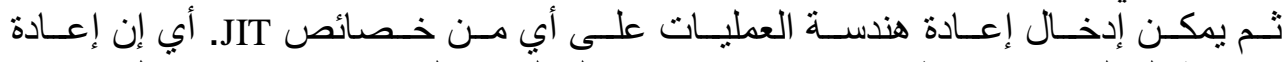

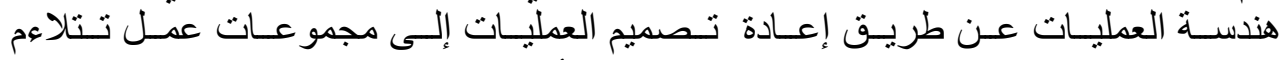

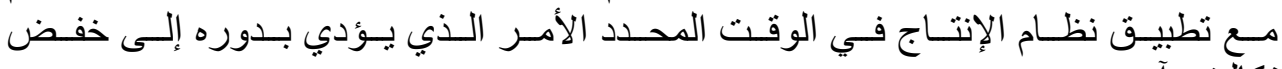
تكاليفي آخر. 
المحور الثالثـ أثث تطبيق إعادة هندسة العمليات الإنتاجية على التكاليف في الثركة قيد

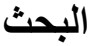

في ضِو خطو ات ومر احل إعادة هندسة العمليات التي وردت في الجانب النظري

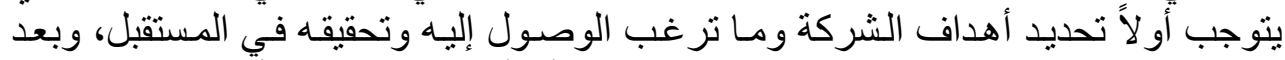

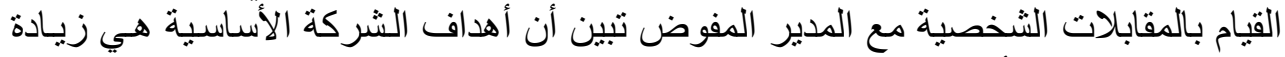

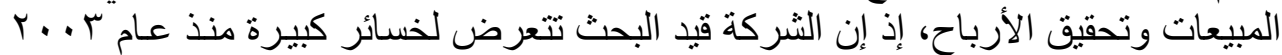

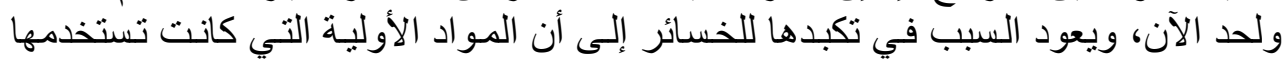

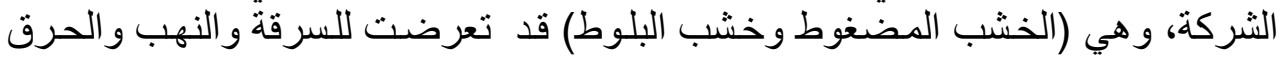

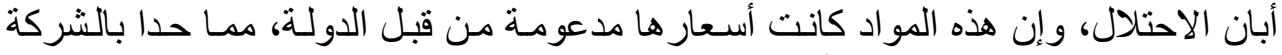

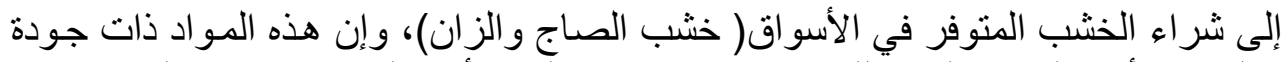

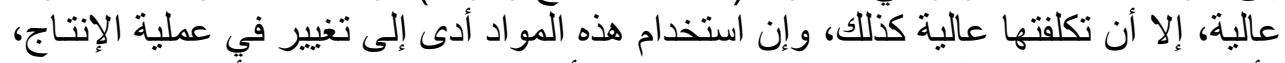

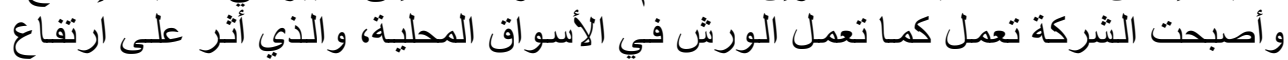

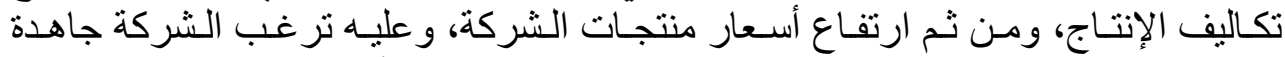

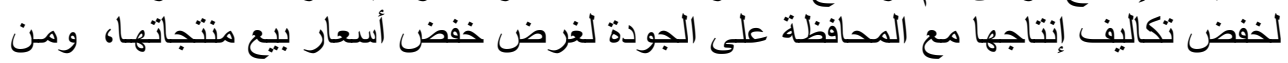

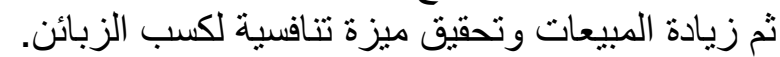

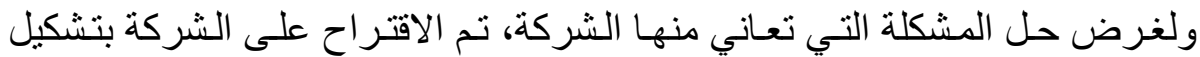

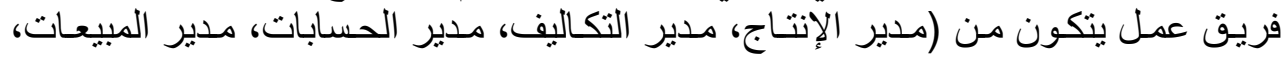

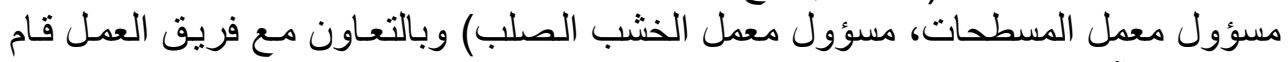

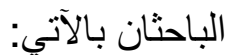
أ. توضيح مفهوم إعـادة هندسة العمليـات الإنتاجيـة و أهيتها و الأهداف التي تسعى إلىى

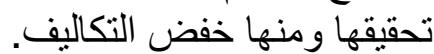

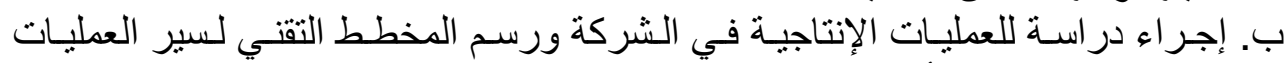

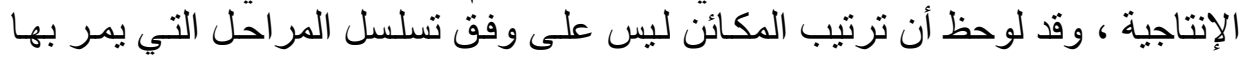

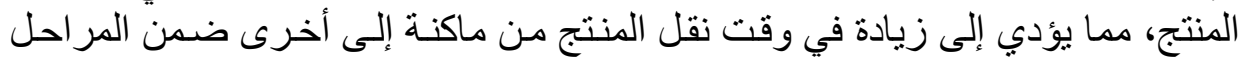

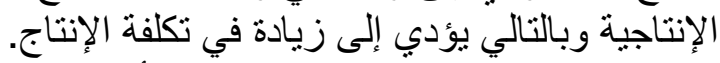

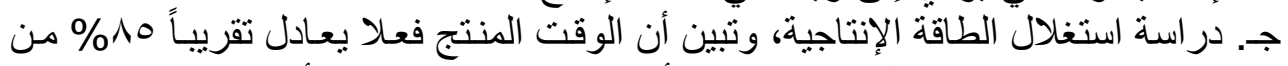

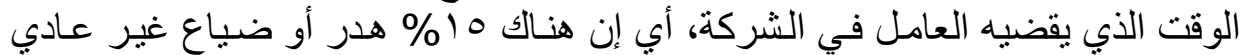

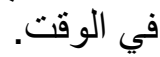

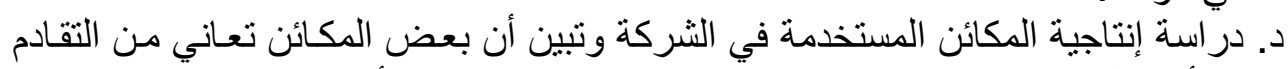

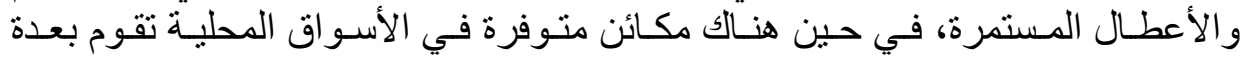

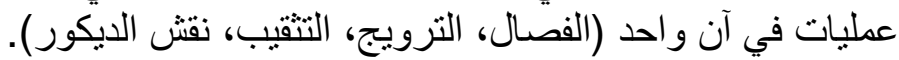

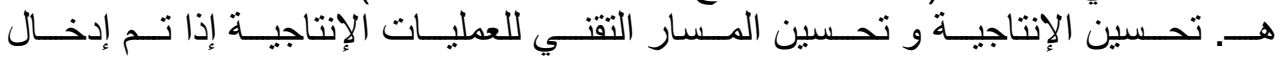
الماكنة المقترحة (المطورة).

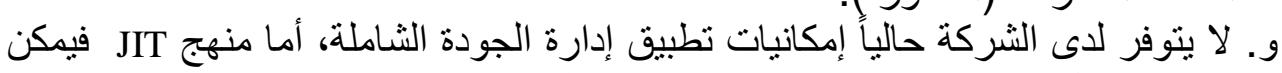

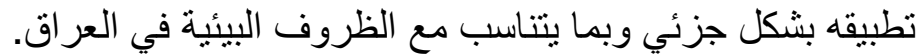

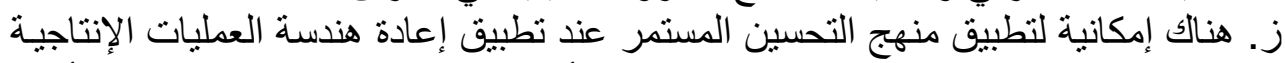

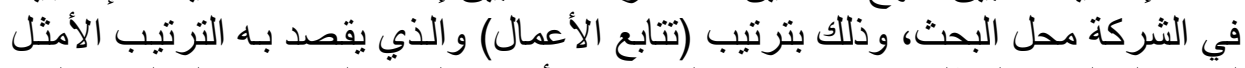

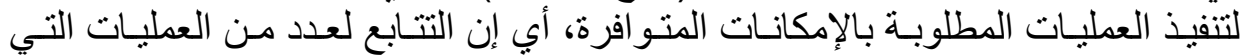

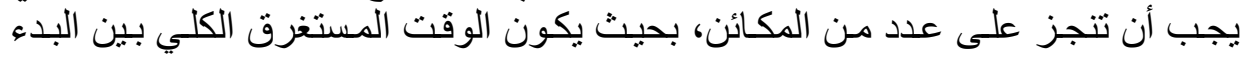


بالعملية الإنتاجية الأولى على الماكنة الأولى ولحين اكتمـال العمليـة الإنتاجية الأخيرة

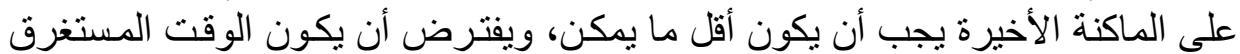

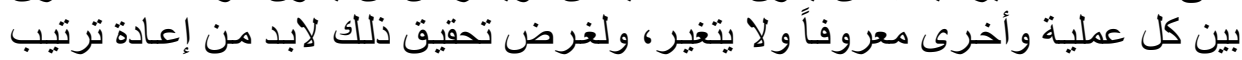

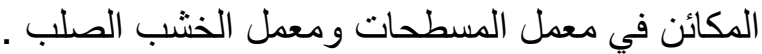

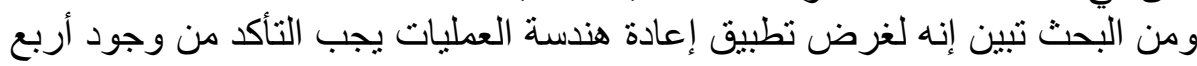

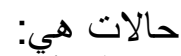
الحالة الأولى: الوضع الحالي للمكائن كما هي الحال في الشركة محل البحث إذ إن ترتيب المكائن ليس على وفق تسلسل الئل المر احل الإنتاجية المانية.

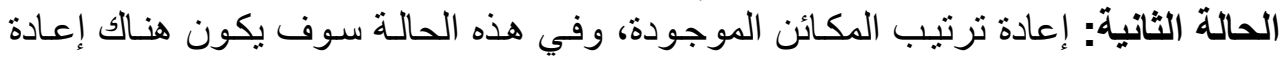

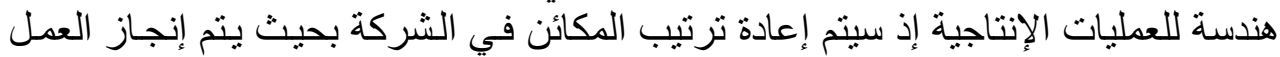

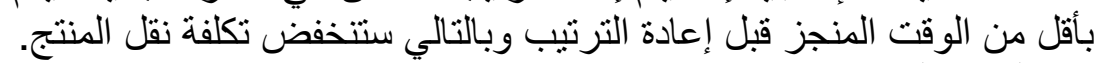

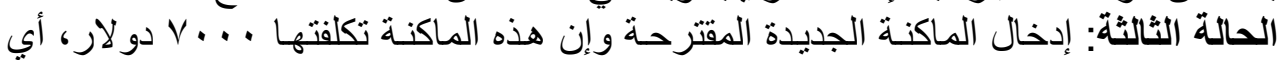

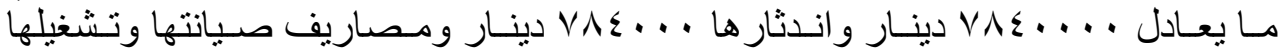
(

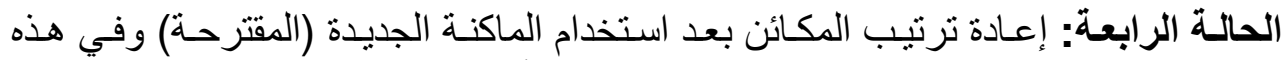

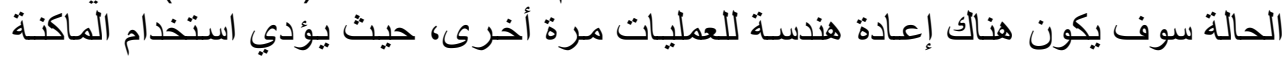

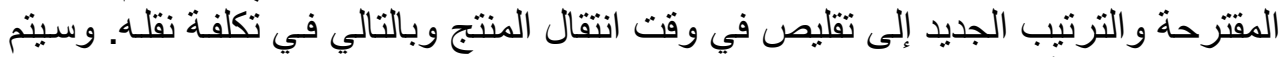
تطبيق البدائل الأربعة في كلا المعملين على وفيد في الآتي:

$$
\text { أولاًَ- تطبيق البدائل الأربعة في معمل الخشب المسطحات }
$$

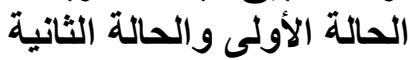

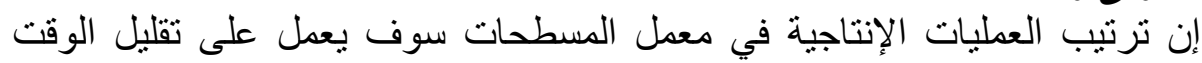

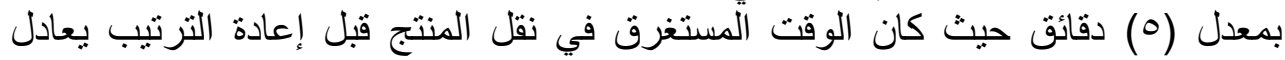

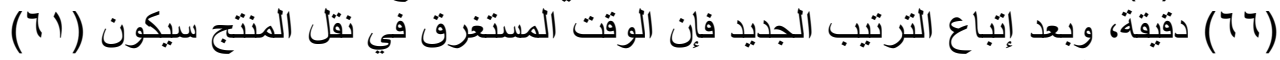

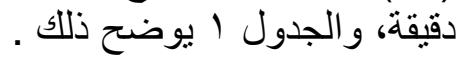

\begin{tabular}{|c|c|c|}
\hline \multicolumn{3}{|c|}{ مقارنة الوقت المستغرق لنقل منتج معين قبل ترتيب المكائن القديم والترتيب الجديد المعلي } \\
\hline الترتيب الجديد المقترح(الحالة الثانية) & التزتيب القديم (الحالة الأولى) & المكائن/الزمن \\
\hline 9 & 1. & تقطيع - فصال \\
\hline 7.0 & $\mathrm{~V} .0$ & فصال - كبس \\
\hline V.o & $\Lambda$ & كبس - ترويج \\
\hline 7.0 & $V_{.0}$ & ترويج - نتقيب \\
\hline$\Lambda$ & 9 & تثقبب - نقش الديكور \\
\hline 1.0 & 9 & نقش الديكور - لصق الحافات \\
\hline 0 & 0 & لصق الحافات - تجميع \\
\hline
\end{tabular}


[rov] الشعباني وثابت

\begin{tabular}{|c|c|c|}
\hline الترتيب الجديد المقترح(الحالة الثاتية) & الترتيب القديم (الحالة الأولى) & المكائن/الزمن \\
\hline 0 & 0 & تجميع - صباغة \\
\hline 0 & 0 & صباغة ـ شد اللوازم \\
\hline 71 & 77 & المجموع \\
\hline
\end{tabular}

و عليـه سـيؤدي اسـتخدام الترنيـب الجديـد إلـى خفض في تكلفـة الوقت في معدـل

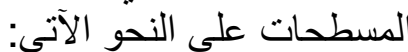

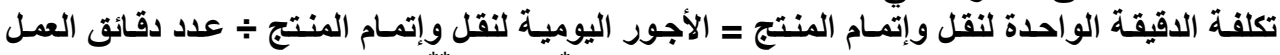
* $\varepsilon$ r. $\div$ * Y $900 Y V=$ اليومية لنقل وإتمام منتج معين

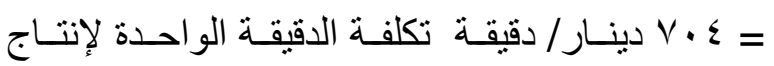
منتج معين

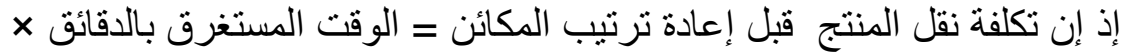

$$
\text { تكلفة الدقيقة الواحدة }
$$

.

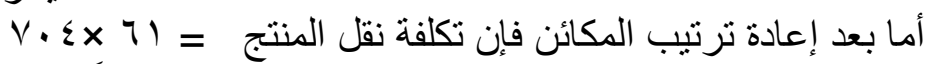
. نصأ

$\varepsilon$ ห $\leqslant \varepsilon-\varepsilon \neg \varepsilon \neg \varepsilon=$

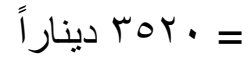
إذا الخفض في تكلفة الوقت عن الحالة الأولى

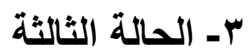

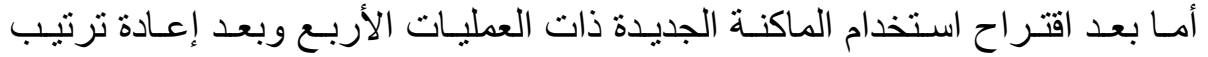

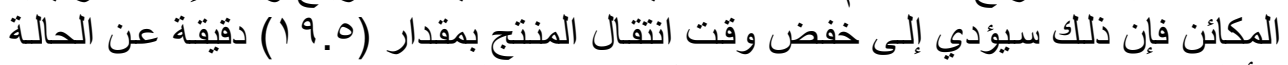

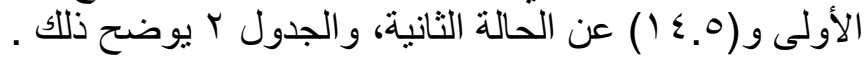

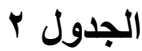

مقارنة الوقت المستغرق لنقل منتج معين قبل وبعد الترتيب المقترح والتحسين باستخدام

\begin{tabular}{|c|c|c|c|}
\hline 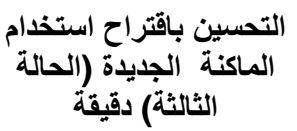 & المقترح (الحالية الجديد & (الحالة الأوتيلى) & المكائن/الزمن \\
\hline 9 & 9 & 1. & تشريح وتقطيع - فصال \\
\hline 7.0 & 7.0 & $V .0$ & فصنال - كبس \\
\hline \multirow[t]{2}{*}{$\mathrm{V.O}$} & $\mathrm{V} .0$ & $\Lambda$ & كبس - ترويج \\
\hline & 7.0 & V.o & ترويج - تثقيب \\
\hline
\end{tabular}

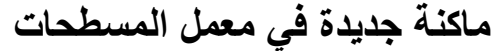

* الأجور اليومية لنقل و إتمام المنتج = الأجور الثهرية لنقل و إتمام منتج معين؟ عدد أيام العمل في الثهر

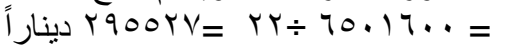

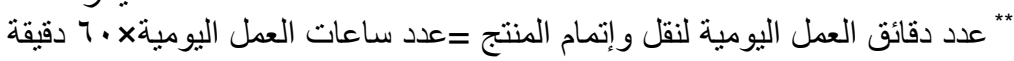

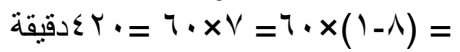




\begin{tabular}{|c|c|c|c|}
\hline 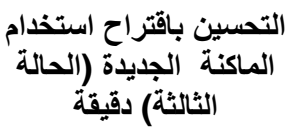 & الثقترتح (الجائة & (الحبلة الالوتئى) & المكائن/الزمن \\
\hline & $\Lambda$ & 9 & تثقيب - نقش الديكور \\
\hline 1.0 & 1.0 & 9 & نقش الديكور - لصق الحافات \\
\hline 0 & 0 & 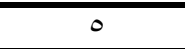 & لصن الحافات - تجميع \\
\hline 0 & 0 & 0 & تجميع - صباغة \\
\hline 0 & 0 & 0 & صباغة - شد اللوازم \\
\hline$\leqslant 7.0$ & 71 & 79 & المجموع \\
\hline
\end{tabular}

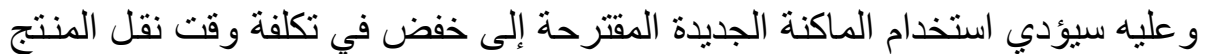

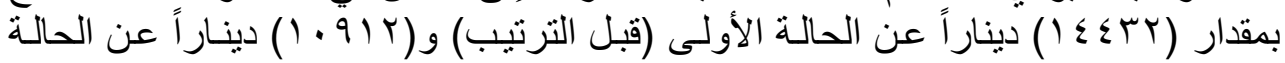

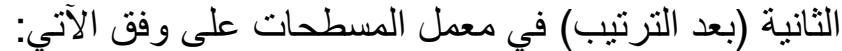

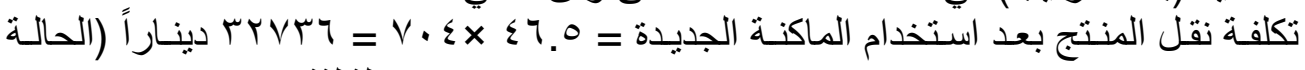
الثالثة)

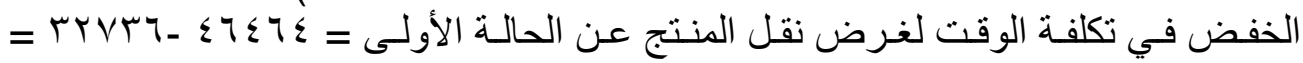

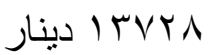

الخفض في تكلفة الوقت لغرض نقل المنتج عن الحالـة الثانيـة = ؟ ؟

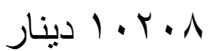

ـ - الحالة الرابعة

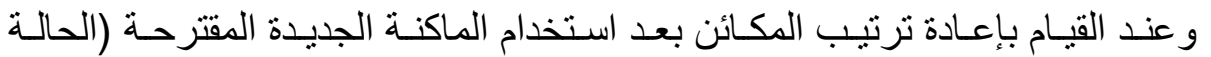

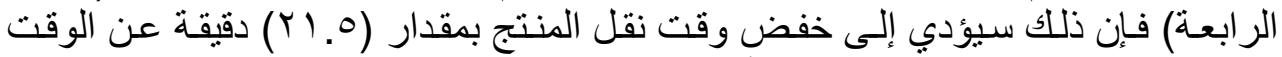

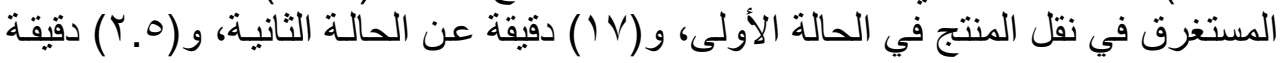

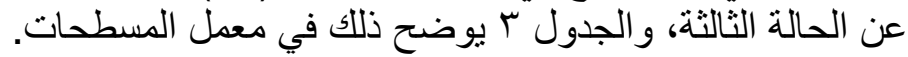

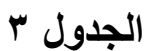

مقارنة الوقت المستغرق لنقل منتج معين قبل وبعد إعادة الترتيب واستخدام الماكنة

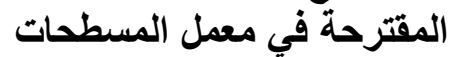

\begin{tabular}{|c|c|c|c|c|}
\hline (الجدايد الترتيب التخبين & 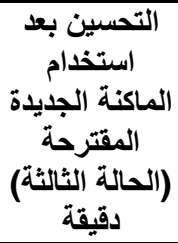 & 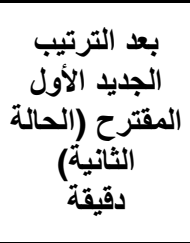 & (الحالة الأولّى) & المكائن/الزمن \\
\hline$\Lambda$ & 9 & 9 & $1 \cdot$ & تشريح وتقطيع - فصال \\
\hline 7 & 7.0 & 7.0 & $\mathrm{V.0}$ & فصال - كبس \\
\hline $\mathrm{V}$ & V.0 & $V .0$ & $\Lambda$ & كبس - ترويج \\
\hline .......... & $\ldots \ldots \ldots$ & 7.0 & $V .0$ & ترويج - تثقيب \\
\hline
\end{tabular}




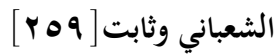

\begin{tabular}{|c|c|c|c|c|}
\hline 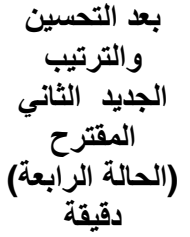 & 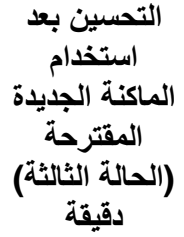 & 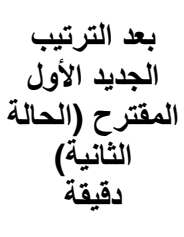 & (الحالة الأولِّ) & المكائن/الزمن \\
\hline$\ldots \ldots \ldots \ldots$ & $\ldots \ldots \ldots$ & $\Lambda$ & 9 & تثقيب - نقش الديكور \\
\hline$\wedge$ & 1.0 & 1.0 & 9 & نقش الديكور - لصق \\
\hline 0 & 0 & 0 & 0 & لصق الحافات ـتجميع \\
\hline 0 & 0 & 0 & 0 & تجميع - صباغة \\
\hline 0 & 0 & 0 & 0 & صباغة - شد اللوازم \\
\hline$\varepsilon \varepsilon$ & $\sum 7.0$ & 71 & 77 & المجموع \\
\hline
\end{tabular}

المصدر: الجدول من إعداد الباحثين

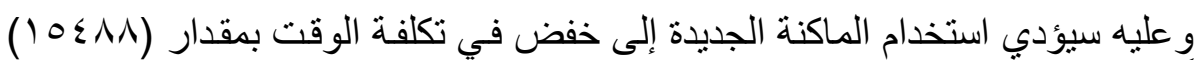

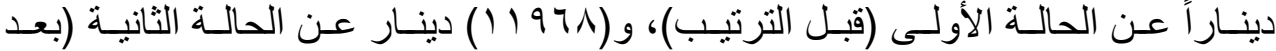

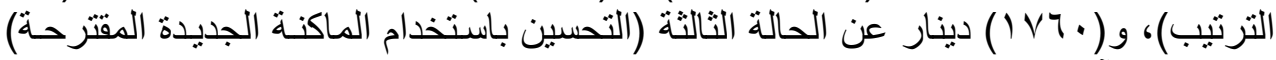

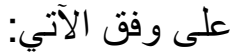

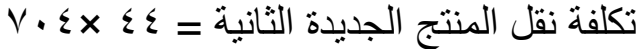

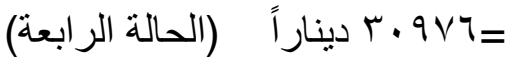

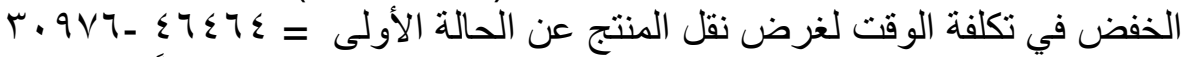

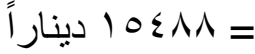

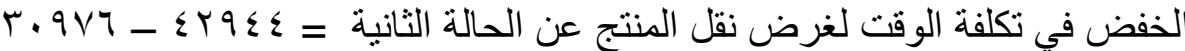
أ دينار $11971=$

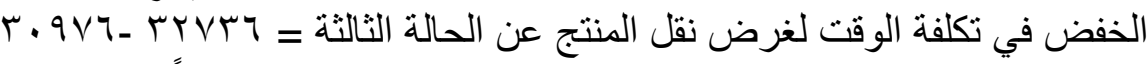

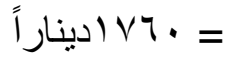

حالة تطبيقية على البدائل الأربعة المقترحة في معمل المسطحات

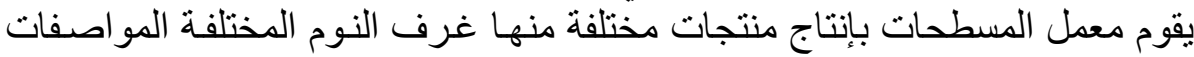

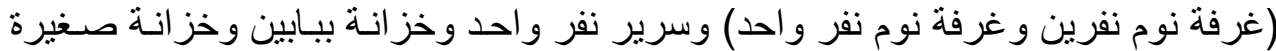

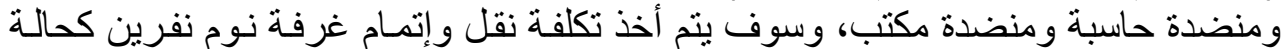

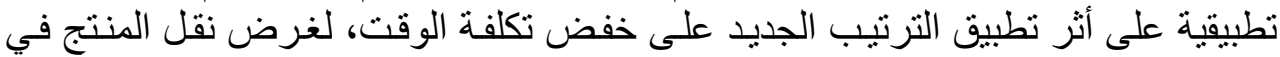

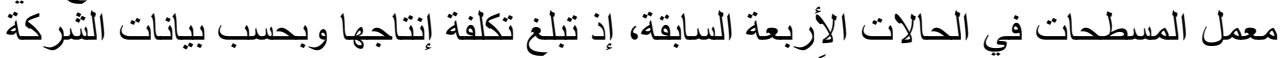

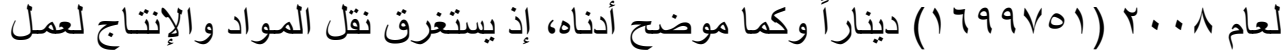

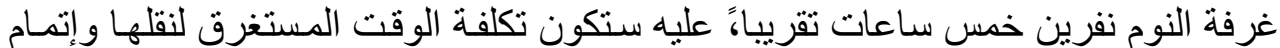
إنتاجها و الإنتاج بين العمليات الإنتاجية كالآتي:

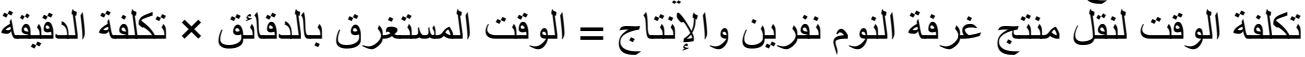
$V \cdot \varepsilon \times(\uparrow \cdot \times 0)=$

(

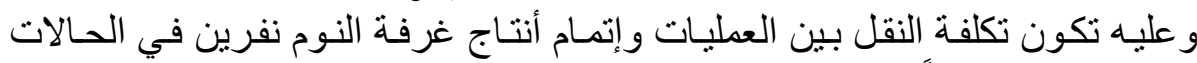
الأربعة المشار إليها سابقاً على النحو الآتي: 


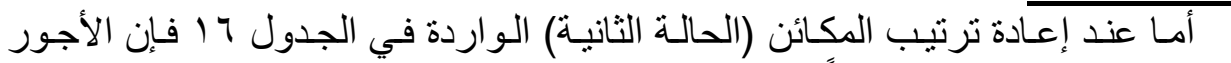

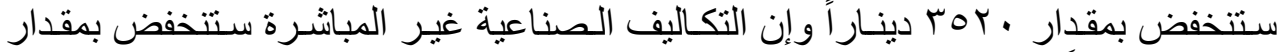

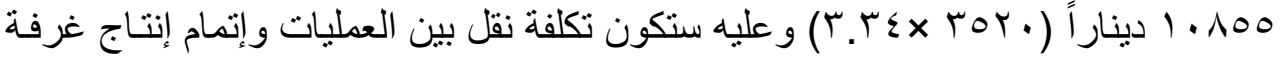

$$
\begin{aligned}
& \text { VATI } \leqslant T \\
& \text { النوم على وفق الآتي: } \\
& \text { r.VuA. } \\
& \text { تكلفة المو اد المباثرة الأني: } \\
& \text { أYنار }
\end{aligned}
$$

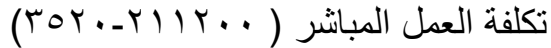

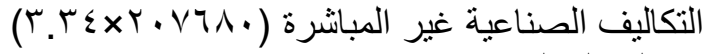

$$
\begin{aligned}
& \text { إجمالي التكاليف }
\end{aligned}
$$

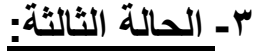

و عند استخدام الماكنة الجديدة واعتمـاد الترتيب الجديد كما في الحالة الثالثة الثنة الواردة

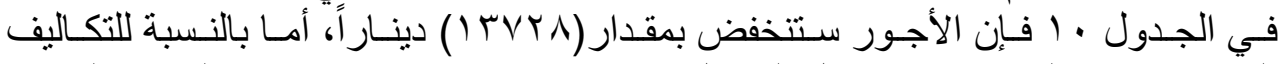

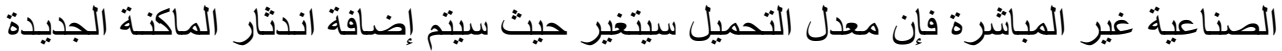

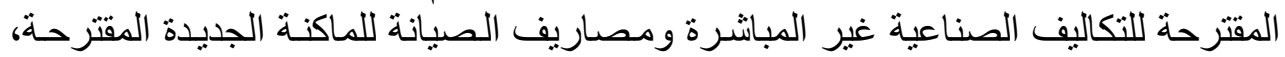

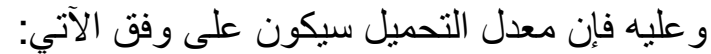

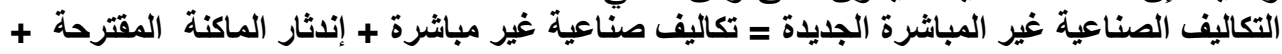
مصأريف صياتة الماكنة المقترحة

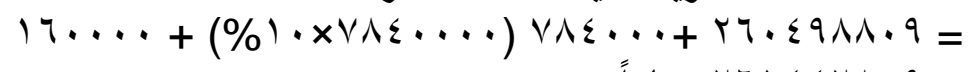
I

$$
\text { إذا معدل التحميل الجديد = PA. }
$$
(

و عليه ستكون تكلفة النقل بين العمليات و إتمام إنتاج غرفة النتور النوم على النحو الآتي:

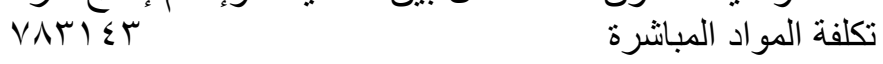

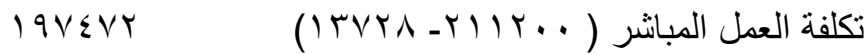
التكاليف الصناعية غير المباثرة (9VYVY

$$
\text { إجمالي التكاليف }
$$

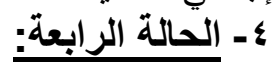

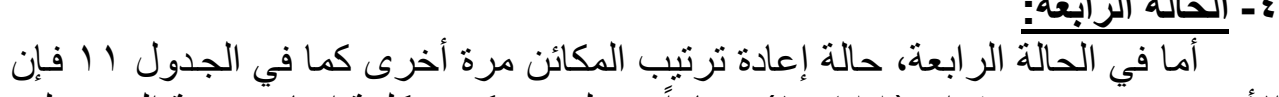

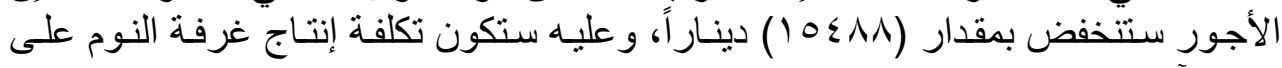

$$
\begin{aligned}
& \text { VATI } \leqslant T \\
& \text { 190VIr } \\
& \text { تكلفة المواد المباثرة }
\end{aligned}
$$

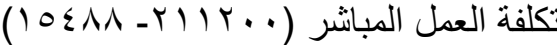

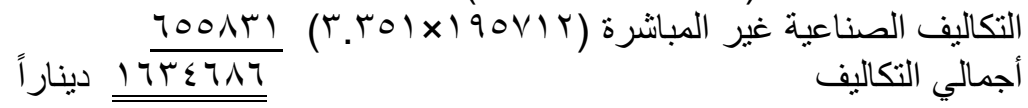




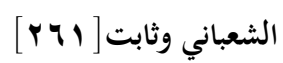

$$
\text { الأربع السابقة. الجدول ؛ الفرق في إجمالي تكاليف إنتاج غرفة نوم نفرين في الحالات }
$$

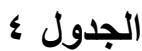

مقارنة بين تكاليف إنتاج وحدة واحدة من غرفة النوم نفرين على وفق الحالات الأربعة

\begin{tabular}{|c|c|c|c|c|}
\hline الحالة الرابعة & الحالة الثالثة & الحالة الثانية & الحالة الأولىي & البيان - البيان \\
\hline VATIET & VATIET & VATIET & VATIEr & تكلفة المواد المباشرة \\
\hline $190 \mathrm{VIT}$ & 19VミVY & $r \cdot V 7 \Lambda$. & $r \| r \ldots$ & تكلفة العطل العباشرة \\
\hline $700 \wedge r 1$ & $771 V Y 9$ & 794701 & $V .0 \xi .1$ & تكاليف صناعبة غبر مباثرة \\
\hline $17 r \leqslant 714$ & $17 \varepsilon Y Y \leq \varepsilon$ & $17 \Lambda \varepsilon \varepsilon V \varepsilon$ & 1799801 & إجمالي التكاليف \\
\hline
\end{tabular}
(المبالغ بالاينار)

المصدر : من إعداد الباحثين

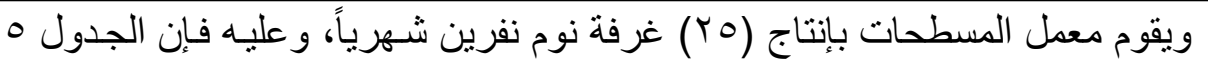

يوضح الفرق في إجمالي تكاليف إنتاج غرفة النوم نفرين على وفق نُقئ الحالات السابقة المشار إليها شهرياً.

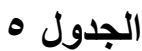

مقارنة بين تكاليف إنتاج غرفة النوم نفرين الثهري على وفق الحالات الأربعة (المبالغ

\begin{tabular}{|c|c|c|c|c|}
\hline الحالة الرابعة & الحالة الثالثة & الحالة الثانية & الحالة الأولى & البيان \\
\hline 190VAOVO & $190 \vee \wedge 0 \vee 0$ & $190 \vee 10 \vee 0$ & $190 \vee \wedge 0 \vee 0$ & تكلفة المو اد المباثرة \\
\hline$\varepsilon \wedge 9 \uparrow \wedge \ldots$ & $\varepsilon q \mu \neg \wedge .$. & $0194 \ldots$ & orA.... & تكلفة العمل المباشرة \\
\hline $17490 \mathrm{VVO}$ & ITOETYYO & IVTEITVO & IVTrOT.. & تكاليف صناعية غير مباشرة \\
\hline$\varepsilon \cdot \wedge T \vee 10$. & $\varepsilon 1.017 \ldots$ & $\varepsilon Y \| 110$. & $\varepsilon r \Sigma q r \vee \vee 0$ & إجمالي التكاليف \\
\hline
\end{tabular}
بالاينار)

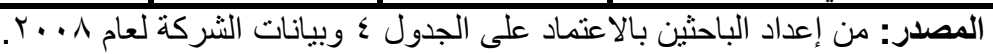

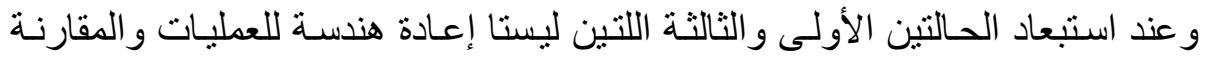

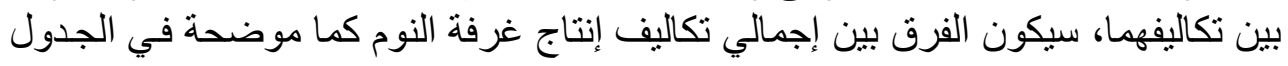

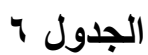

المقارنة بين تكاليف إنتاج غرفة النوم نفرين في حالتي إعادة هندسة العمليات الإنتاجية

\begin{tabular}{|c|c|c|}
\hline الحالة الرابعة & الحالة الثانية & البيان \\
\hline $190 \vee 10 \vee 0$ & $190 V 10 V 0$ & تكلفة المواد المباثرة \\
\hline$\varepsilon \wedge 9 \uparrow \wedge \ldots$ & $0194 \ldots$ & تكلفة العمل المباشرة \\
\hline $17 r 90 \vee v 0$ & IVTEITVO & تكاليف صناعية غبر مباثرة \\
\hline$\varepsilon . \wedge 7 \vee 10$. & $\varepsilon Y 1110$. & إجمالي التكاليف \\
\hline
\end{tabular}
(المبالغ بالاينار) 


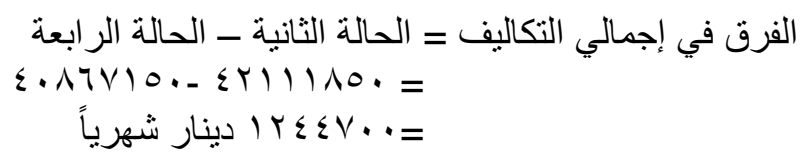

ثانياً. تطبيق البدائل الأربعة في معمل الخشب الصلب

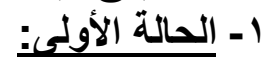

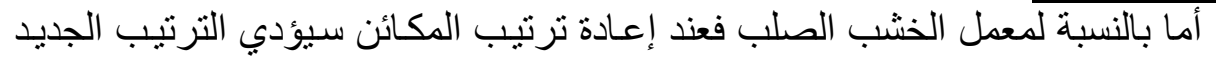

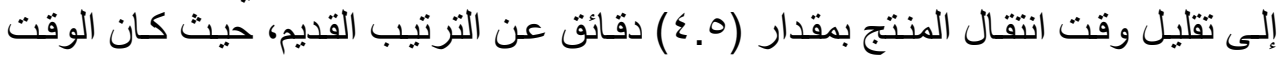

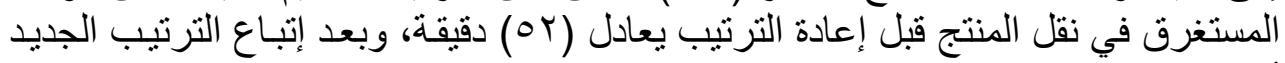
أصبح (

\section{V الجدول ve}

مقارنة الوقت المستغرق لنقل المنتج معين قبل وبعد تطبيق المقترح الجديد في معمل الخثب الصلب معلب ويعا

\begin{tabular}{|c|c|c|}
\hline الترتيب الجديد(الحالة الثانية) دقيقة & الترتيب القديم (الحالة الأولى) دقيقة & المكائن/الزمن \\
\hline 9 & 1. & تقطيع - فصال \\
\hline 7 & $V_{.0}$ & فصال - كبس \\
\hline 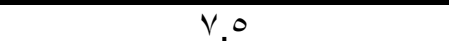 & $\Lambda$ & كبس - ترويج \\
\hline 7.0 & $V_{.0}$ & ترويج - تثقيب \\
\hline 1.0 & 9 & تيقيب - لصق الحافات \\
\hline 0 & 0 & لصق الحافات - تجميع \\
\hline 0 & 0 & تجميع - صباغة \\
\hline$\varepsilon V_{.0}$ & Or & المجموع \\
\hline
\end{tabular}

و عليه سيؤدي استخدام الترتيب الجديد في معمل الخشب الصلب إلى خفض في في تكلفة

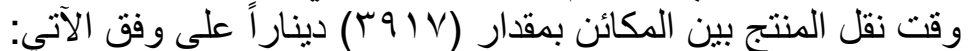

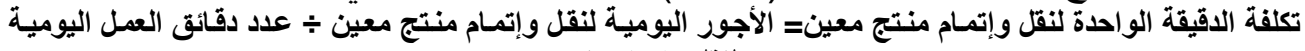
لنقل وإتمام منتج معين

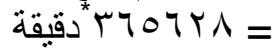

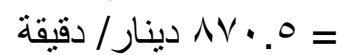

لذلك فإن تكلفة نقل المنتج بين العمليات قبل إعـادة ترتيب المكائن تكون على النحو

تكلفة نقل المنتج = الوقت المستغرق بالدقائق × تكلفة الدقيقة الواحدة

$$
\Lambda V \cdot .0 \times \text { Or }=
$$

. (الحالة الأولى) = 


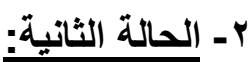
أما بعد إعادة ترتيب المكائن فإن تكلفة نقل المنتج تكون على وفق الآتي:

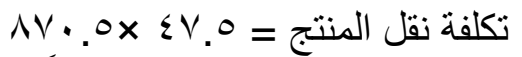
.

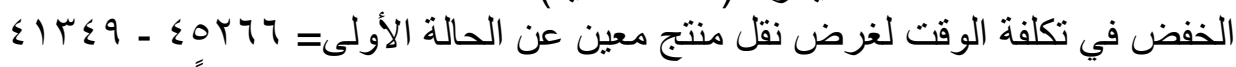
( )

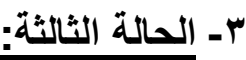

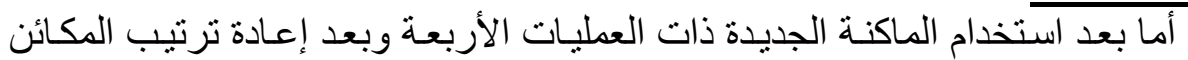

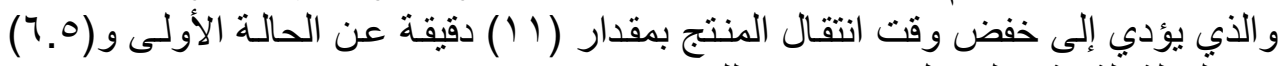
عن الحالة الثنانية، فالجذول ^ يوضح ذلك. لكن.

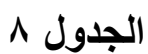

مقارنة الوقت المستغرق لنقل منتج معين قبل وبعد المقترح باستخدام الماكنة الجديدة في

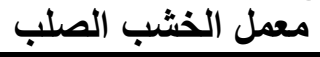

\begin{tabular}{|c|c|c|c|}
\hline التصتسين باستخلة الثالماكنة & الثقترحيب (الجليدة & (الحايلة الأوتِّى) & المكائ/الزمن \\
\hline$\overline{9}$ & 9 & T. & تثريح وتقطيع - فصال \\
\hline 7 & 7 & $V_{0} 0$ & فصال - كبس \\
\hline V.o & V.o & $\Lambda$ & كبس - ترويج \\
\hline & 7.0 & V.o & ترويج - نتقيب \\
\hline 1.0 & 1.0 & $\overline{9}$ & تثقيب - لصق الحافات \\
\hline o & o & 0 & لصق الحافات - تجميع \\
\hline o & o & - & تجميع - صباغة \\
\hline \&1 & $\varepsilon V_{0} \mathrm{O}$ & or & المجموع \\
\hline
\end{tabular}

و عليه سيؤدي استخدام الماكنة الجديدة إلى خفض في تكلفة الوقت لنقل منتج معنين

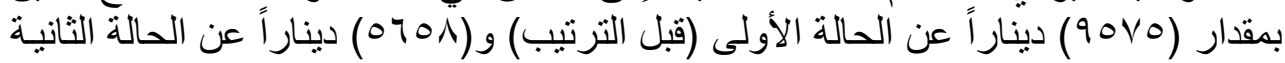

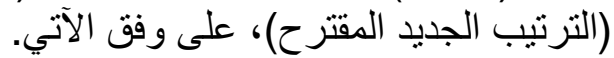

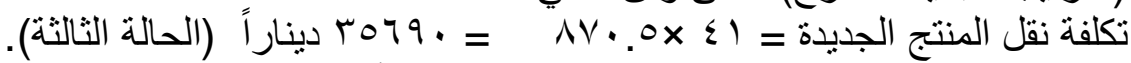

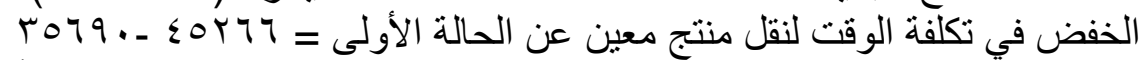

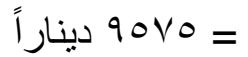

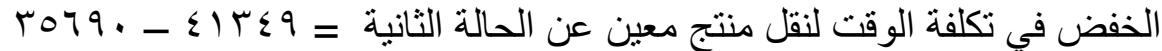
أ. $0709=$

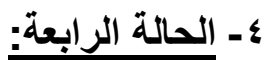

و وعند القيام بإعادة ترتيب المكائن مرة أخرى بعد التحسين باستخدام الماكنة الجديدة

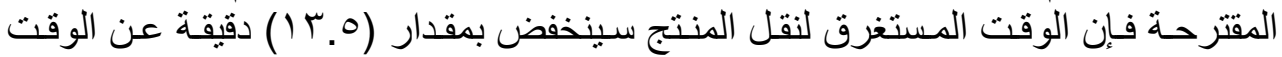


المستغرق في نقل المنتج في الحالـة الأولى، و (9) دقيقة عن الحالـة الثانية، و(0.ب) دقيقة عن الحالة الثالثة، والجدول في و يوضح ذلك .

\section{الجدول و 9}

مقارنة الوقت المستغرق لنقل منتج معين قبل وبعد الترتيب الجديد باستخدام الماكنة

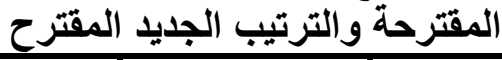

\begin{tabular}{|c|c|c|c|c|}
\hline بعد التحسبن المقترح وإعادة & الجديدة التخدم الماكنة & الثقترتيب الجثايد (الحالة & (الحالة الأيل الترتيب & المكائن/الزمن \\
\hline$\Lambda$ & 9 & 9 & 1. & تشريح وتقطيع - فصال \\
\hline 0.0 & 7 & 7 & V.o & فصال - كبس \\
\hline V & V.o & V.o & $\Lambda$ & كبس - ترويج \\
\hline & & 7.0 & $V .0$ & ترويج - تتقيب \\
\hline$\Lambda$ & 1.0 & 1.0 & 9 & تثقيب - لصق الحافات \\
\hline 0 & 0 & 0 & 0 & لصق الحافات -تجميع \\
\hline 0 & 0 & 0 & 0 & تجميع - صباغة \\
\hline$r \wedge .0$ & $\leqslant 1.0$ & $\leqslant V .0$ & or & 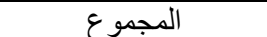 \\
\hline
\end{tabular}

المصدر: الجدول من إعداد الباحثين بالتعاون مع فريق العمل في الثركة

و عليه سيؤدي استخدام الماكنة الجديدة إلى خفض في تكلفة الوقت لنقل منتج معين التبار بمقدار

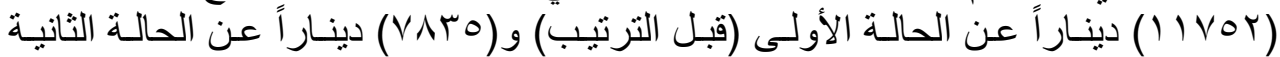

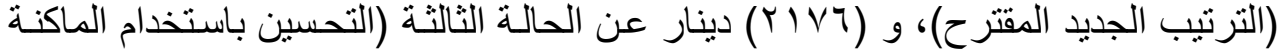
الجديدة)، على وفق الجن الآتي:

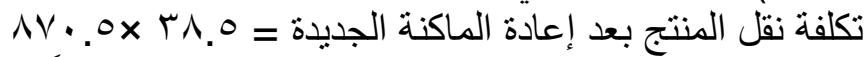
= $=$

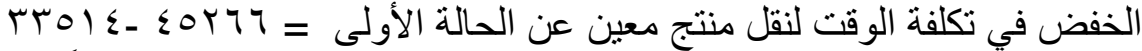

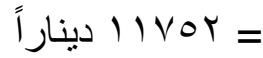

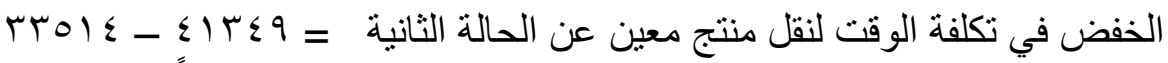

VAro=

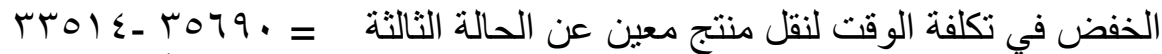

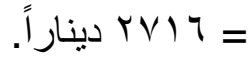

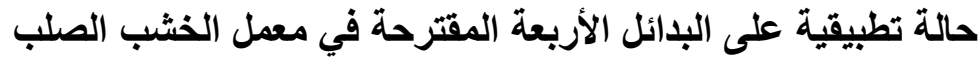

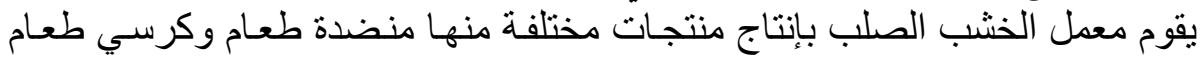

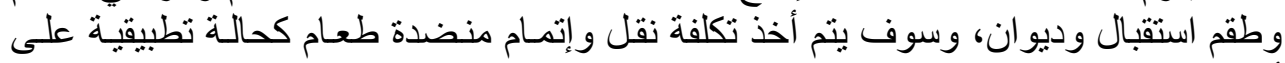
أثر تطبيق الترتيب الجديد على خفض تكلفة الوقت، لغرض نقل المنتج في معدل الخشب أنس 


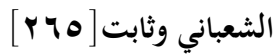

الصلب في الحالات الأربعة السابقة، إذ تبلغ تكلفة إنتاجها وبحسب بيانـات الشركة لعام

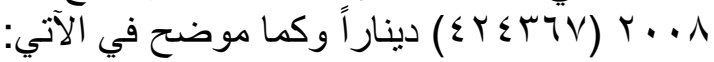

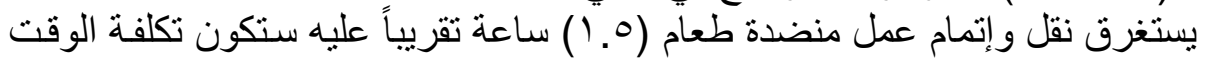

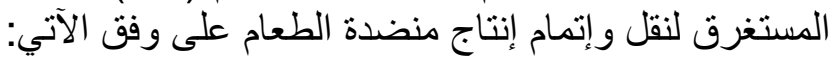

تكلفة الوقت لنقل وإتمام إنتاج منضدة الطعام= الوقت المستغرق بالدقائق ×اتكلفة الدقيقة AV. .0 × $(7 \times 1.0)=$ . و وعليه تكون تكلفة نقل و إتمام إنتاج منضدة طعام على النحو الآتي:

$$
\begin{aligned}
& \text { 7) } \\
& \text { 1- الحالة الأولى: } \\
& \text { VAT } \\
& \text { تكلفة المواد المبانشرة } \\
& \text { إلتماليف التكاليفة }
\end{aligned}
$$

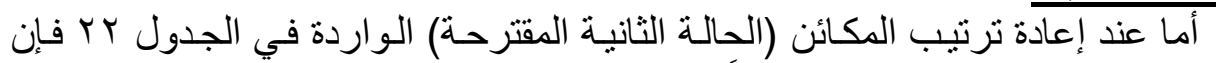

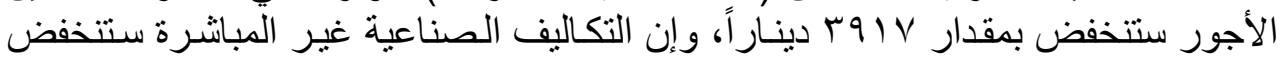

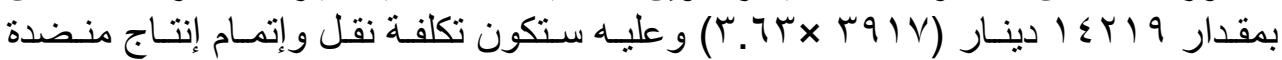

т)т.

$V \leqslant \leqslant Y \wedge$

$\frac{Y V \cdot I V \varepsilon}{T Y Y Y}$

$\underline{\underline{\varepsilon \cdot T Y M r}}$

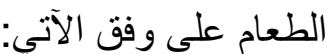

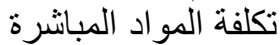

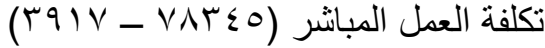

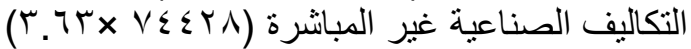

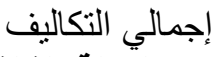

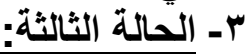

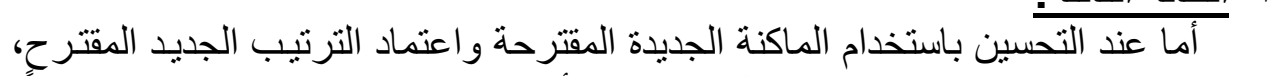

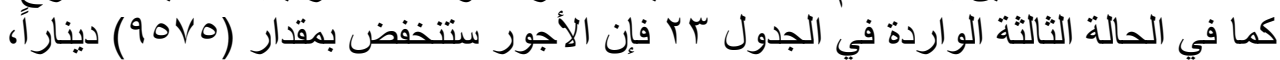

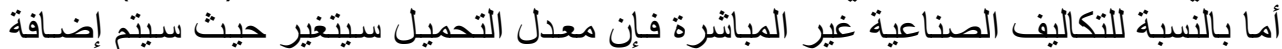

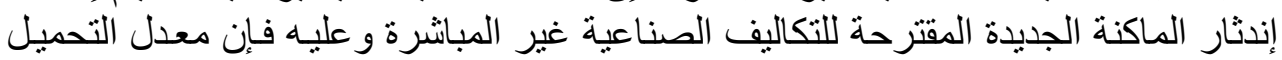
سيكون على وفق الآتي:

التكاليف الصناعية غير المباثرة الجديدة= تكاليف صناعية غير مباثرة + إندثار الماكنة المقترحة +

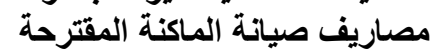

$$
\begin{aligned}
& 17 \cdots+(\%) \cdot \times \vee \wedge \varepsilon \cdots
\end{aligned}
$$

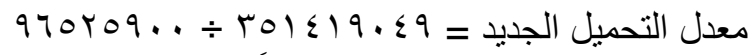

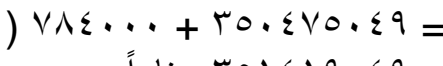$$
\text { أ. }
$$

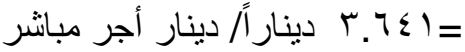

و عليه ستكون تكلفة نقل وإتمام إنتاج منضدة الطعام على وفق الآتي:

تكلفة المو اد المباشرة

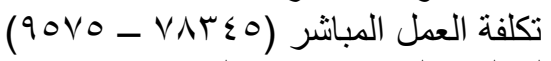

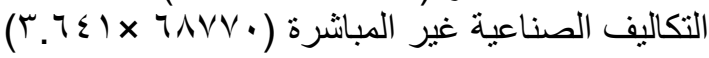


ع - الحالة الرابعة:

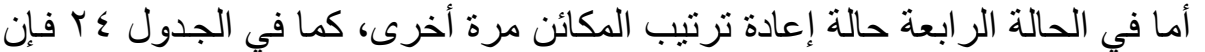

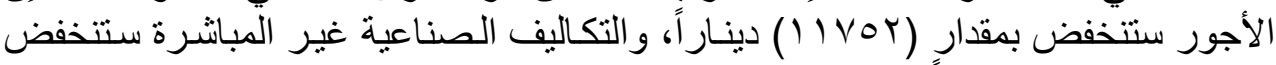

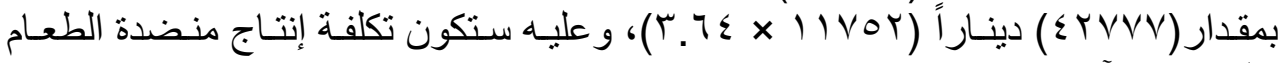

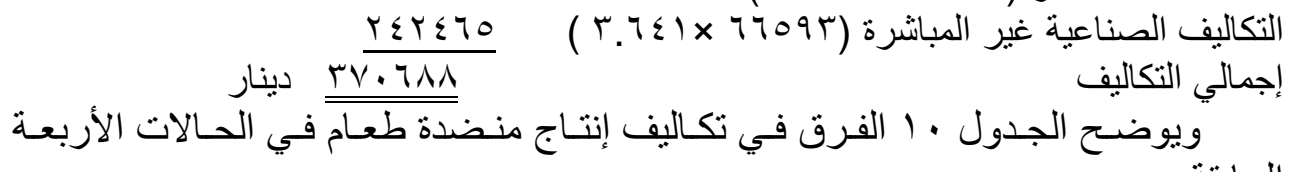

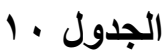

كشف تكاليف إنتاج وحدة واحدة من منتج منضدة الطعام على وفق الحالات الأربعة (المبالغ بالانانير)

\begin{tabular}{|c|c|c|c|c|}
\hline الحالة الرابعة & الحالة الثالثة & الحالة الثانية & الحالة الأولى & البيان \\
\hline דוT. & 7וT. & דו. & ד. & تكلفة المو اد المباشرة \\
\hline 77094 & TAVV. & $V \varepsilon \leqslant Y \wedge$ & VAT & تكلفة العمل المباشرة \\
\hline$r \leqslant r \leqslant 70$ & ro.rqT & $T V \cdot 1 V \varepsilon$ & 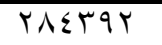 & تكاليف صناعية غير مباثرة \\
\hline$r V \cdot T \Lambda \Lambda$ & rᄉ.Vqr & E.TYKY & 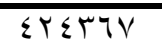 & اجمالى التكالبف \\
\hline
\end{tabular}

المصدر : من إعداد الباحثين

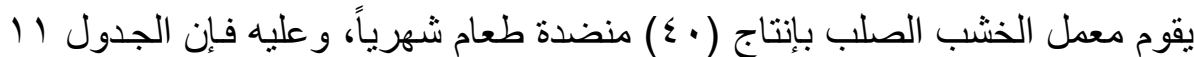

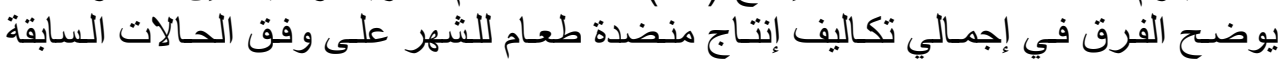

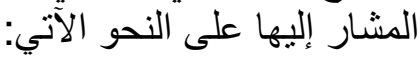

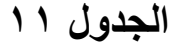

مقارنة بين تكاليف إنتاج منضدة الطعام الشهري وفق الحالات الأربعة (المبالغ بالدنانير)

\begin{tabular}{|c|c|c|c|c|}
\hline الحالة الرابعة & الحالة الثالثة & الحالة الثاتية & الحالة الأولى & البيان \\
\hline rะTOY.. & rะ70Y.. & 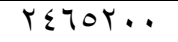 & $r \leqslant 70$... & تكلفة المو اد المباشرة \\
\hline TITYVY. & rVo.1.. & rqVVIr. & rITr... & تكلفة العمل المباشرة \\
\hline $97917 \ldots$ & 1.1071. & 1.1 .797$. & 11 rvorA. & تكاليف صناعية غير مباشرة \\
\hline I ENYVOY. & 10YM171. & $17 r \leq 9 r \wedge$. & $179 \vee \leq 71$. & إجمالي التكاليف \\
\hline
\end{tabular}

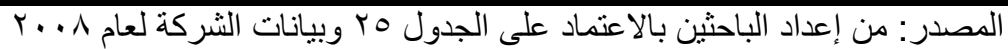

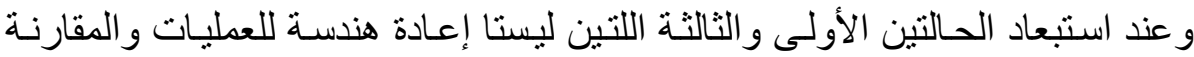

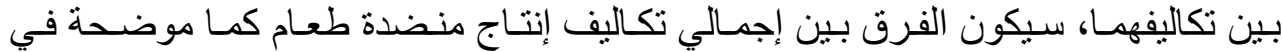




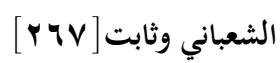

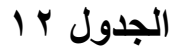

المقارنة بين تكاليف إنتاج منضدة طعام في حالتي إعادة هندة العمليات الإنتاجية (المبالغ بآلدنانير)

\begin{tabular}{|c|c|c|}
\hline الحالة الرابعة & الحالة الثانية & البيان \\
\hline$r \leq 70 Y \ldots$ & $r \leqslant 70 Y .$. & تكلفة المو اد المباشرة \\
\hline YITYVY. & rqVVIr. & تكلفة العمل \\
\hline $979 \wedge 7 \ldots$ & 1.1 .797$. & تكاليف صناعية غير مباشرة \\
\hline IEATVOY. & ITYะ9YA. & إجمالي التكاليف \\
\hline
\end{tabular}

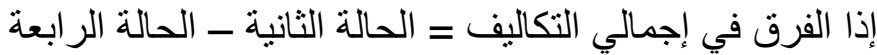

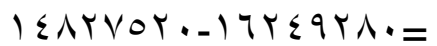

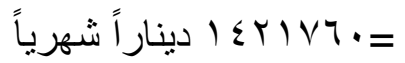

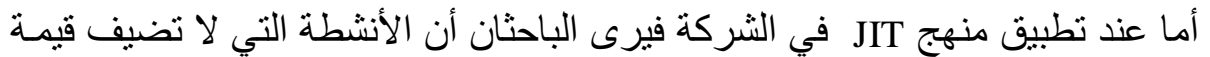

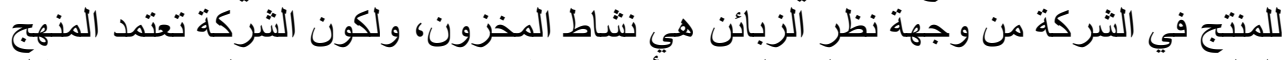

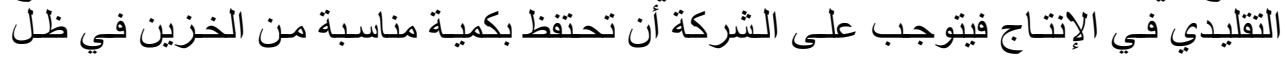

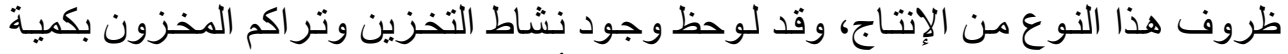

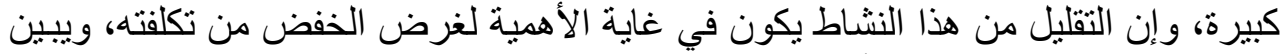

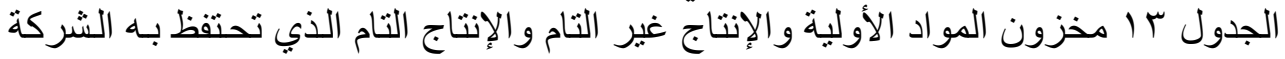

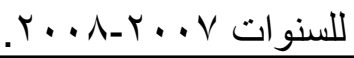

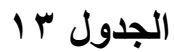

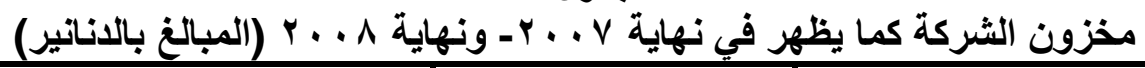

\begin{tabular}{|c|c|c|}
\hline$r \cdots \Lambda / T r / r \mid$ & $r \ldots V / T r / r \mid$ & البيان \\
\hline $1 \leqslant \varepsilon \vee 4 \wedge \vee 90$ & $0 Y 01.797$ & مخزون المواد الأولية \\
\hline $1 / 9001 \wedge \varepsilon$ & TrVTARYO & مخزون الإنتاج غبر التام \\
\hline rrotrq11. & MIOVETONY & مخزون الإنتاج التام \\
\hline 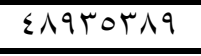 & $r A Y .907 . r$ & المجموع \\
\hline
\end{tabular}

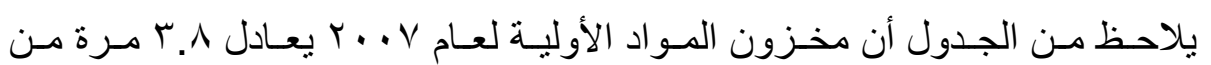

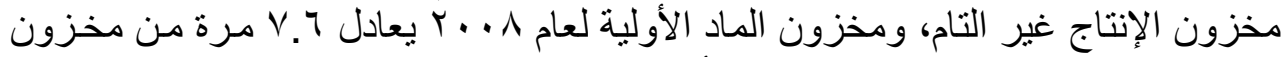

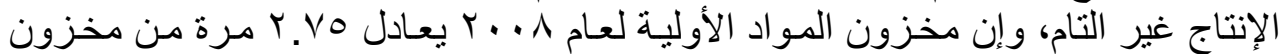

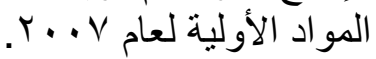

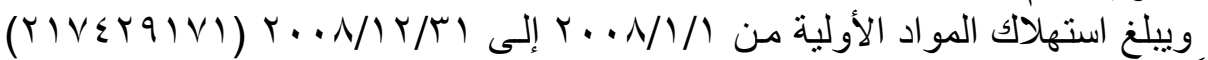

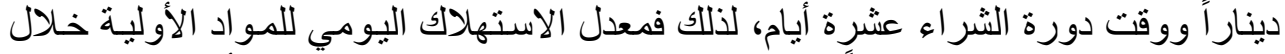

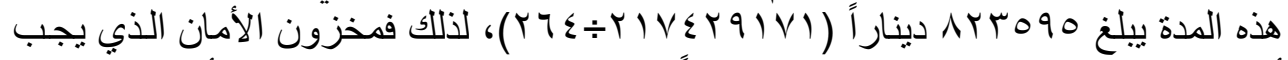

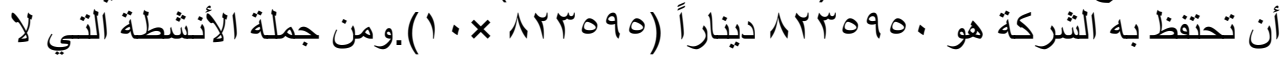

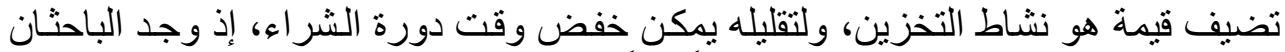
أن دورة الثراء تستغرق عشرة أيام تقريباً بدءاً من إصدار طلب الثراء والى دئ حين وصول 


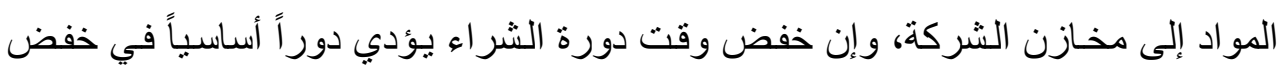

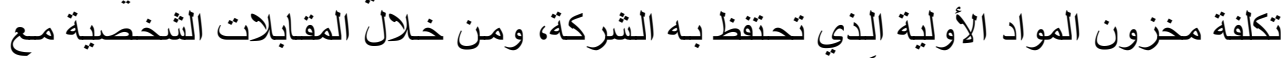

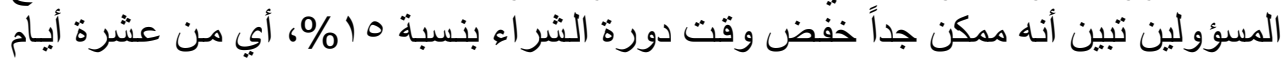

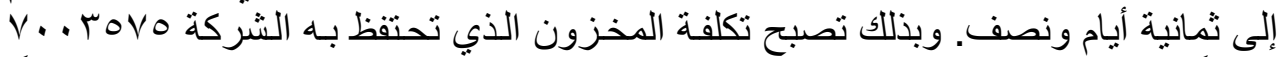

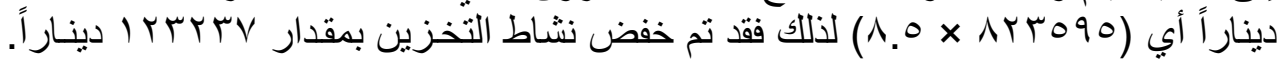

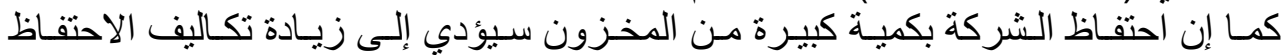

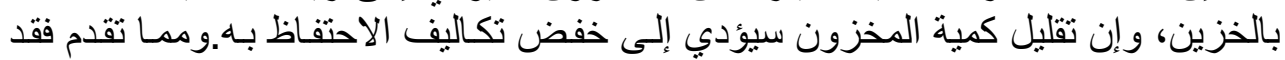

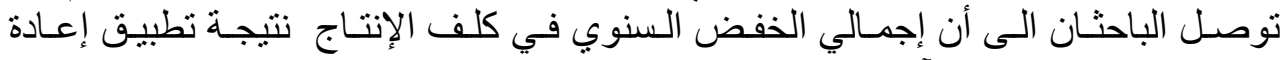

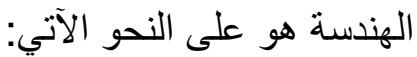

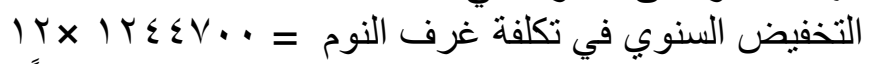

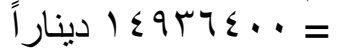

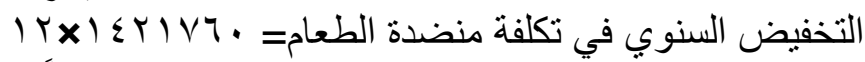

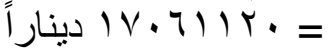

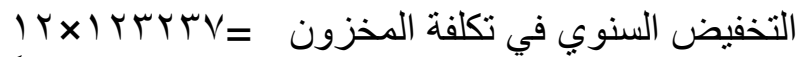

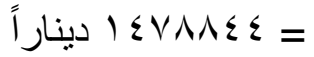

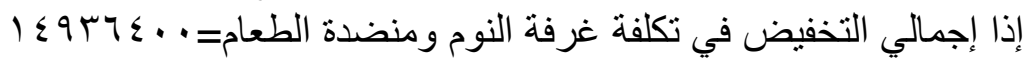
$\mid V \cdot T 11 \mathrm{r}++$

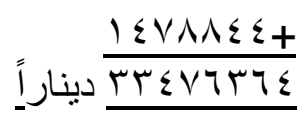

و عليه تكون نسبة الخفض في تكلفة الإنتاج نتيجة تطبيق إعادة الهندسة إجمالي ألخفض في تكلفة المنتجات الات تلناج

إجمالي تكلفة إنتاج المنتجات

$$
\begin{aligned}
& \text { צT }
\end{aligned}
$$

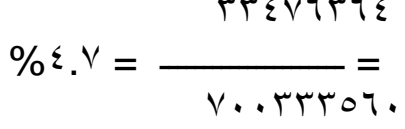

ويمكن تعميم هذه النسبة في الخفض على كافة منتجات الثركة.

الاستنتاجات و التوصيات

- - الاستنتاجات

سيتم عرض أهم الاستتناجات التي توصل إليها الباحثان وهي على النحو الآتي:

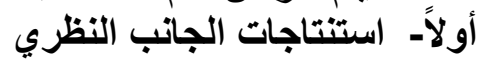

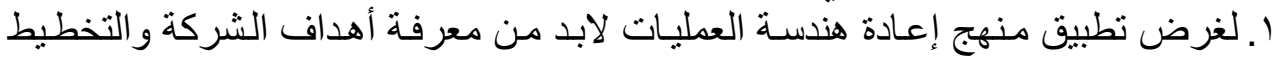

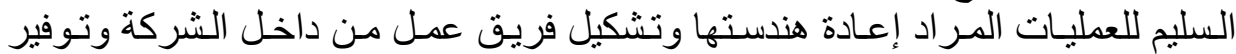

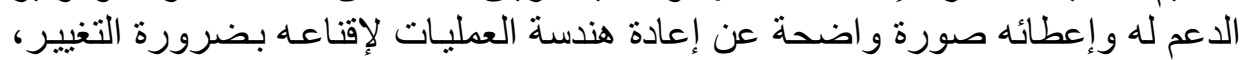
ويجب إثر الك جميع المستويات فيه. 


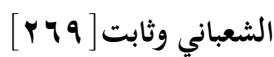

r. إن مفهوم خفض التكاليف يستهدف الخفض الحقيقي و المستمر في التكاليف مـع عدم إهمال الجودة و الحد من حالات الهدر و الضياع.

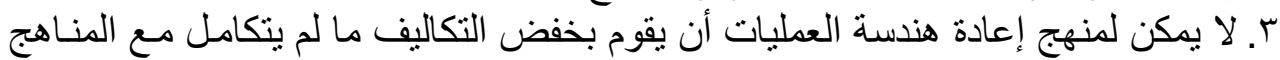

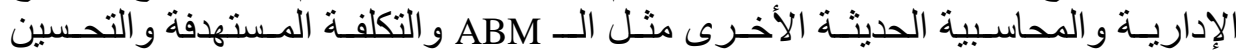

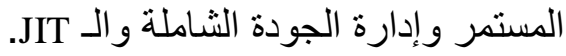

ثانياً استتناجات الجانب العملي

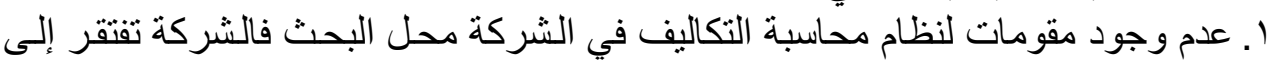

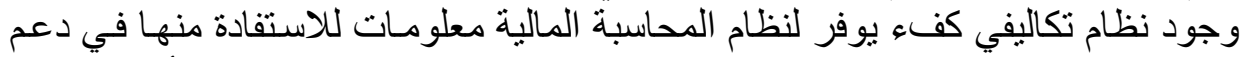

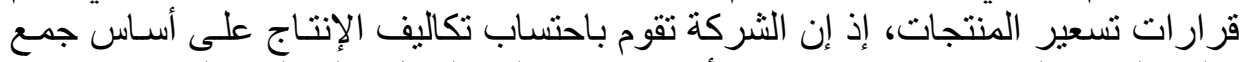

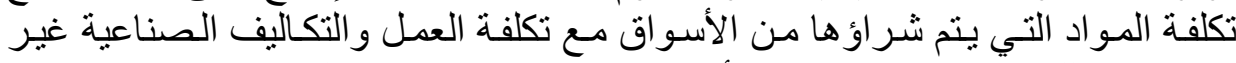

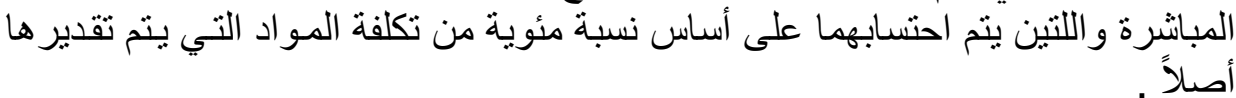

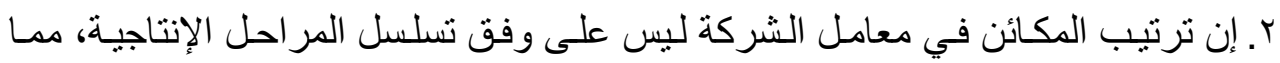

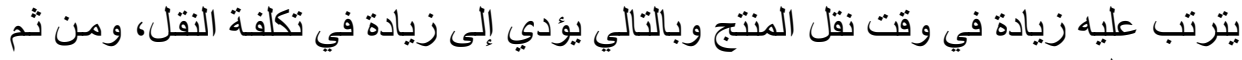
زيادة تكاليف الإنتاج.

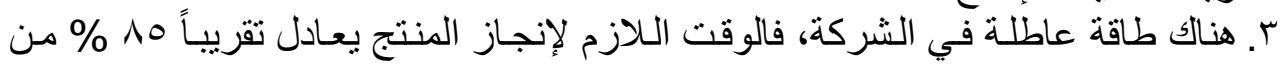

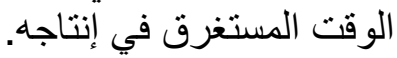
ع. إن معظم مكائن الثركة تعاني من التقادم وكثرة الأعطال وعدم توافر قطع غيـار عليها

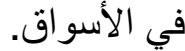

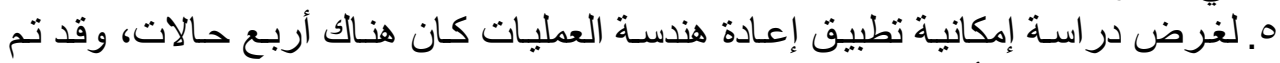

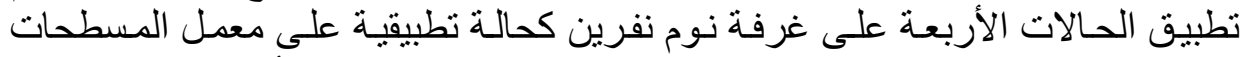

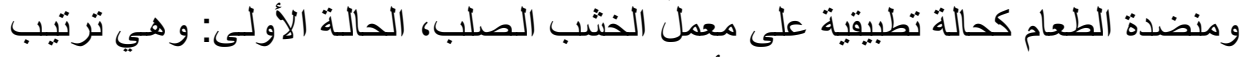

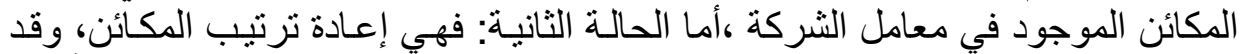

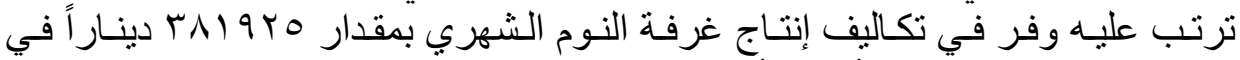

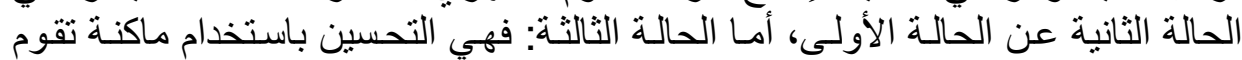

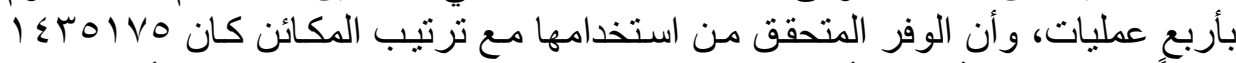

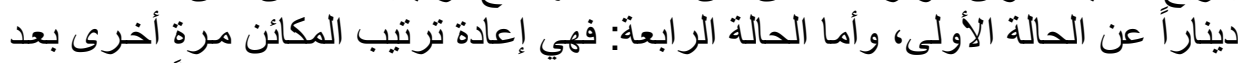

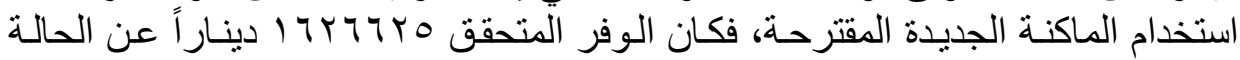

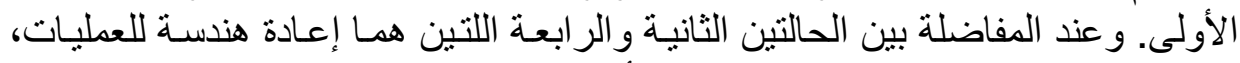

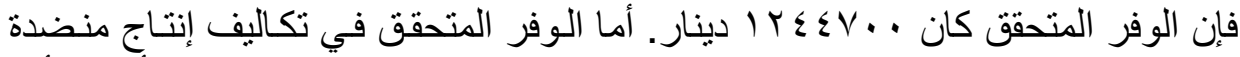

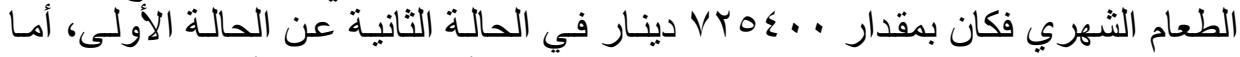

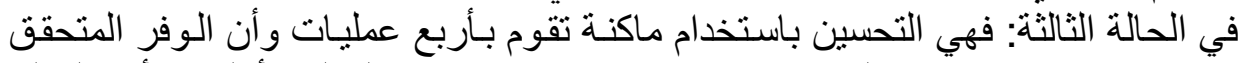

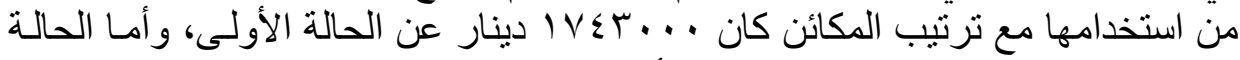

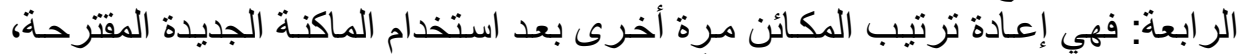

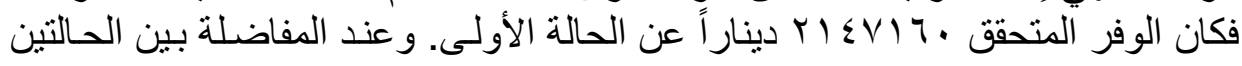

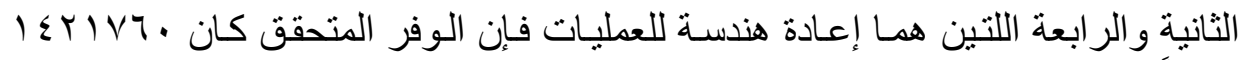

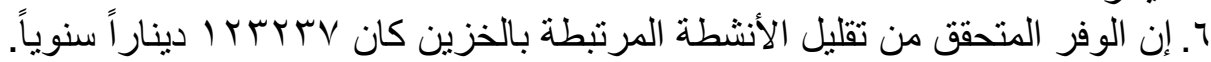




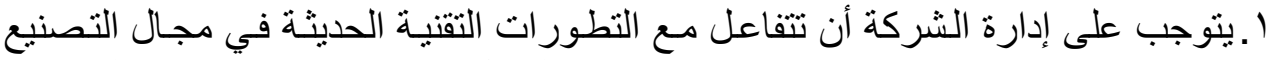

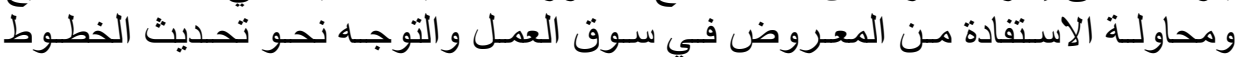
الإنتاجية لتحقيق الخفض الحقيقي في التكاليف.

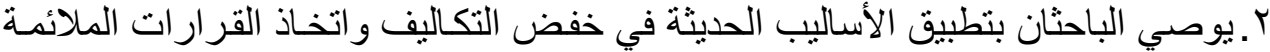

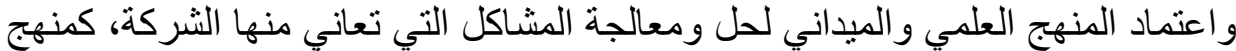

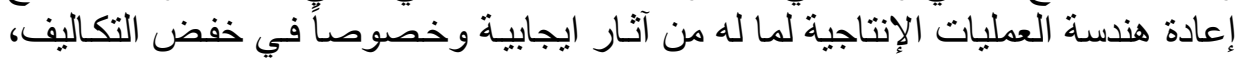

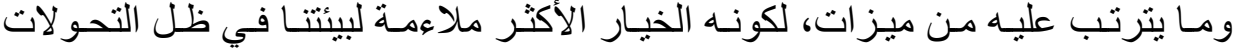
الجديدة.

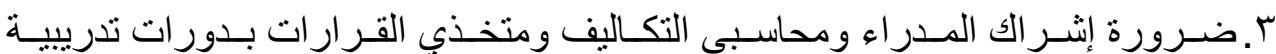

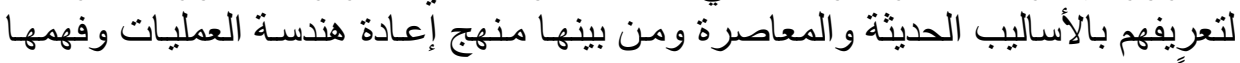
ع ـيوصي الباحثان بإجر اء در اسات مستقبلية أخرى مكملة ومتممـة لهذه البحث من خـاتلال

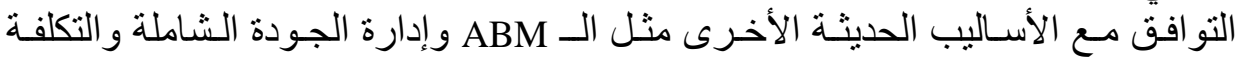

\section{أمراجِ الثعر اجع باللغة العربية}

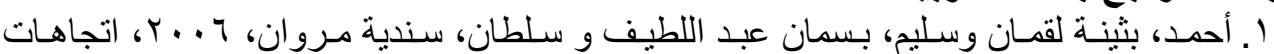

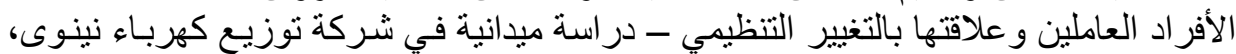

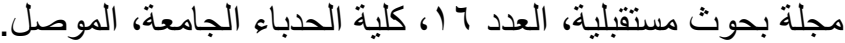

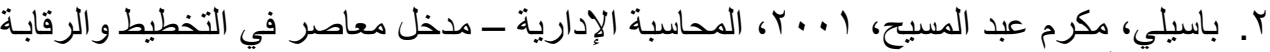

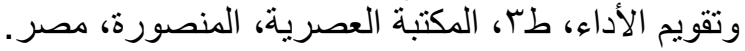

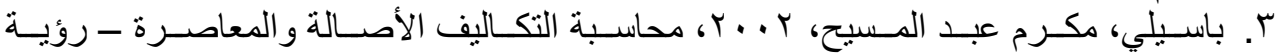

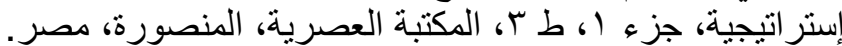

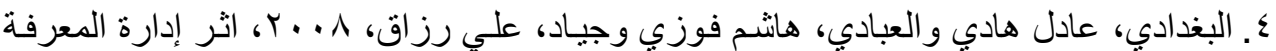

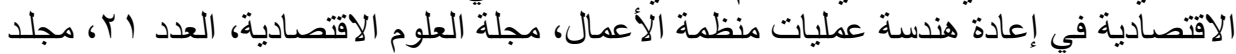

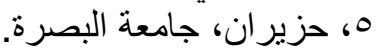

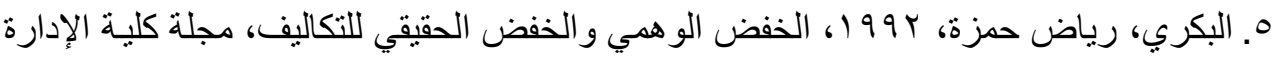

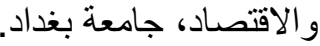

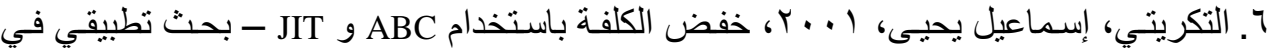

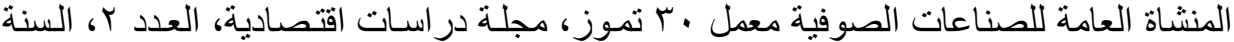

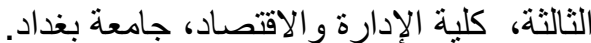

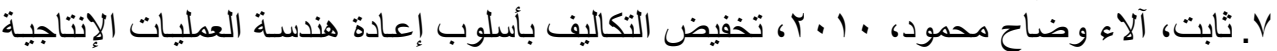

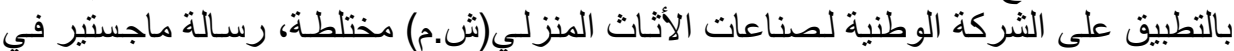

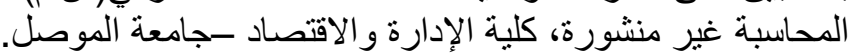

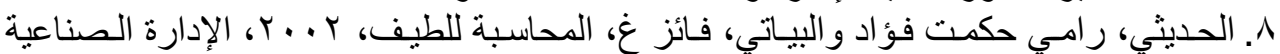

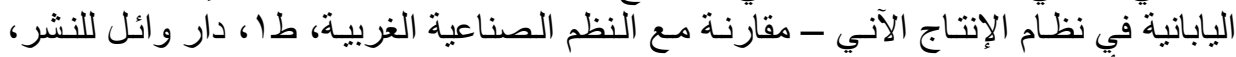




\section{الشعباني وثابت] [rv}

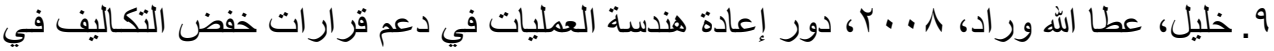

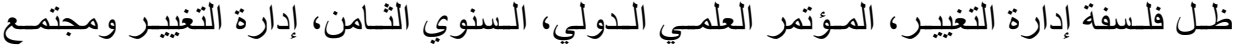

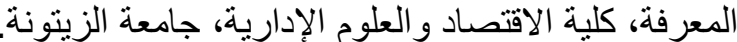

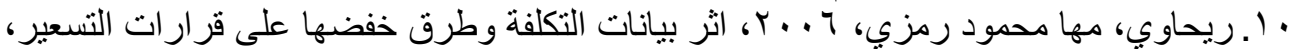

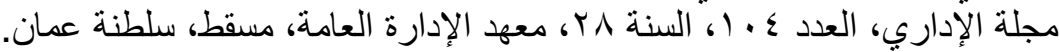

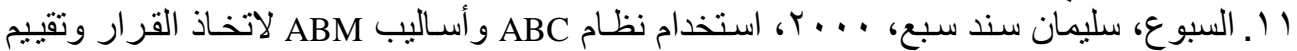

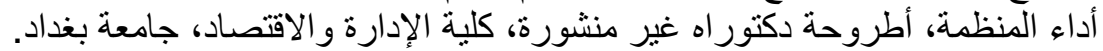

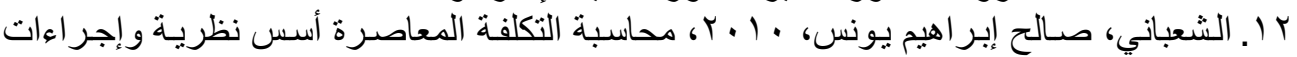

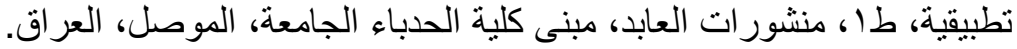

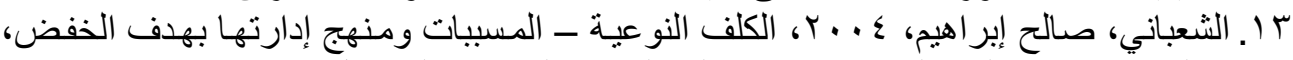

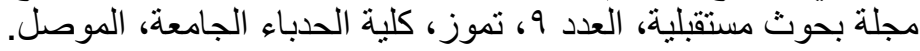

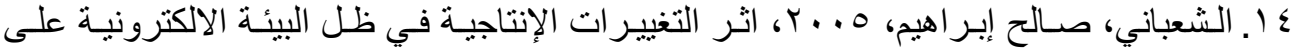

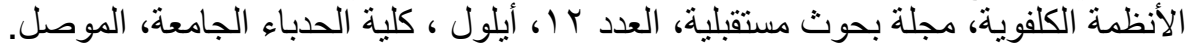

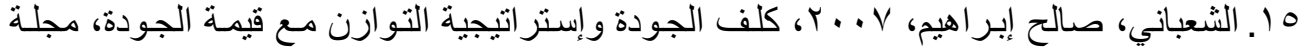

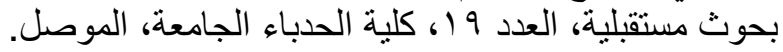

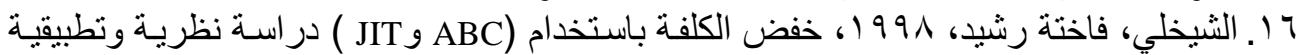

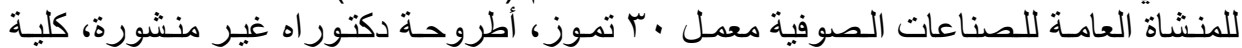
الإدارة والاقتصاد، جامعة بغدادة الماد.

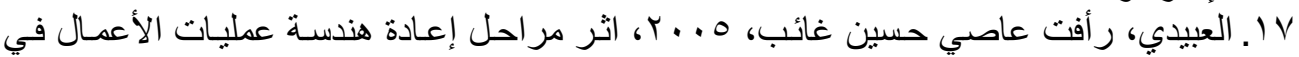

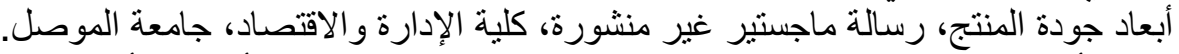

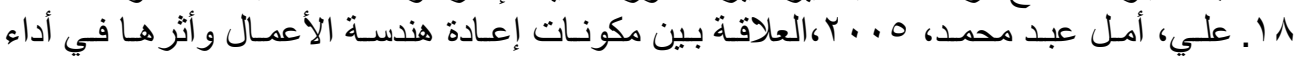

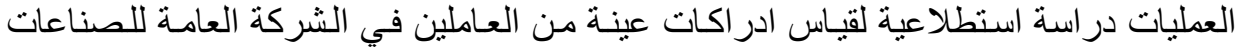

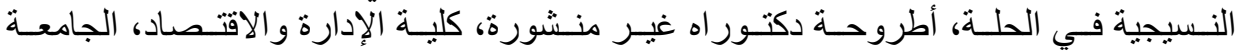

$$
\text { المستتصرية. }
$$

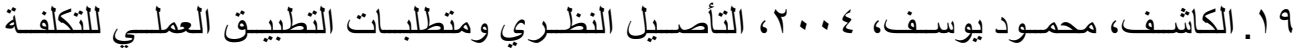

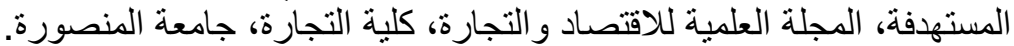

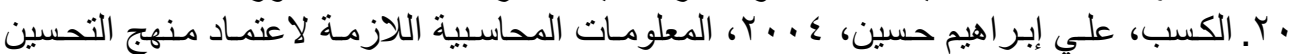

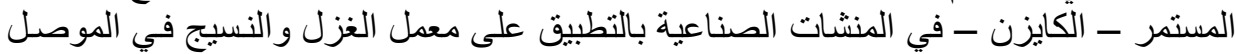

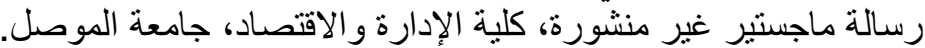

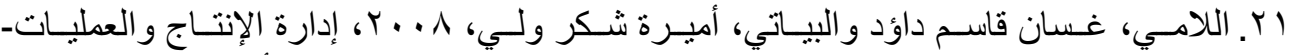

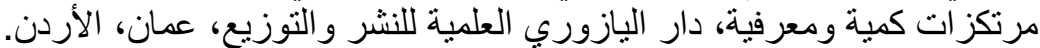

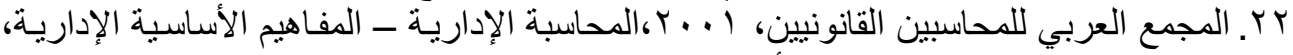

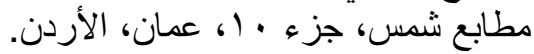

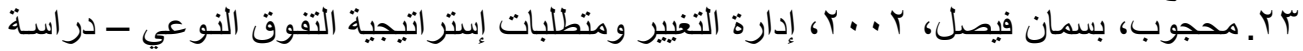

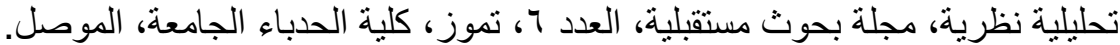
ع Y. هامر ، مايكل وشامبي، جيمس،

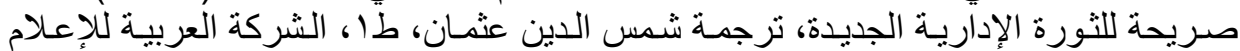

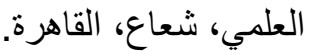

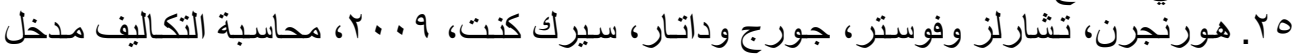

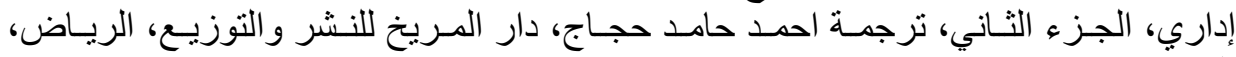


1. Blocher, Edward D., Chem, Hing H., and Thomas W., 2005, Management A strategic Emphasis, Mc- Grew Hill Co.

2. Daft, Richard L., 2000, Management, $5^{\text {th }}$ Ed, the Duyden Press, U.S.A.

3. Durry, Colin, 2000, Management and Cost Accounting, $5^{\text {th }}$ Ed, Business Press, London.

4. Frances, Gammell and Mcnair, C.J., 1994, Jumping the Growth through Activity Based cost Management

5. Hammer, Makil, 1990, Reengineering Work. Don't Automate Obliterate, Harvard Business Review, July- August.

6. Hilton, Ronald W. and Maher, Michael W. and Selto, Frank H., 2006, Cost Management Strategies For Business Decisions, Mc. Graw- Hill, U.S.A.

7. Ovenden, Tony R., 1994, Business Process Re- engineering Definitely Worth Considering, The TQM Magazine, Vol. 6. No.3.

8. Kaplen, Roberts and Atkinson, Anthony, 1998, Advanced Management Accounting, 3th Ed Prentice -Hall .International Inc. U.S.A.

9. Sofroniou, A., 1998, Business Information System, Psy Sys limited, London

10. Weetman, Plauline, 1996, Management Accounting, Pitman Publishing, London. 